LA W RENCE LIVERMORE N A TIONAL LABORATORY
Performance Analysis: Issues Tracking System Data through June 2012

C. Kerr, N. J. Mctyer, G. Holman, C. E. De Grange

February 1, 2013 
This document was prepared as an account of work sponsored by an agency of the United States government. Neither the United States government nor Lawrence Livermore National Security, LLC, nor any of their employees makes any warranty, expressed or implied, or assumes any legal liability or responsibility for the accuracy, completeness, or usefulness of any information, apparatus, product, or process disclosed, or represents that its use would not infringe privately owned rights. Reference herein to any specific commercial product, process, or service by trade name, trademark, manufacturer, or otherwise does not necessarily constitute or imply its endorsement, recommendation, or favoring by the United States government or Lawrence Livermore National Security, LLC. The views and opinions of authors expressed herein do not necessarily state or reflect those of the United States government or Lawrence Livermore National Security, LLC, and shall not be used for advertising or product endorsement purposes.

This work performed under the auspices of the U.S. Department of Energy by Lawrence Livermore National Laboratory under Contract DE-AC52-07NA27344. 


\section{Performance Analysis:}

Issues Tracking System Data through June 2012

December 2012

Performance Analysis and Reporting Section

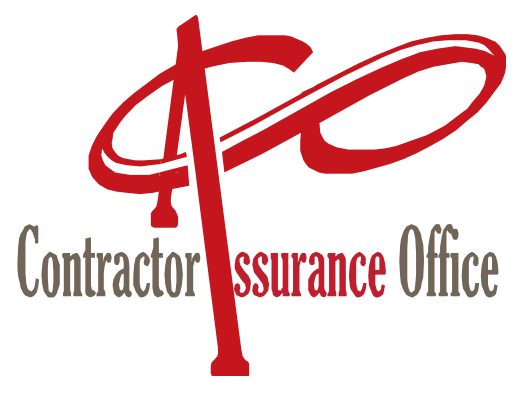




\section{Disclaimer}

This document was prepared as an account of work sponsored by an agency of the United States government. Neither the United States government nor Lawrence Livermore National Security, LLC, nor any of their employees makes any warranty, expressed or implied, or assumes any legal liability or responsibility for the accuracy, completeness, or usefulness of any information, apparatus, product, or process disclosed, or represents that its use would not infringe privately owned rights. Reference herein to any specific commercial product, process, or service by trade name, trademark, manufacturer, or otherwise does not necessarily constitute or imply its endorsement, recommendation, or favoring by the United States government or Lawrence Livermore National Security, LLC. The views and opinions of authors expressed herein do not necessarily state or reflect those of the United States government or Lawrence Livermore National Security, LLC, and shall not be used for advertising or product endorsement purposes.

This work performed under the auspices of the U.S. Department of Energy by Lawrence Livermore National Laboratory under Contract DE-AC52-07NA27344. 


\section{Contents}

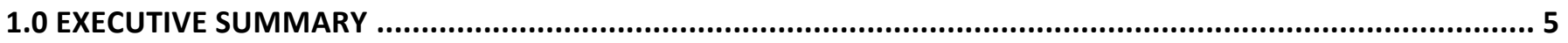

2.0 INTRODUCTION

3.0 ASSESSMENTS

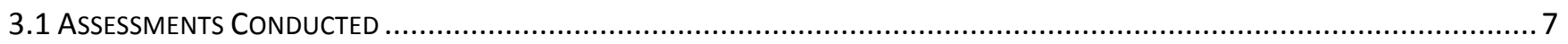

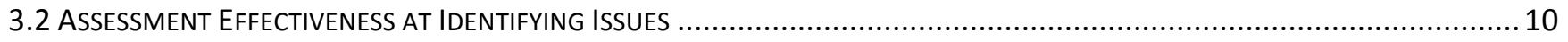

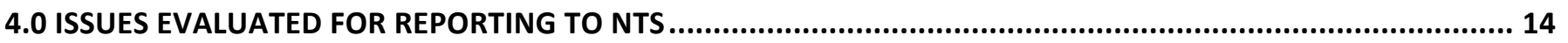

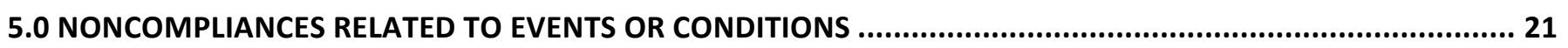

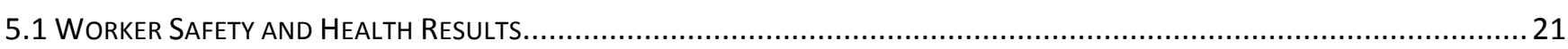

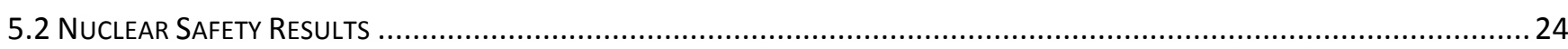

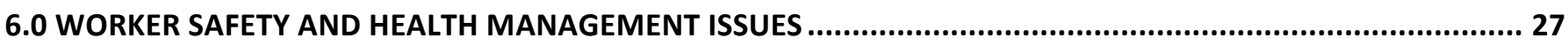

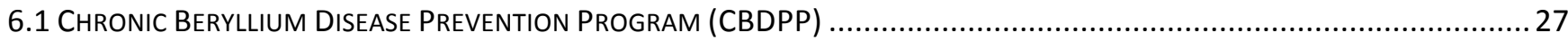

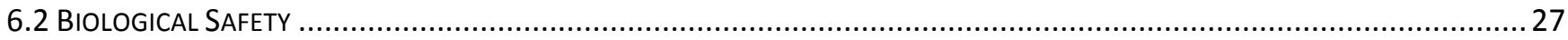

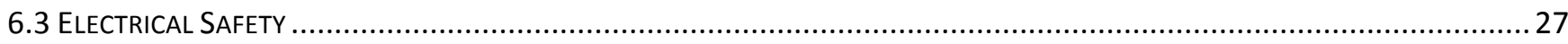

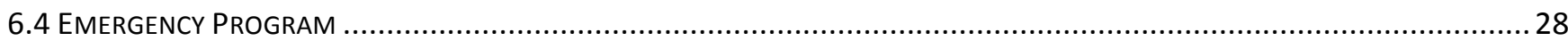

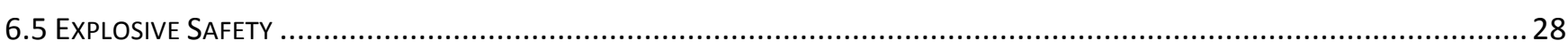

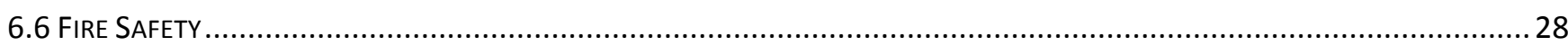

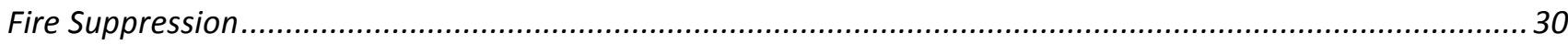

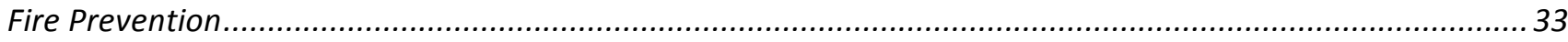

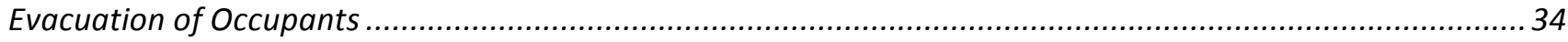

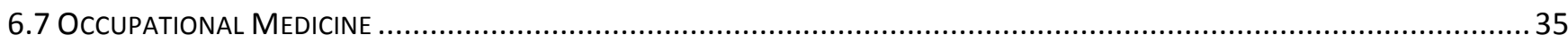

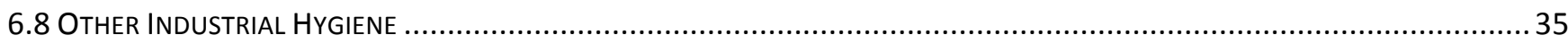

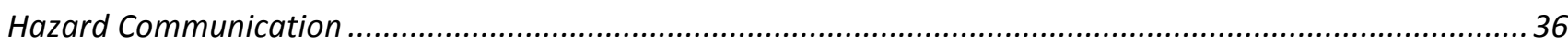

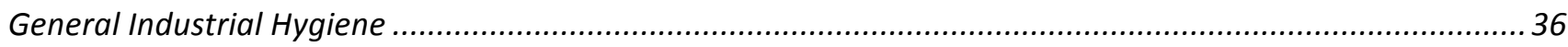

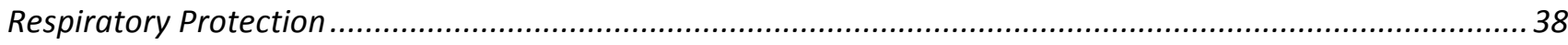

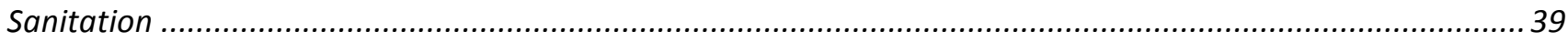

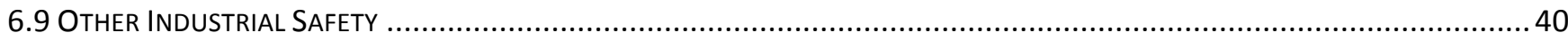

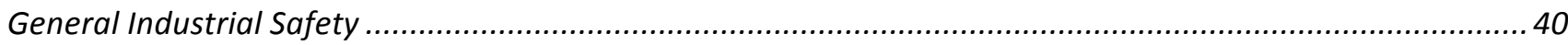

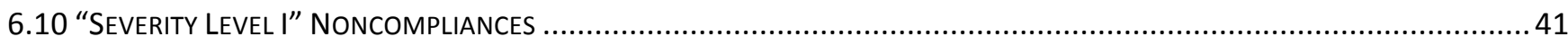

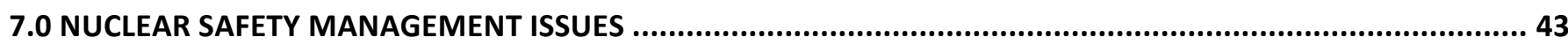

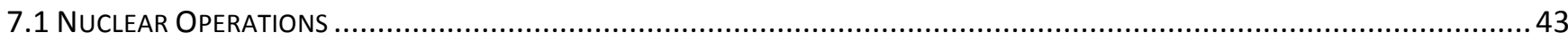

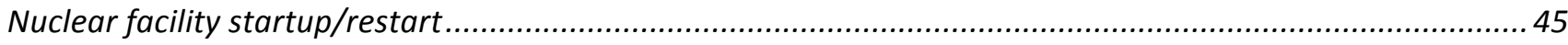

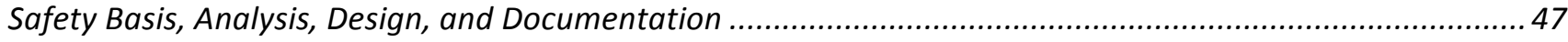

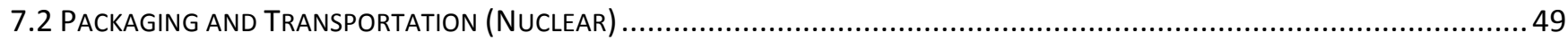

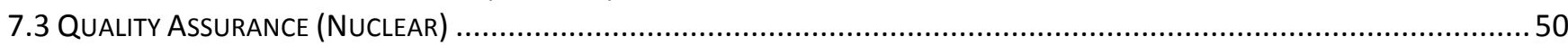

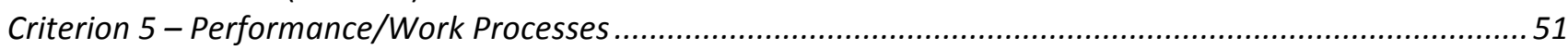

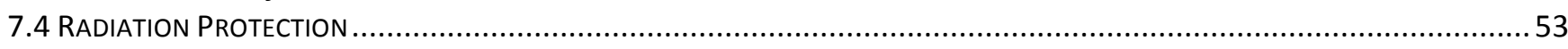

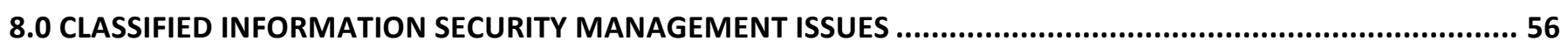

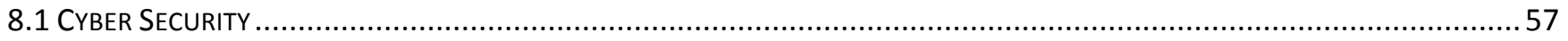

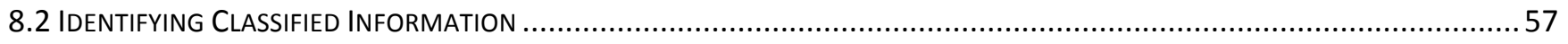

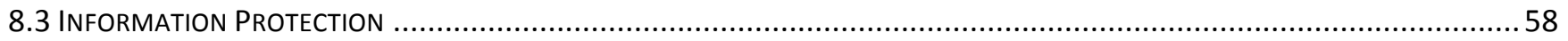

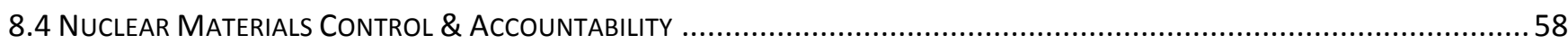


Performance Analysis: Issues Tracking System Data through June 2012

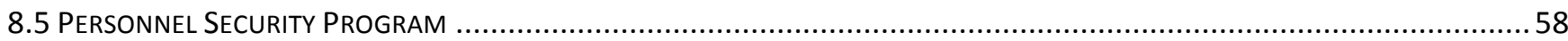

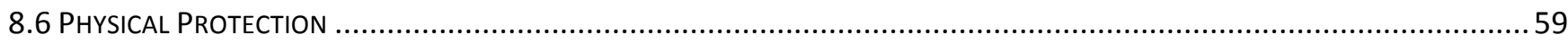

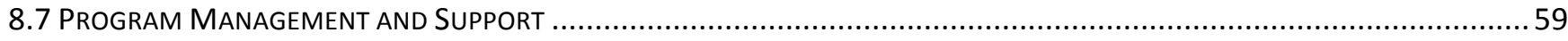

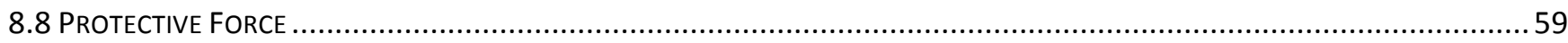

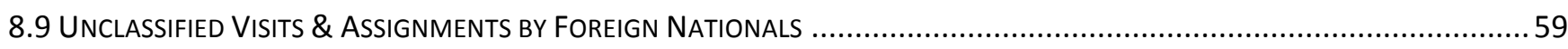

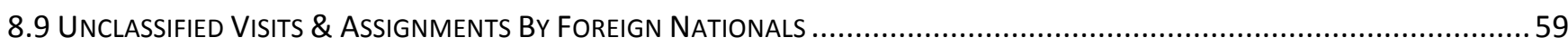

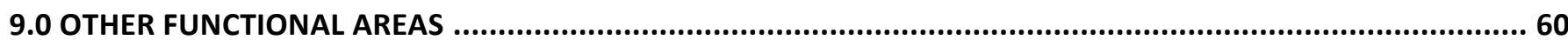

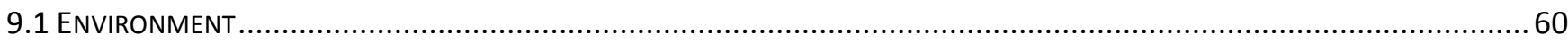

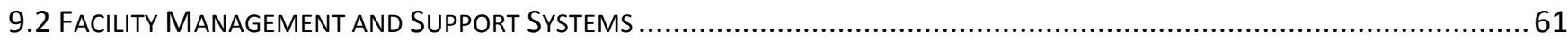

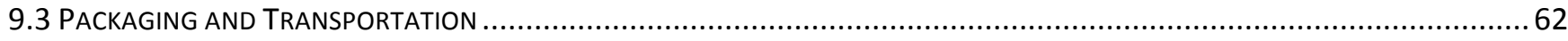

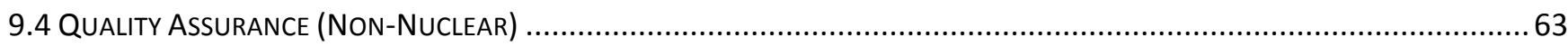

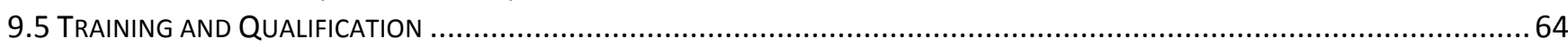

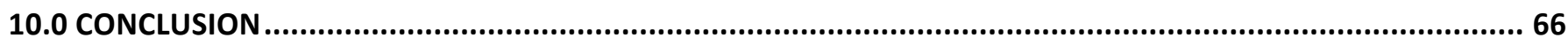

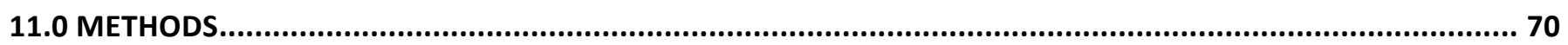

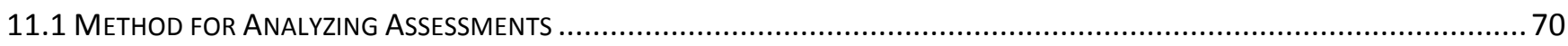

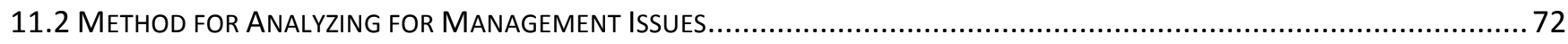

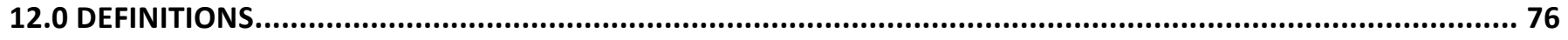

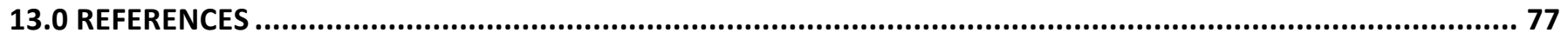




\subsection{Executive Summary}

This report presents the results from an analysis of issues and assessments in LLNL's Issues Tracking System (ITS). The analysis is conducted to identify issues that may require additional management attention and noncompliances that may not have been previously identified that meet the threshold for reporting to the DOE Noncompliance Tracking System (NTS) or to the DOE Safeguards and Security Information Management System (SSIMS).

This report includes all data in ITS through June 2012; however, the analysis in this report primarily focuses on deficiencies identified in the last twelve months that fall within the DOE Office of Enforcement regulated subjects.

The analysis of issues concluded that data for 15 of the 23 Office of Enforcement regulated safety/ security subjects were within expected variation or there was a decreasing trend in the data. The data for six safety subjects and two security subject met a common test and were discussed further. Three of the six safety subjects met an action limit and were analyzed to resolution.

Analysis of data from one of the security subjects where a common test was met did identify a potential security related programmatic (systemic) or repetitive noncompliance. Additional analysis is needed to make a final determination. The complete Section 8.0 of this report is considered Official Use Only. For a copy of the complete Section 8.0 contact Norma McTyer at mctyer1@1lnl.gov. 


\subsection{Introduction}

The DOE Office of Enforcement expects all contractors, including LLNL, to "implement comprehensive management and independent assessments that are effective in identifying deficiencies and broader problems in safety and security programs, as well as opportunities for continuous improvement within the organization." In addition, the DOE Office of Enforcement expects that "issues management databases are used to identify adverse trends, dominant problem areas, and potential repetitive events or conditions."

LLNL has an assessment program of management and independent assessments to identify deficiencies, management issues and opportunities for improvement.

Document DES-0048, LLNL Assessment Program, Section 3.0 discusses assessments that address the subjects regulated by DOE Rules.

LLNL has in place a process to identify, report and manage deficiencies of nuclear safety, worker safety and health (WSH), and classified information security (CIS) requirements. LLNL requires that all nuclear safety, WSH, and CIS deviations from requirements be tracked as "deficiencies" in the LLNL ITS. Individual deficiencies are analyzed for nuclear safety, WSH, and CIS noncompliances that may meet the threshold for reporting to the DOE NTS or the SSIMS. This report presents the results of the analysis of the set of issues in the ITS.

This report meets the expectations defined by the DOE Office of Enforcement to evaluate implementation of internal processes for conducting assessments to identify noncompliances, analyzing the noncompliances found in these assessments, screening and reporting noncompliances, and evaluating the data in the ITS database to identify adverse trends, dominant problem areas, and potential repetitive events or conditions.

This performance analysis is designed to answer two questions:

1. Is LLNL assessing its programs (e.g., electrical safety program) and their state of compliance? (Section 3.0)

2. What is LLNL finding in its assessments? (Sections 4.0 through 9.0)

The results from analyzing the deficiencies are presented in accordance with the two primary NTS and SSIMS reporting thresholds:

1) WSH and nuclear safety noncompliances related to certain events or conditions and

2) WSH, nuclear safety, and CIS noncompliances that are management issues.

In addition, the report analyzes WSH noncompliances to determine if any fall under the "Severity Level I Noncompliance" threshold. This threshold applies to WSH noncompliances only. 


\subsection{Assessments}

Assessments were evaluated to assure that LLNL management and independent assessments are comprehensive and are effective in identifying deficiencies and broader problems in safety and security programs and opportunities for continuous improvement within LLNL.

\subsection{Assessments Conducted}

During the 12-month period ending June 2012, 1,123 internal assessments were completed, a 3\% increase from the previous 12-month period. More specifically, LLNL completed 760 management observations, verifications and inspections (MOVIs), 234 management self-assessments (MSAs), 63 other internal assessments, 39 internal independent assessments (IIAs), 14 joint functional area manager (FAM) / line assessments (JFLMAs), seven quick ITS assessments, and six readiness reviews. During this same 12-month period, 142 external assessments, 101 events, and one other external assessment were also completed.

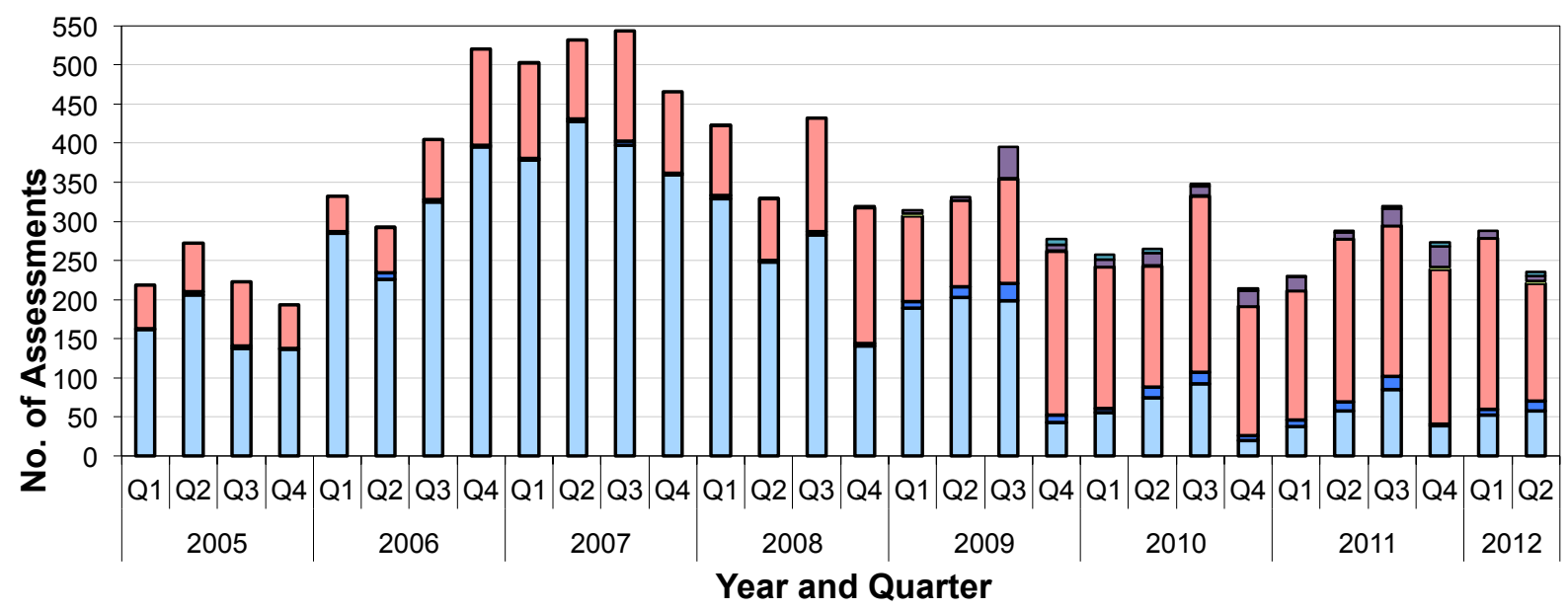

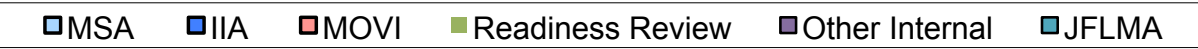

Figure 1. The number of internal assessments by type categories and quarter.

From the first to the second quarter in 2012, there was an increase in the number of MSAs, IIAs, readiness reviews, and JFLMAs completed; however, the overall number of internal assessment completed decreased, as shown in Figure 1. It appears that the reason for the decrease is that the number of MOVIs and other internal assessments completed decreased from the first to the second quarter in 2012. Fire protection inspections and NIF 2012 annual walkabouts of Integration Work Sheets (IWSs) were completed in both quarters of 2012, with more in the first quarter than the second quarter. Also, 24 walkthroughs within the Materials Engineering Division were completed in the first quarter of 2012 and none were completed in the second quarter of 
2012. Five of the eight Principal Directorates completed fewer MOVIs in the second quarter of 2012 compared to the first quarter, the Director's Office, Engineering, Global Security, NIF and Photon Science, and the Operations and Business Directorate. The number of other internal assessments completed decreased by three from the first to the second quarter in 2012.

There has been a common pattern in the number of internal assessments conducted since 2009 through 2011; the number of internal assessments increases from the first to the third quarter of the calendar year and then decreases in the fourth quarter (Figure 1). Assessments are scheduled by fiscal year and must be completed by September 30 of each year. This pattern was discussed in detail in the previous analysis report. This pattern did not continue through the second quarter in 2012 because the number of assessments completed decreased from the first to the second quarter in 2012, as discussed above.

LLNL develops the LLNL Institutional Assessment Plan (IAP) for each fiscal year and the IAP schedules six main types of formal assessments performed at LLNL. The development of the LLNL Assessment Program (DES-0048) and the Institutional Assessment Plan (PRO-0049), ensure that results from these assessments are entered into ITS and responses are generated. 
Since MSAs and IIAs are included in the IAP, IAP data was reviewed and it was determined that the same pattern is seen in the planning of assessments included in the IAP. More assessments included in the IAP are scheduled or due in the third quarter of the calendar year, or the fourth quarter of the fiscal year, as shown in Figure 2.

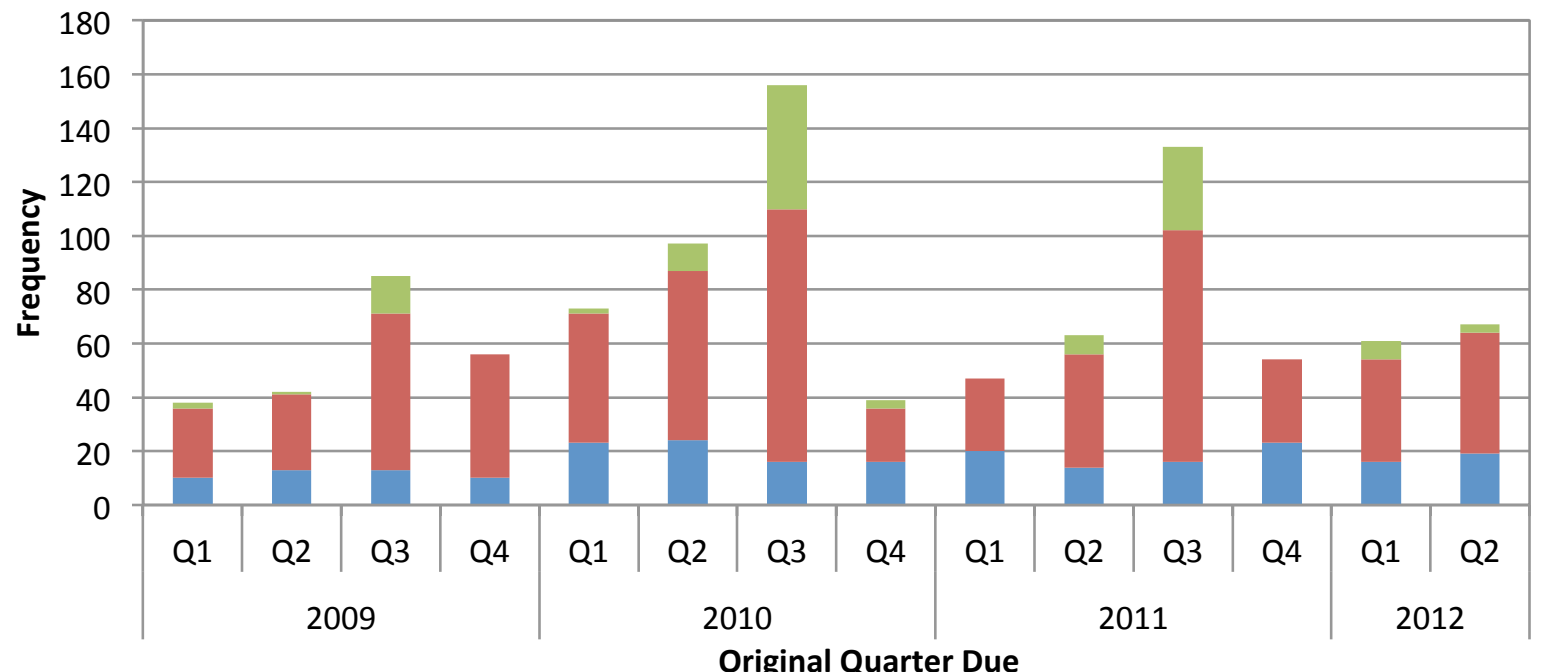

\footnotetext{
Assessments completed before original quarter due $\quad$ Assessments completed in original quarter due Assessments completed after original quarter due
}

Figure 2. Assessments from the IAP by the quarter due and completed early, on-time, or late.

When evaluating the number of assessments completed each quarter using the process control chart shown in Figure 3, no common tests were recently met. Section 11.0 explains the common tests related to assessment data.

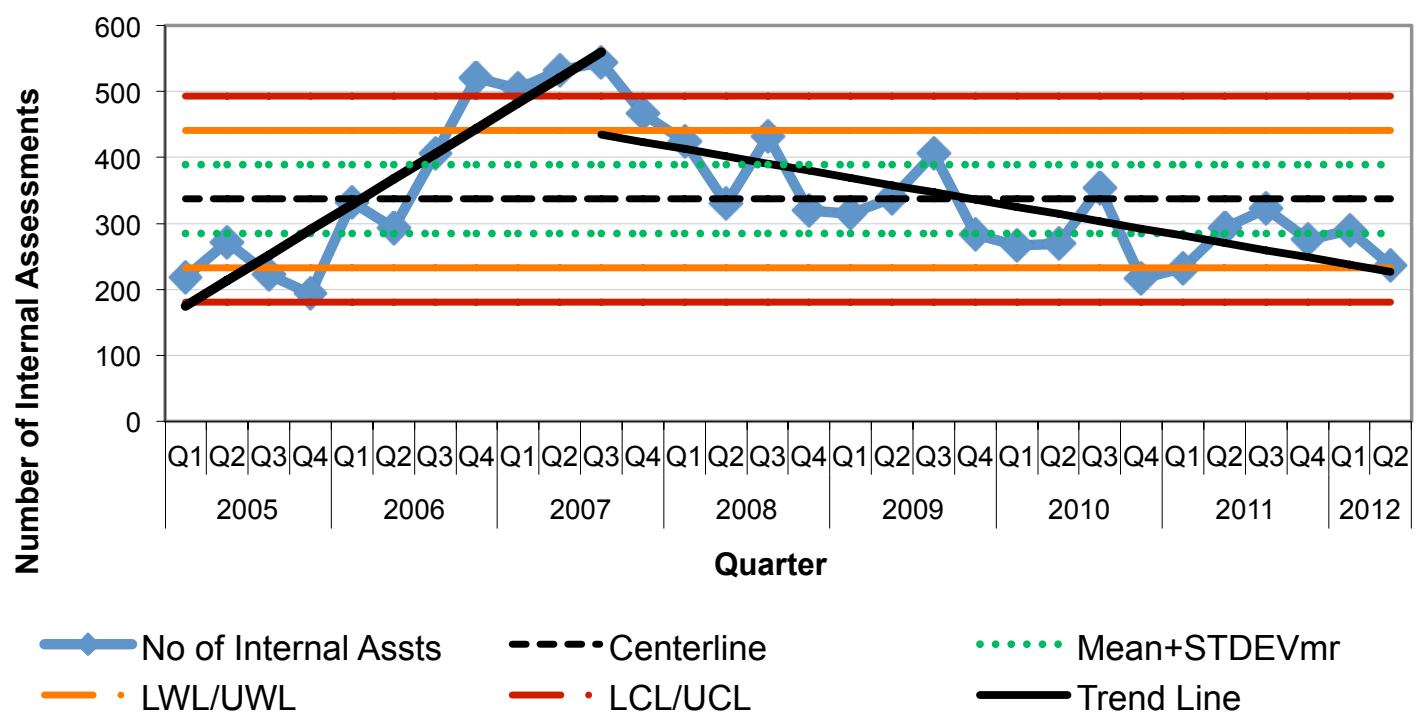

Figure 3. Frequency control chart of internal assessment data. 
In reviewing all internal assessment data from 2005 through the second quarter of 2012, there appears to be a non-random pattern, an increasing trend in the number of internal assessments from the first quarter in 2005 to the third quarter in 2007, and a decreasing trend from the third quarter in 2007 to the second quarter in 2012. Testing these potential trends using simple linear regression shows both the increasing and decreasing trends are statistically significant ( $p$-value $<0.01$ ); they are shown in Figure 3 as two separate trend lines. The results of the statistical test support the observation that the number of assessments entered into ITS has continued to decreased since the third quarter in 2007.

The decreasing trend since 2007 can be attributed to assessment process changes and fewer unique assessments being conducted in 2009, 2010, 2011, and 2012. Following the transition to LLNS management, discussions began regarding changing the structure and processes for conducting management and independent assessments. Prior to contract transition, most assessments were conducted by the directorates, following requirements in the LLNL ESEH Manual that prescribe the topical areas and frequency for self-assessments, subject matter inspections, and facility inspections. This practice resulted in unique entries in ITS for each assessment at each location because each directorate scheduled its own assessments and inspections. In late 2008, LLNL assigned the Facilities and Infrastructure Directorate to manage most of the facilities and to inspect them. These centralized responsibilities have resulted in fewer assessment entries in ITS and account for current reduced entries. Also in 2008, responsibility for entering the results of self-assessments of ES\&H-related functional/topical areas began to transition from the directorates to the functional area managers.

This analysis concludes that the number of internal assessments increased when comparing the recent 12-month period to the previous 12-month period. In comparing the most recent quarter of data analyzed to the previous quarter, the number of internal assessments decreased. This decrease is due to a decrease in MOVIs and other internal assessments completed in the second quarter of 2012. The fact that fewer assessments are completed is not in itself an indication of a weaker assessment program. It is possible that the assessments conducted are more effective. When evaluating the number of assessments conducted each quarter using a process control chart no common tests were met.

\subsection{Assessment Effectiveness at Identifying Issues}

To evaluate whether there has been a change in assessment effectiveness, issues in all functional areas from all sources were extracted from the LLNL ITS. The data showed 1,240 deficiencies with issue identification dates in July 2011 - June 2012, a 4\% reduction from the previous 12-month period and 1,119 observations with issue identification dates in July 2011 - June 2012, a 14\% reduction from the previous 12-month period. Of the 1,240 deficiencies, 950 were designated as WSH and/or nuclear safety deficiencies, a $2 \%$ increase from the previous 12 -month period and 42 were designated as CIS, a $2 \%$ increase from the previous 12-month period.

The number of deficiencies and observations identified each quarter has been fairly consistent since the fourth quarter of 2010 (Figure 4). There was a decrease in the number of deficiencies and observations identified from the first to the second quarter in 2012. Typically more than half of deficiencies identified per quarter are categorized as 
WSH, nuclear safety, and / or CIS (Figure 4). The average number of issues identified per assessment completed in the12-month period (July 2011 - June 2012) is two, the same as the previous 12-month period, and $51 \%$ of all assessments completed in the twelve months had at least one issue. Five assessments completed in the twelve months identified a total of 30 issues: the Work Control-work scope review, Facility Management Walkthrough, Blue Ribbon Assessment Team Assessment, FY-12 Security Incidents, and the FY11 Annual Full-Participation Emergency Exercise.

Although the number of deficiencies and observations identified each quarter has been fairly consistent since the fourth quarter of 2010 (Figure 4), a statistical test based on simple linear regression concludes that the number of deficiencies and observations have a statistically significant decreasing trend over time from 2009 to the second quarter in 2012 ( $\mathrm{p}$-value $<0.05$ ).

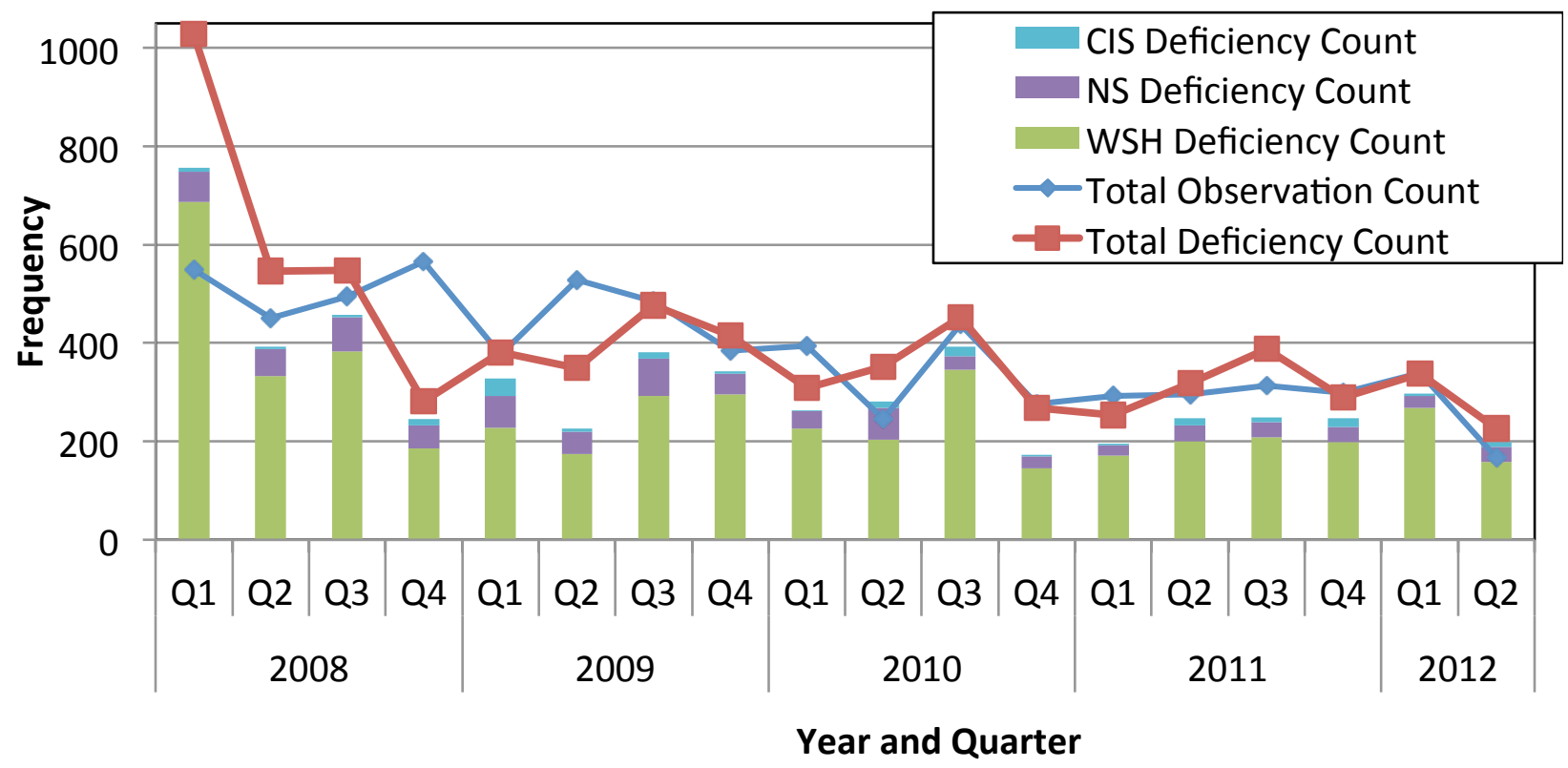

Figure 4. The number of ITS deficiencies and observations per quarter by deficiency category (WSH, nuclear safety, and CIS). 
Figure 5 displays deficiencies across all functional areas and highlights those related to nuclear safety (green), WSH (red), and CIS (orange). The most frequent functional areas with identified deficiencies are quality assurance, WSH, emergency management, and safeguards and security (Figure 5). The data also included six deficiencies identified in the last twelve months without a designated functional area, three of which are in open status. Subjects in the Office of Enforcement regulated safety and security functional areas are analyzed and the results are discussed in Sections 6.0, 7.0, and 8.0.

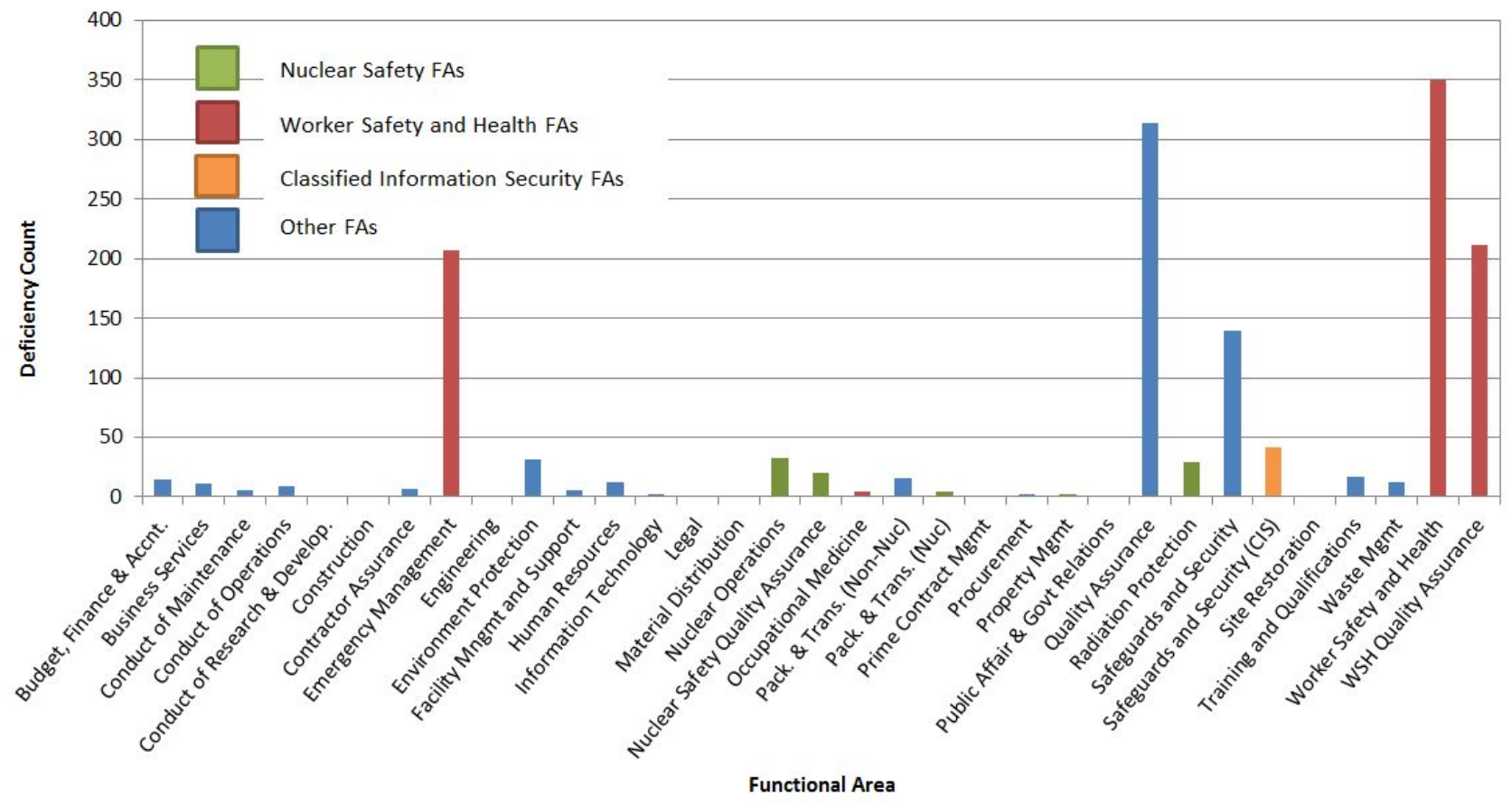

Figure 5. Number of deficiencies identified in July 2011 - June 2012 per functional area. 
Formal internal sources of WSH and nuclear safety deficiencies are IIAs and JFLMAs. Figure 6 displays the number of IIAs and JFLMAs performed from 2009 to 2012 (as of October 1, 2012). For the most recent four years, $(2009,2010,2011$, and 2012) at least one IIA or JFLMA has been completed in all of the six regulated functional areas. In the last four years only one JFLMA was performed in the occupational medicine functional area; however, since the beginning of 2009, 10 external assessments, four MSAs, and four MOVIs within the occupational medicine functional area have been completed.

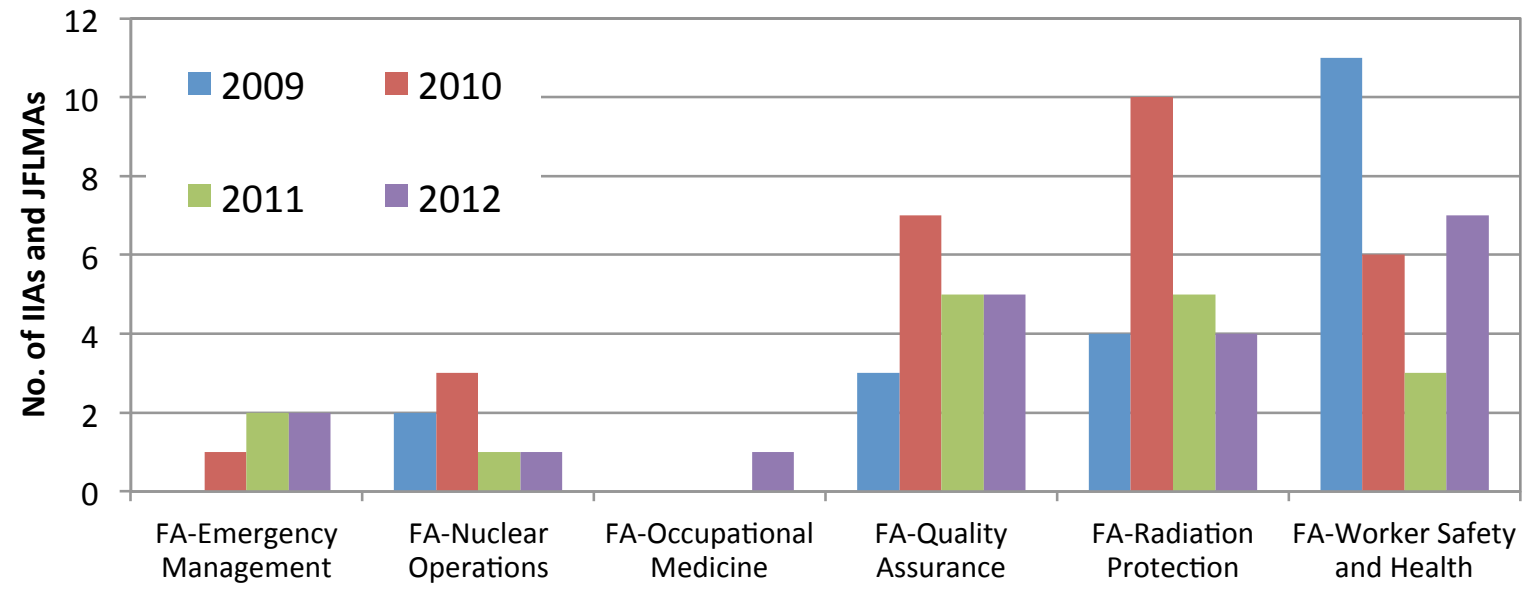

Nuclear Safety and WSH Functional Areas

Figure 6. Number of IIAs and JFLMAs of regulated functional areas.

This analysis concludes that both the total number of deficiencies and observations decreased from the previous 12-month period. In comparing the most recent quarter of data analyzed to the previous quarter, the total number of deficiencies and observations also decreased; however, the average number of issues per assessment is the same for this 12-month period compared to the previous 12-month period. Typically more than half of deficiencies identified per quarter are categorized as WSH, nuclear safety, and/ or CIS. In this 12-month period, LLNL saw an increase in the percentage of deficiencies categorized as nuclear safety and WSH or CIS. This increase may be attributed to the completion of IIAs and JFLMAs in all six regulated functional areas in the first six months of 2012. 


\subsection{Issues Evaluated for Reporting to NTS}

Issues from assessment, occurrence, and analysis reports are evaluated as the reports are distributed to determine whether NTS-reportable deficiencies are being identified. From January 2012 through September 2012, 37 reports were prepared and made available and 106 issues were evaluated for noncompliance reporting. Figure 7 shows the number of reports completed each month and subject to independent evaluation for noncompliance reporting, and the number of issues to be evaluated each month. As of October 2012, seven reports were pending a documented noncompliance evaluation, as shown in red in Figure 7. Many of these reports have been evaluated, but the documentation of the evaluation is pending entry into ITS.

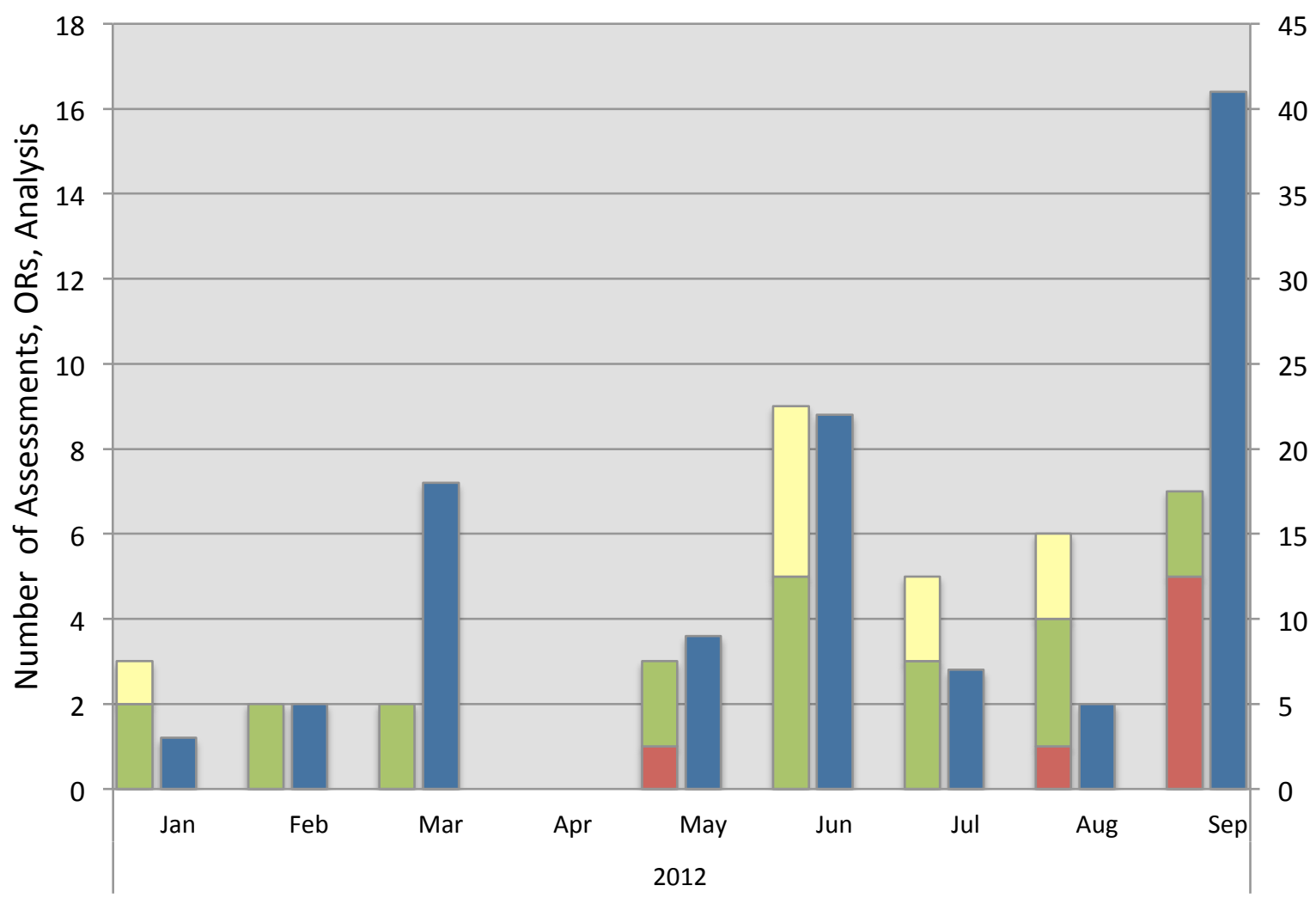

\section{Pending Evaluation \\ $\square$ Evaluated-Not Reportable $\square$ Evaluated-Reportable \\ Pending Submittal to NTS Number of Issues}

Figure 7. Assessments, final occurrence reports and analysis reports issued each month and their evaluation status. 
In the 12-month period, $67 \%$ percent of deficiencies entered into ITS were marked as WSH deficiencies, 9\% were marked as nuclear safety deficiencies, and 3\% were marked as CIS deficiencies. The WSH and CIS percentage is the same as the previous 12-month period, the nuclear safety percentage is a slight increase from the previous 12-month period of $8 \%$.

In the second quarter of 2012, the most recent quarter analyzed, $70 \%$ of deficiencies entered into ITS were marked as WSH deficiencies, $14 \%$ of deficiencies were marked as nuclear safety deficiencies, and $4 \%$ were marked as CIS deficiencies. The WSH percentage decreased from the previous quarter, but the nuclear safety and CIS percentages increased from the previous quarter, as shown in Table 1.

Table 1. ITS deficiencies entered and noncompliances reported to NTS or SSIMS.

\begin{tabular}{|c|c|c|c|c|c|c|c|c|}
\hline Year & Qrt & $\begin{array}{l}\text { Obs. } \\
\text { in ITS }\end{array}$ & $\begin{array}{l}\text { Defs. } \\
\text { in ITS }\end{array}$ & $\begin{array}{c}\text { WSH } \\
\text { Noncompliances } \\
\text { (NCs) }\end{array}$ & $\begin{array}{l}\text { WSH NCs } \\
\text { Reported } \\
\text { to NTS }\end{array}$ & NS NCs & $\begin{array}{l}\text { NS NCs } \\
\text { Reported } \\
\text { to NTS }\end{array}$ & CIS NCs \\
\hline \multirow{4}{*}{2010} & Q1 & 395 & 309 & $226(73 \%)$ & $6(3 \%)$ & 35 (11\%) & $0(0 \%)$ & $2(1 \%)$ \\
\hline & Q2 & 246 & 352 & $204(58 \%)$ & $4(2 \%)$ & $64(18 \%)$ & $4(9 \%)$ & $13(4 \%)$ \\
\hline & Q3 & 438 & 453 & $346(76 \%)$ & $5(1 \%)$ & $28(6 \%)$ & $1(4 \%)$ & $19(4 \%)$ \\
\hline & Q4 & 276 & 268 & $146(54 \%)$ & $3(2 \%)$ & $23(9 \%)$ & $1(4 \%)$ & $4(1 \%)$ \\
\hline \multirow{4}{*}{2011} & Q1 & 292 & 254 & $171(67 \%)$ & $3(2 \%)$ & $21(8 \%)$ & $1(5 \%)$ & $3(1 \%)$ \\
\hline & Q2 & 296 & 319 & $200(63 \%)$ & $4(2 \%)$ & $32(10 \%)$ & $3(9 \%)$ & $15(5 \%)$ \\
\hline & Q3 & 313 & 388 & 209 (54\%) & $3(1 \%)$ & $30(8 \%)$ & $2(7 \%)$ & $9(2 \%)$ \\
\hline & Q4 & 299 & 289 & $198(69 \%)$ & $1(<1 \%)$ & $31(11 \%)$ & $1(3 \%)$ & $18(6 \%)$ \\
\hline \multirow{2}{*}{2012} & Q1 & 340 & 337 & $168(80 \%)$ & $2(1 \%)$ & $25(7 \%)$ & $0(0 \%)$ & $5(1 \%)$ \\
\hline & Q2 & 167 & 226 & $158(70 \%)$ & $1(<1 \%)$ & 31 (14\%) & $0(0 \%)$ & $10(4 \%)$ \\
\hline
\end{tabular}

Note: The data in columns 6 and 8 include "combination reports" (i.e., NUC/WSH noncompliance reports as both a report for nuclear safety and a report for WSH).

Of the WSH and nuclear safety deficiencies, 99\% were site-reported and 1\% were reported to the DOE NTS in the second quarter of 2012,, a decrease from previous analyses where the percent reported to the DOE NTS is around two or three percent. No comparison was made between site-reported and SSIMS reported noncompliances. 
LLNL's reporting of WSH and nuclear safety noncompliances was compared to other NNSA sites. From July 2011 through June 2012, LLNL reported the fourth highest number of noncompliances to the DOE NTS and LLNL had the fourth highest number of effort hours (hours worked), as shown in Figure 8. Like all NNSA sites, LLNL's number of reported noncompliances is less than the number of occurrences that meet the DOE NTS reporting threshold, implying that no NNSA site reports a noncompliance to NTS for every occurrence that meets the DOE defined reporting thresholds.

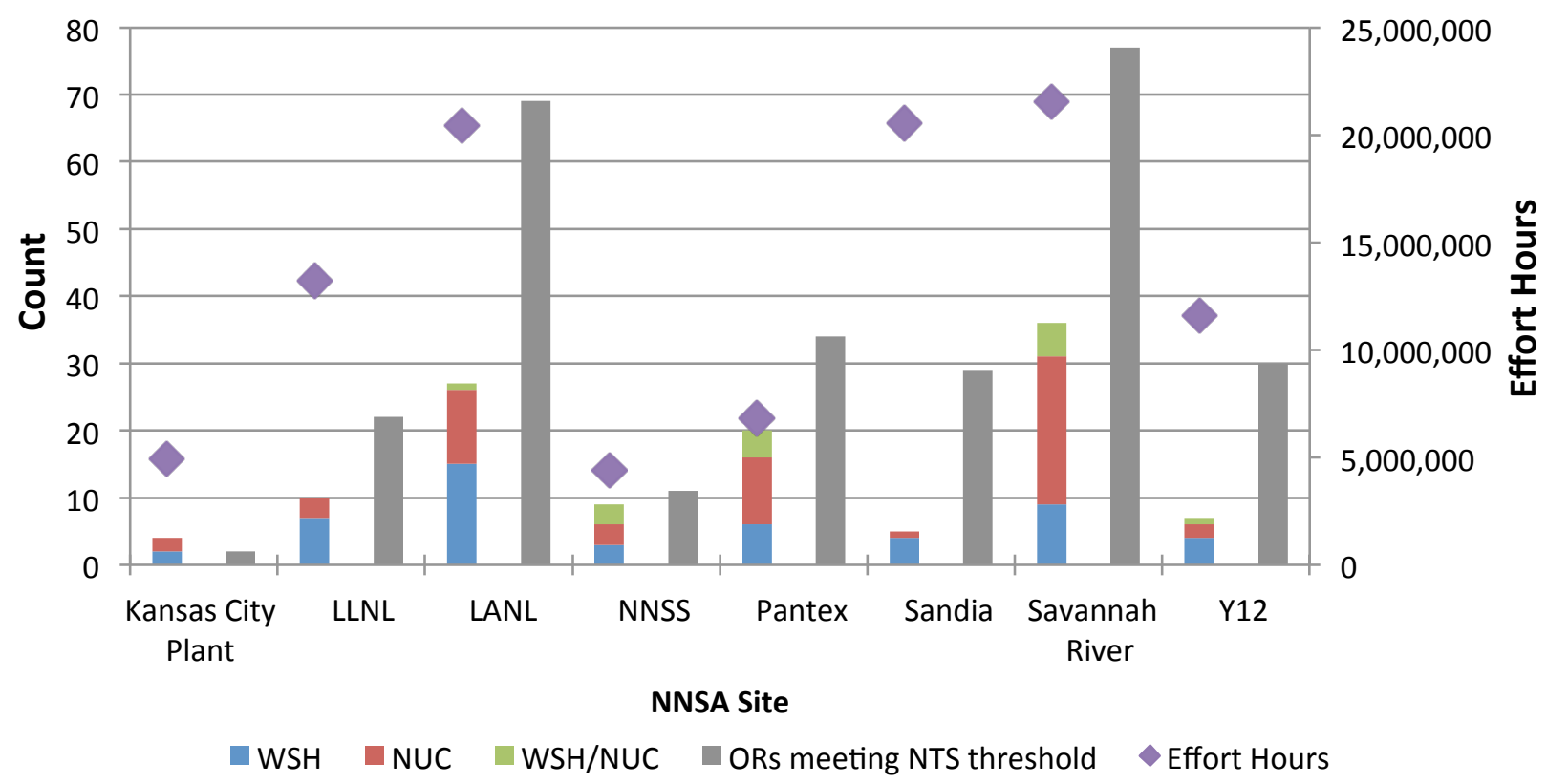

Figure 8. Noncompliances reported to the DOE NTS across NNSA sites from July 2011 through June 2012.

In comparing LLNL's number of NTS reported noncompliances to other NNSA sites in the last three years, LLNL's position has changed having the second highest number of NTS reported noncompliances in 2010 to having the fourth highest number of NTS reported noncompliances in 2012 (as of October 15, 2012). LLNL is expecting at least three NTS reports to be submitted to the DOE NTS by January 1, 2013; however, the year-end total would still be a decrease from 2011. 
In Figure 9, LLNL shows a decreasing number of noncompliances reported to the DOE NTS per year from 2010 to October 15, 2012. NNSS and Sandia show a similar trend; however, the Kansas City Plant, LANL, and Pantex all show an increasing trend in the number of noncompliances reported to the DOE NTS from 2010 to October 15, 2012.

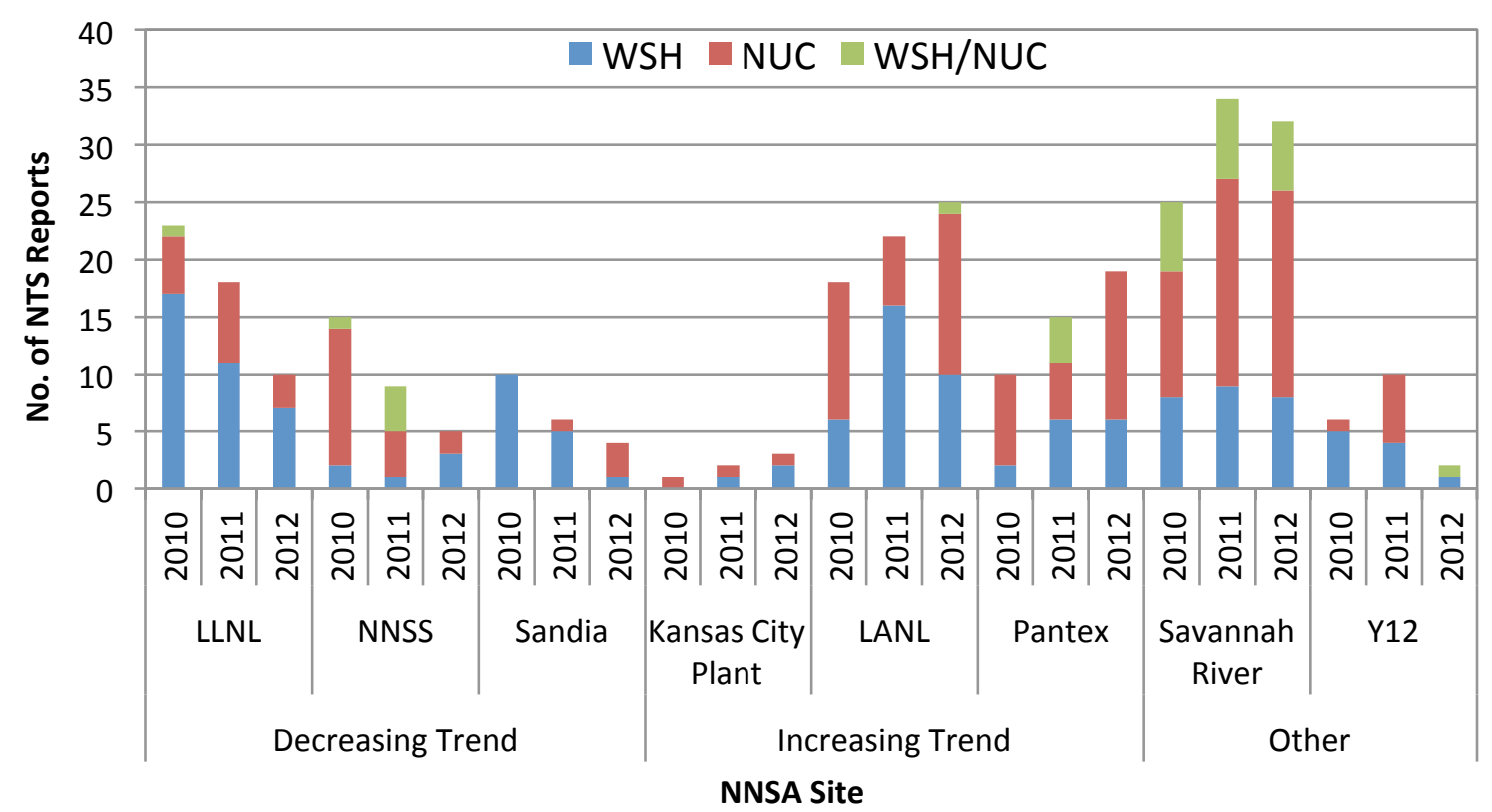

Figure 9. Noncompliances reported to the DOE NTS across NNSA sites for the last three years (as of October 15, 2012).

One possible reason for a decrease in LLNL NTS reported noncompliances is: fewer occurrences were identified that met the NTS reporting threshold. So far in 2012 (as of October 15, 2012), 23 occurrences have met the DOE NTS reporting threshold, compared to 25 in 2011 and 23 in 2010. Therefore, there has not been a decrease in the groups of occurrences meeting the NTS reporting threshold (Figure not shown).

However, Figure 10 shows a decrease in occurrences reported in 2012 that are typically automatic noncompliances, occurrences categorized as exposures above limits (treatment or no treatment) and positive Unreviewed Safety Questions. Also, eight of the 23 occurrences reported in 2012 were categorized as near miss occurrences, the highest number of near miss occurrences in five years (Figure 10). This type of occurrence requires an evaluation of whether a noncompliance was related to or caused the occurrence. Not all near miss occurrences have an associated safety noncompliance.

Even though the number of occurrences meeting the NTS reporting threshold is similar for the last three years, the proportion of near miss occurrences is different for each year. This variation can affect the number of noncompliances identified and reported to the DOE NTS. 


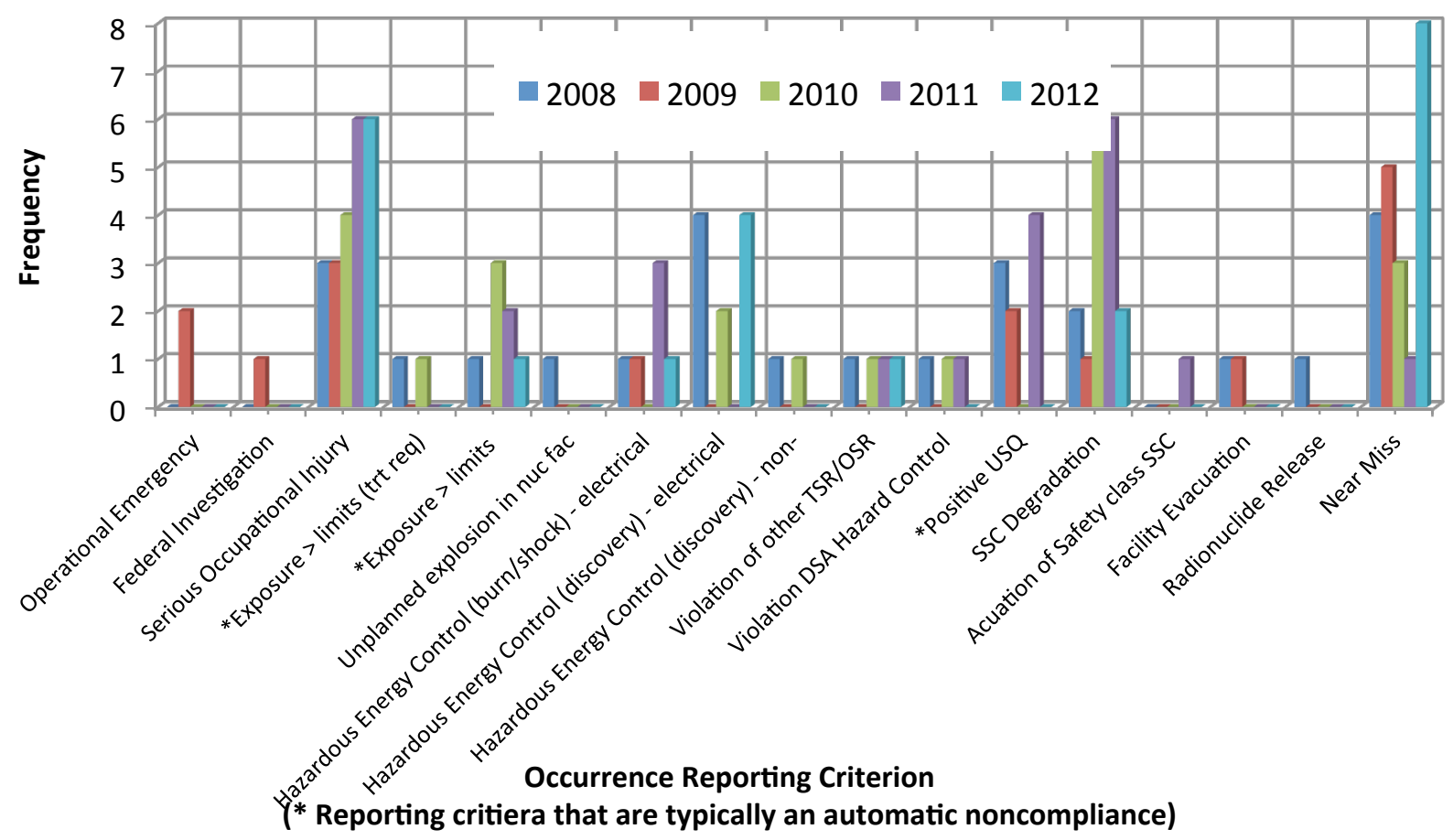

Figure 10. LLNL reported noncompliances to the DOE NTS for the last three years (as of October 15, 2012).

Another possible reason for the decrease in LLNL NTS reported noncompliances is that LLNL has a better understanding of what the Office of Enforcement wants and expects to see reported to the DOE NTS rather than to site-reported in the LLNL ITS. In the past three years, LLNL has undergone regulatory assistance reviews in each of the three regulated areas, WSH, CIS, and nuclear safety. During these reviews the Office of Enforcement provided feedback to LLNL regarding our noncompliance reporting, specifically those noncompliances related to occurrences. LLNL has also discussed a number of occurrences and potential noncompliances with LSO and the Office of Enforcement to determine the level of reporting. These interactions have helped LLNL better determine those noncompliances that the Office of Enforcement expects to see reported to the DOE NTS.

Figure 11 shows that in 2008, 2009, and 2010 occurrences that met the DOE NTS reporting threshold were either determined to have a safety noncompliance associated with the occurrence and were reported to NTS, or no safety noncompliance existed. However, in more recent years, 2011 - 2012 (as of October 15, 2012), LLNL has been sitereporting some noncompliances revealed by occurrences that meet the DOE NTS reporting threshold and determining that fewer occurrences meeting the reporting threshold have an associated specific noncompliance, but the occurrence may have identified a general noncompliance. 


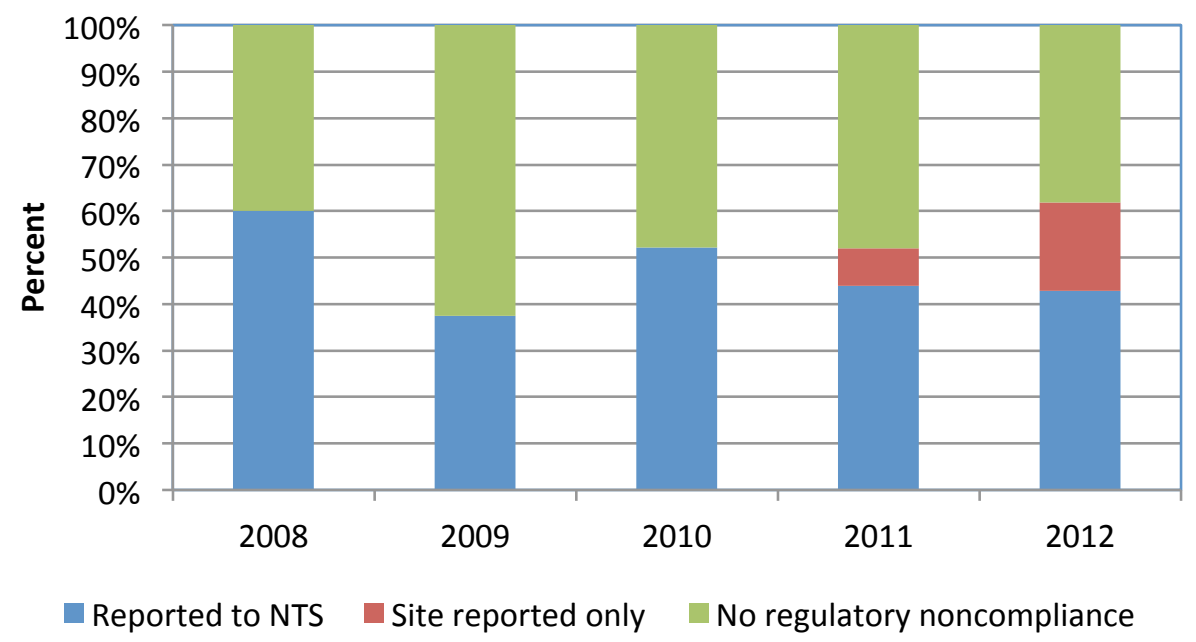

Figure 11. Noncompliance reporting status for those occurrences that meet the NTS reporting threshold.

All of the site-reported noncompliances reported in 2011 and 2012 were related to worker safety and health, not nuclear safety. The site-reported noncompliance is often related to a hazard or task not identified, a noncompliances with an internal procedure, ES\&H Manual Document 2.2, "LLNL Institutional-Wide Work Planning and Control Process." Table 2 describes the specific noncompliance citation for the site reported WSH noncompliances reported in 2011 and 2012. Two of the site-reported WSH noncompliances from Table 2 were discussed with both LSO and the Office of Enforcement; all agreed that site-reporting these noncompliances was sufficient. There are a number of occurrences categorized as performance degradation related occurrences that do not have a nuclear safety regulatory noncompliance associated with the occurrence, but a physical nuclear safety deficient condition was discovered during the routine surveillance process. These deficient conditions are categorized in the LLNL ITS as nuclear safety deficiencies; however, these are not considered to be site reported to the DOE Office of Enforcement and are not included in Figure 11.

Table 2. Details of site-reported WSH noncompliances in 2011 and 2012.

\begin{tabular}{|lll|}
$\begin{array}{l}\text { Site reported } \\
\text { noncompliance }\end{array}$ & Related OR & Notes \\
\hline $\begin{array}{l}\text { ES\&H Manual Document } \\
\begin{array}{l}\text { 16.1, an employee was not } \\
\text { taken to health services as } \\
\text { required }\end{array}\end{array}$ & $\begin{array}{l}\text { Security Worker Receives Minor } \\
\text { Electrical Shock In Building OS651N } \\
\text { (OR-11-03) }\end{array}$ & $\begin{array}{l}\text { This noncompliance was not a } \\
\text { cause of the event }\end{array}$ \\
\hline $\begin{array}{l}\text { ES\&H Manual Document } \\
\begin{array}{l}\text { 2.1 and 2.2, a task was not } \\
\text { identified }\end{array}\end{array}$ & $\begin{array}{l}\text { Custodian Fractures Wrist During } \\
\text { Floor Maintenance Activities in }\end{array}$ & \\
\hline $\begin{array}{l}\text { General 851, hazard not } \\
\text { identified }\end{array}$ & $\begin{array}{l}\text { Finger tip severed while closing } \\
\text { bullet resistant enclosure south of } \\
\text { Building 332 (OR-12-03) }\end{array}$ & $\begin{array}{l}\text { This noncompliance was discussed } \\
\text { with LSO and the Office of }\end{array}$ \\
& & $\begin{array}{l}\text { Enforcement. All agreed that site } \\
\text { reporting was sufficient. }\end{array}$ \\
\hline General 851 and general & Building 151 Uncontrolled & This noncompliance was discussed \\
\hline
\end{tabular}




\begin{tabular}{|c|c|c|}
\hline $\begin{array}{l}\text { NFPA 70E, uncontrolled } \\
\text { electrical hazardous } \\
\text { energy source }\end{array}$ & $\begin{array}{l}\text { Hazardous Electrical Energy Source } \\
\text { Discovery With Relocatable Power } \\
\text { Tap (OR-12-04) }\end{array}$ & $\begin{array}{l}\text { with LSO and the Office of } \\
\text { Enforcement. All agreed that site } \\
\text { reporting was sufficient. }\end{array}$ \\
\hline $\begin{array}{l}\text { ES\&H Manual Document } \\
2.2 \text {, hazard not identified }\end{array}$ & $\begin{array}{l}\text { Worker Fractures Ankle Accessing } \\
\text { Space Below Computer Floor in } \\
\text { Building } 451 \text { (OR-12-22) }\end{array}$ & \\
\hline $\begin{array}{l}\text { California Vehicle Code } \\
\text { and ES\&H Manual } \\
\text { Document 21.3, LLNL } \\
\text { bike used inappropriately }\end{array}$ & $\begin{array}{l}\text { Bicycle Accident on Outer Loop } \\
\text { Road Results in Fractured Bones } \\
\text { (OR-12-45) }\end{array}$ & \\
\hline
\end{tabular}

This review found that the 12-month percentage of site-reported WSH and CIS deficiencies did not change from the previous 12-month period, and the 12-month nuclear safety percentage slightly increased from the previous 12 -month period. In comparing the quarterly percent, there was a recent decrease in the percent of WSH site-reported deficiencies and an increase in the percent of nuclear safety and CIS sitereported deficiencies. LLNL shows a decreasing number of noncompliances reported to the DOE NTS per year from 2010 to October 15, 2012. NNSS and Sandia show a similar trend; however, Kansas City Plant, LANL, and Pantex all show an increasing trend in the number of noncompliances reported to the DOE NTS from 2010 to October 15, 2012. These results are subject to change based on the input of data in the fourth quarter of 2012. Like all NNSA sites, LLNL's number of reported noncompliances is less than the number of occurrences that meet the DOE NTS reporting threshold, implying that no NNSA site reports a noncompliance to NTS for every occurrence that meets the DOE defined reporting thresholds.

There are three known possible reasons for the decrease in LLNL NTS reported noncompliances. First, there was a decrease in occurrences reported in 2012 that are typically automatic noncompliances, such as, occurrences categorized as exposures above limits and positive Unreviewed Safety Questions. Second, even though the number of occurrences meeting the NTS reporting threshold is similar for the last three years, suggesting that the number of noncompliances reported to the DOE NTS is also similar, the proportion of near miss occurrences reported in 2012 is the highest it has been in the last five years. This can affect the number of noncompliances identified and reported to the DOE NTS because near miss occurrences do not result in an automatic noncompliance. Third, in working with the Office of Enforcement and LSO, LLNL has developed a better understanding of those noncompliances related to occurrences that the Office of Enforcement would expect to see reported to the DOE NTS. In 2011 and 2012, six noncompliances related to occurrences were site-reported-only using the LLNL ITS, which would affect the number of reports LLNL submits to the DOE NTS. Two of the six site-reported-only noncompliances were discussed with the Office of Enforcement and LSO and it was determined that site-reporting was sufficient. 


\subsection{Noncompliances Related to Events or Conditions}

DOE expects that noncompliances associated with certain Occurrence Reporting and Processing System (ORPS) reporting criteria be reported to the Noncompliance Tracking System (NTS), regardless of the severity of the noncompliance. LLNL uses the NTS reporting thresholds specified in the DOE Safety and Security Enforcement Coordinator Handbook, Tables III-1 and III-3, and described in DES-0083, Regulatory Compliance Assurance Program for DOE Safety and Security Requirements.

Occurrences are promptly reviewed for NTS-reportable worker safety and health (WSH) and nuclear safety noncompliances as they are reported into the ORPS. The initial review is based on the description of the occurrence; however, after the occurrence is further characterized and analyzed for causes, additional information may be available that identifies noncompliances that should be reported. The Contractor Assurance Office works with the directorate points-of-contact (POCs) to make this determination.

\subsection{Worker Safety and Health Results}

LLNL submitted 62 occurrence reports to ORPS from July 2011 to June 2012. Fifteen occurrences submitted to ORPS were assigned a reporting criterion that satisfied the DOE Office of Enforcement WSH criteria for mandatory reporting to the DOE NTS. Each occurrence was evaluated for possible noncompliances; four occurrences were identified as having WSH deficiencies reportable to the DOE NTS:

1. NA-LSO-LLNL-LLNL-2012-0012, Recurring Subcontractor Hazardous Electrical Energy Control Issues. The associated noncompliance was reported in NTS-LSOLLNL-LLNL-2012-0002, Repetitive noncompliance with vendor implementation of the hazardous energy process.

2. NA-LSO-LLNL-LLNL-2012-0025, Improper use of portable ladder in Building 331. The associated noncompliance was reported in NTS-LSO-LLNL-LLNL-20120007, Improper use of portable ladder in Building 331.

3. NA-LSO-LLNL-LLNL-2012-0027, B194 vacuum ion pump controller unexpected electrical source. The associated noncompliance was reported in NTS-LSO-LLNLLLNL-2012-0005, Discovery of an unexpected hazardous electrical energy source.

4. NA-LSO-LLNL-LLNL-2012-0026, Building 381 Falling Threaded Bolt - Near Miss. NTS-LSO-LLNL-LLNL-2012-0011, A barricade was not put in place, exposing employees to falling objects.

The remaining 11 occurrences were determined for the following reasons to not reveal noncompliances with DOE WSH requirements or they did not warrant a noncompliance report to the DOE NTS. All of the noncompliance evaluations for the following 11 occurrences are documented in the LLNL ITS.

1. NA-LSO--LLNL-LLNL-2011-0045, Insect Bite Results in Employee Hospital Stay Exceeding 48-Hours, did not constitute a noncompliance with DOE WSH 
requirements, neither NTS-reportable nor site-reportable only. The causal analysis determined that, according to the Health Services clinician, the dispensing of the antibiotic to the patient was reasonable and consistent with medical practice.

2. NA-LSO--LLNL-LLNL-2011-0046, Minor Shock During Precision Machining Work, did not constitute a noncompliance with DOE WSH requirements, neither NTSreportable nor site-reportable only. The defective and failed controller/motor involved in this event met the criteria for legacy Authority Having Jurisdiction (AHJ) accepted equipment and was accepted during the implementation of the AHJ program. Therefore, and as stated in the final occurrence report, the AHJ inspection was not required for this legacy piece of equipment and the lack of an $\mathrm{AHJ}$ inspection is not a WSH noncompliance.

3. NA-LSO--LLNL-LLNL-2011-0059, Employee Fall While Walking Outside Building 132S Resulting in Broken Bone and Hospitalization, did not constitute a noncompliance with DOE WSH requirements, neither NTS-reportable nor sitereportable only. A review of the walkway involved in this event indicated no tripping hazards or issues.

4.NA-LSO--LLNL-LLNL-2012-0003, Finger tip severed while closing bullet resistant enclosure south of Building 332, did not constitute a NTS-reportable WSH noncompliance. A noncompliance was identified, but it was not related to the design of the bullet resistant enclosure. The noncompliance related to the pinch point hazard was site reported in the LLNL ITS.

5. NA-LSO--LLNL-LLNL-2012-0004, Building 151 Uncontrolled Hazardous Electrical Energy Source Discovery With Relocatable Power Tap (RPT), did not constitute a NTS-reportable WSH noncompliance. A WSH general noncompliance related to the existence of a potential shock hazard and the lack of control of a source of electrical energy was site reported in the LLNL ITS.

6. NA-LSO--LLNL-LLNL-2012-0005, Worker receives shock to little finger while plugging dual RPT (relocatable power tap) into wall outlet in Building 482 office, did not constitute a noncompliance with DOE WSH requirements, neither NTSreportable nor site-reportable only. The causal analysis determined that LLNL did not assemble the RPT and LLNL processes did not cause the event.

7. NA-LSO-LLNL-LLNL-2012-0009, Inadvertent action in building 321D results in arc causing GFCI device to trip - No Shock, did not constitute a noncompliance with DOE WSH requirements, either NTS-reportable nor site-reportable only. NFPA 70E and 1910.303 were reviewed and the only citations that were found to possibly be applicable were general citations. For example, because the plug made contact with the receptacle creating an electrical hazard, 1910.303(b)(1) could be applicable, "Electrical equipment shall be free from recognized hazards that are likely to cause death or serious physical harm to employees." However, the configuration was not a recognized hazard because the plug was never meant to contact the receptacle. The contact was due to the body movement of the employee simulating plugging in the cord that the plug made contact with the receptacle creating an electrical hazard. Therefore, it was determined that the general citations were not applicable.

8. NA-LSO--LLNL-LLNL-2012-0014, Spiral fracture of left fibula by (Akima) Security Escort in Building 453, did not constitute a noncompliance with DOE WSH requirements, neither NTS-reportable nor site-reportable only. The case 
investigator determined through an onsite analysis that the coefficient of friction (COF) met the minimum requirement of the ASTM ADA (a COF of 0.5), which is a consensus standard.

9. NA-LSO--LLNL-LLNL-2012-0022, Worker Fractures Ankle Accessing Space Below Computer Floor in Building 451, did not constitute a NTS-reportable WSH noncompliance. The causes of the occurrence were evaluated for WSH noncompliances and it was determined that a general WSH noncompliance exist with ES\&H Manual Document 2.2, the hazard was not analyzed and controls were not implemented. This noncompliance was site reported in the LLNL ITS.

10. NA-LSO--LLNL-LLNL-2012-0024, Building 151 Improper Transuranic Waste Generation, did not constitute a noncompliance with DOE WSH requirements, neither NTS-reportable nor site-reportable only. This was reported to the DOE NTS as a nuclear safety noncompliance.

11. NA-LSO--LLNL-LLNL-2012-0028, Light Fixture Diffuser Falls on Worker's Desk in Building 335, did not constitute a noncompliance with DOE WSH requirements, neither NTS-reportable nor site-reportable only. The identified cause was that the diffuser's gripping mechanism failed due to age, and possibly UV light interaction with the plastic material. ES\&H Manual Document 22.4, "Earthquakes" states, "Grills, diffusers, and lenses shall be permanently fastened to the fixture or provided with safety chains." However, ES\&H Manual Document 22.4 is not a part of the LLNL Worker Safety and Health Program, which means this issue is out of the scope of 10 CFR 851. 


\subsection{Nuclear Safety Results}

LLNL submitted 62 occurrence reports to ORPS from July 2011 to June 2012. Twelve occurrences submitted to ORPS were assigned a reporting criterion that satisfied the DOE Office of Enforcement nuclear safety criteria for mandatory reporting to the DOE NTS. Six of these 12 occurrences were determined to have a nuclear safety nexus (i.e., a potential to cause radiological harm) and were evaluated for possible nuclear safety noncompliances. The following two occurrence reports were each determined to have an associated nuclear safety noncompliance, which LLNL reported to the NTS:

1. NA-LSO-LLNL-LLNL-2011-0039, PISA: Inconsistent Method Used to Determine Pu-239 Equivalent Curie (PE-Ci) Values in the Waste Storage Facility DSA/TSR. The associated noncompliance was reported in NTSLSO-LLNL-LLNL-2011-0015, Noncompliance with DOE Nuclear Safety Requirements for Waste Storage Facilities DSA Hazard Analysis.

2. NA-LSO-LLNL-LLNL-2011-0055, PISA: Security Firearm Inadvertent Discharge Scenario involving Bish Cans not Evaluated in the DSA for Building 334. The associated noncompliance was reported in NTS-LSO-LLNLLLNL-2011-0018, Noncompliance with DOE Nuclear Safety Requirements for the Building 334 DSA Hazard Analysis.

The remaining four of these six occurrences were determined for the following reasons to not constitute noncompliances with DOE nuclear safety requirements and therefore did not warrant an NTS report.

1. NA-LSO--LLNL-LLNL-2011-0036, Degradation Of The Building 332 Safety Significant Emergency Battery Lighting System - July Test, reported that during the performance of a scheduled surveillance of the Building 332 Emergency Battery Lighting System, one of the Emergency Battery Lights failed to illuminate as required by the surveillance procedure. The deficiency did not constitute a noncompliance with DOE nuclear safety requirements because (1) the degraded condition was discovered by LLNL personnel during a routine scheduled surveillance being performed in accordance with facility procedures and under an approved facility Work Permit, (2) upon the identification of the failed surveillance and in accordance with facility procedures, the Facility Operators entered into a Limiting Condition for Operation (LCO) for the affected Radioactive Materials Area Laboratory, and (3) as allowed by the approved facility work permit, the electrician immediately replaced the failed bulb in the affected unit, retested the unit, and it was returned to operation. At that time the facility exited the LCO. Consequently, the discovered condition did not constitute a noncompliance with DOE nuclear safety requirements.

2. NA-LSO--LLNL-LLNL-2011-0041, Degraded Safety Significant Compressed Air Panel in Building 332, reported the discovery during a routine unscheduled system check that the safety-significant compressed air bottle supplying the compressed air panel servicing one of the Building 332 Increment 3 glovebox exhaust fans was at its low pressure limit of 1000 psig. In accordance with facility procedures, the facility entered into an LCO and the compressed air bottle was replaced. After the replacement, the surveillance was successfully completed and the 
exhaust fan was returned to operational status. Because the compressed air panels are a backup to the house-supplied compressed air system and the laboratory compressed air system, both of which remained operable, a failure of the compressed air panels would not have prevented the Increment 3 glovebox exhaust system from performing its designated safety function. Consequently, the discovered condition did not constitute a noncompliance with DOE nuclear safety requirements.

3. NA-LSO--LLNL-LLNL-2011-0044, Loss of Facility Power to Increment 3 in Building 332 , reported a loss of power to Building 332 Increment 3 when a normal electric power supply breaker inadvertently opened. The circuit breaker that opened is not itself a safety-class or safety-significant component. When the breaker opened, the appropriate safety-class emergency diesel generator started and the associated safety-class automatic transfer switch activated as designed to restore power to Increment 3. All Building 332 safety systems operated as designed during the momentary interruption of Increment 3 power. No adverse conditions or other equipment problems resulted from the event. Building 332 Increment 1 was unaffected and continued to be supplied by the normal electric power system. All responses by personnel to the loss of power were performed in accordance with facility procedures. Consequently, the reported loss of power did not constitute a noncompliance with DOE nuclear safety requirements.

4. NA-LSO--LLNL-LLNL-2012-0018, Performance Degradation of the Safety Class Water Tank Nitrogen Skid After a Relief Device Leak in Building 332, reported the discovery during a routine surveillance of a leak from a failed fusible plug relief device attached to a fill gauge on a Safety Class (SC) nitrogen skid. The nitrogen skid, located outside Building 332, supports the SC fire suppression system by providing a backup source of pressure for discharge of the firewater tanks. The primary source of pressure is the house compressed air system, which remained operational. In accordance with facility procedures, the leak was isolated and a section of piping was bled down to allow repair. The facility entered LCO Action 3.3.1.C, then placed the facility into STANDBY mode as required by the LCO Action. In order to allow operation during repairs, facility management requested a temporary deviation from LCO 3.3.1.b from the Livermore Site Office; this deviation was approved. The repair was completed and the facility was returned to operation. Because the discovery and subsequent repair were made in accordance with facility procedures, and because the safety function of the fire suppression system was not impaired, the discovered condition did not constitute a noncompliance with DOE nuclear safety requirements.

Additionally, the following occurrence, although the reported event did not itself satisfy the criteria for mandatory reporting to the NTS, was determined together with a second related event (reported to ORPS in an update to the original occurrence report) to reveal noncompliances reportable to the NTS as a programmatic noncompliance with DOE nuclear safety requirements:

1. NA-LSO-LLNL-LLNL-2012-0024, Building 151 Improper Transuranic Waste Generation, reported the discovery that a low-level radioactive waste drum generated in a Building 151 chemistry laboratory exceeded transuranic (TRU) levels. Radioactive waste is classified as TRU when it exceeds $100 \mathrm{nCi} /$ gram of alpha-emitting TRU nuclides with a half-life greater than 20 years. The gamma 
assay revealed a calculated activity of approximately 1,200 nCi/gram. This finding confirmed that the waste was not only improperly assumed to be lowlevel waste, but also that the drum exceeded individual container activity limits established in the waste generation documentation (comprising primarily an "Information Gathering Document," or IGD). Approximately six weeks later, another low-level waste drum generated under the same radioactive waste profile was determined to have an activity level that exceeded the IGD limits and contained an isotope not identified by the generator. Unlike the initial event, however, the waste did not exceed the transuranic threshold or the intended waste disposal site's acceptance criteria. While the second drum event would not have generated significant interest by itself, further evaluation determined that the combined issues of the two events indicated similar weaknesses that were evidence of a programmatic problem. This problem involves administrative or management controls established to detect and prevent the shipment offsite of waste materials that do not meet the acceptance criteria of the facility with which LLNL has contracted for disposal of low-level radioactive wastes from Laboratory operations. This programmatic problem was determined to constitute a noncompliance with DOE nuclear safety requirements and was reported in NTS-LSO-LLNL-LLNL-2012-0006, Programmatic Noncompliance with Nuclear Safety Requirements for Management of Radioactive Waste. 


\subsection{Worker Safety and Health Management Issues}

Worker safety and health (WSH) includes programs in chronic beryllium disease prevention, biological safety, electrical safety, emergency preparedness, explosive safety, fire safety, occupational medicine, and other safety and health subjects. Data from 2005 through the second quarter in 2012 were extracted from ITS in July 2012 using the ITS Basic Issue Report.

As discussed in the sections below, the analysis for WSH identified one WSH subject with a point above the UCL (an action limit), one WSH subject with eight points on one side of the centerline (an action limit), and five WSH subjects with a common test met, either a point above the UWL, an increase in deficiencies or the rate of deficiencies in the second quarter of 2012, or a recent consecutive increase in deficiencies. Three WSH subjects were identified in previous analyses as needing follow-up analysis: emergency program, sanitation, and respiratory protection.

\subsection{Chronic Beryllium Disease Prevention Program (CBDPP)}

The visual analysis step did not warrant further analysis of deficiencies in ITS categorized as beryllium safety. Therefore, this safety subject was not discussed or analyzed further in this report.

\subsection{Biological Safety}

The visual analysis step did not warrant further analysis of deficiencies in ITS categorized as biological safety. Therefore, this safety subject was not discussed or analyzed further in this report.

\subsection{Electrical Safety}

The visual analysis step did not warrant further analysis of deficiencies in ITS categorized as electrical safety. Therefore, this safety subject was not discussed or analyzed further in this report. 


\subsection{Emergency Program}

The visual analysis step did not warrant further analysis of the deficiencies in ITS categorized as emergency program; however, this safety subject was determined to need continued analysis in a previous performance analysis due to an increase in deficiencies from the first to the third quarter in 2011. Therefore, this safety subject was analyzed using a control chart. The 16 deficiencies in the second quarter of 2010 that caused the point to be above the UCL were discussed in a previous analysis report, Performance Analysis: Issues Tracking System Data through December 2010. Recently, there were no emergency program deficiencies identified in the second quarter of 2012 (Figure 12). Therefore, this safety subject is not discussed further.

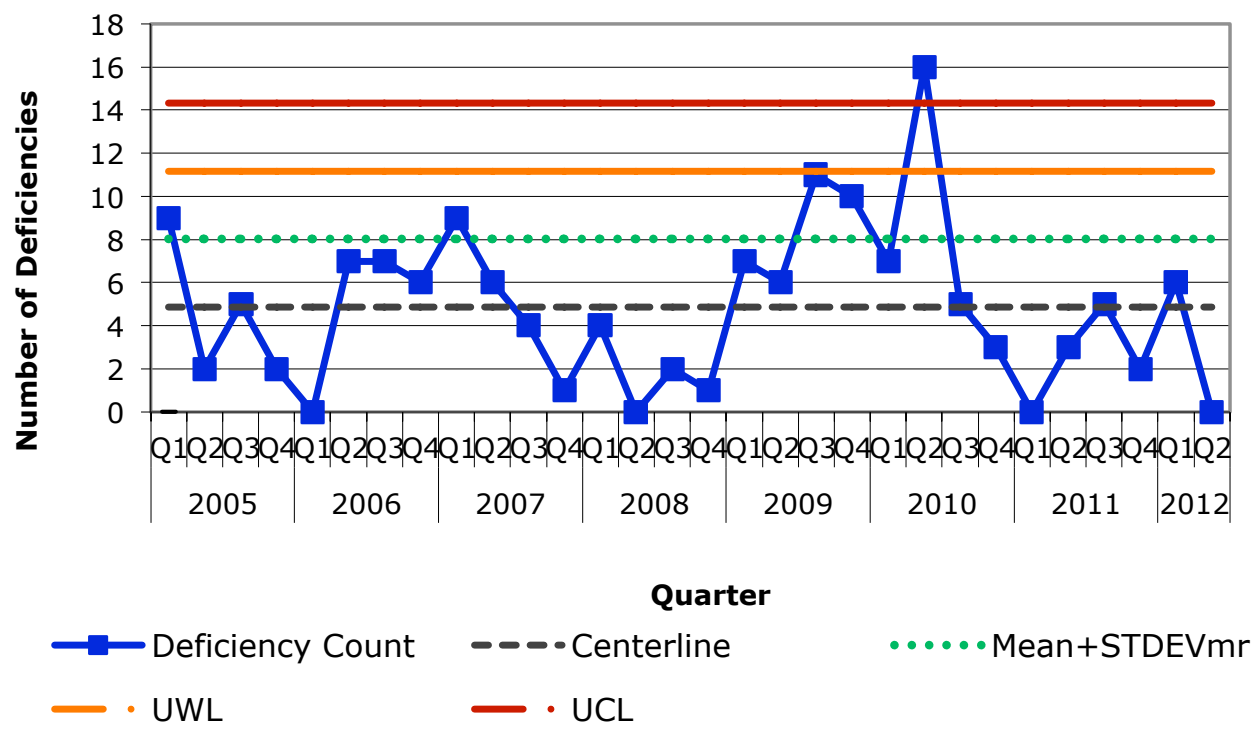

Figure 12. Frequency control chart of emergency program deficiencies.

In summary, recent emergency program deficiencies did not meet a common test, and data within this subject is considered within expected variation.

Potential Significant, Systemic or Repetitive $\square$ Meets Common Tests $\bigotimes$ Within Expected Variation
Downward Trend

\subsection{Explosive Safety}

The visual analysis step did not warrant further analysis of deficiencies in ITS categorized as explosive safety. Therefore, this safety subject was not discussed or analyzed further in this report.

\subsection{Fire Safety}

The visual analysis step warranted further analysis of deficiencies in ITS categorized as fire safety, specifically related to fire prevention and fire suppression. Therefore, this 
safety subject was analyzed using a control chart (Figure 13). Based on the control chart analysis, a point was above the UWL in the first quarter of 2012, a common test. Therefore, this safety subject is discussed further.

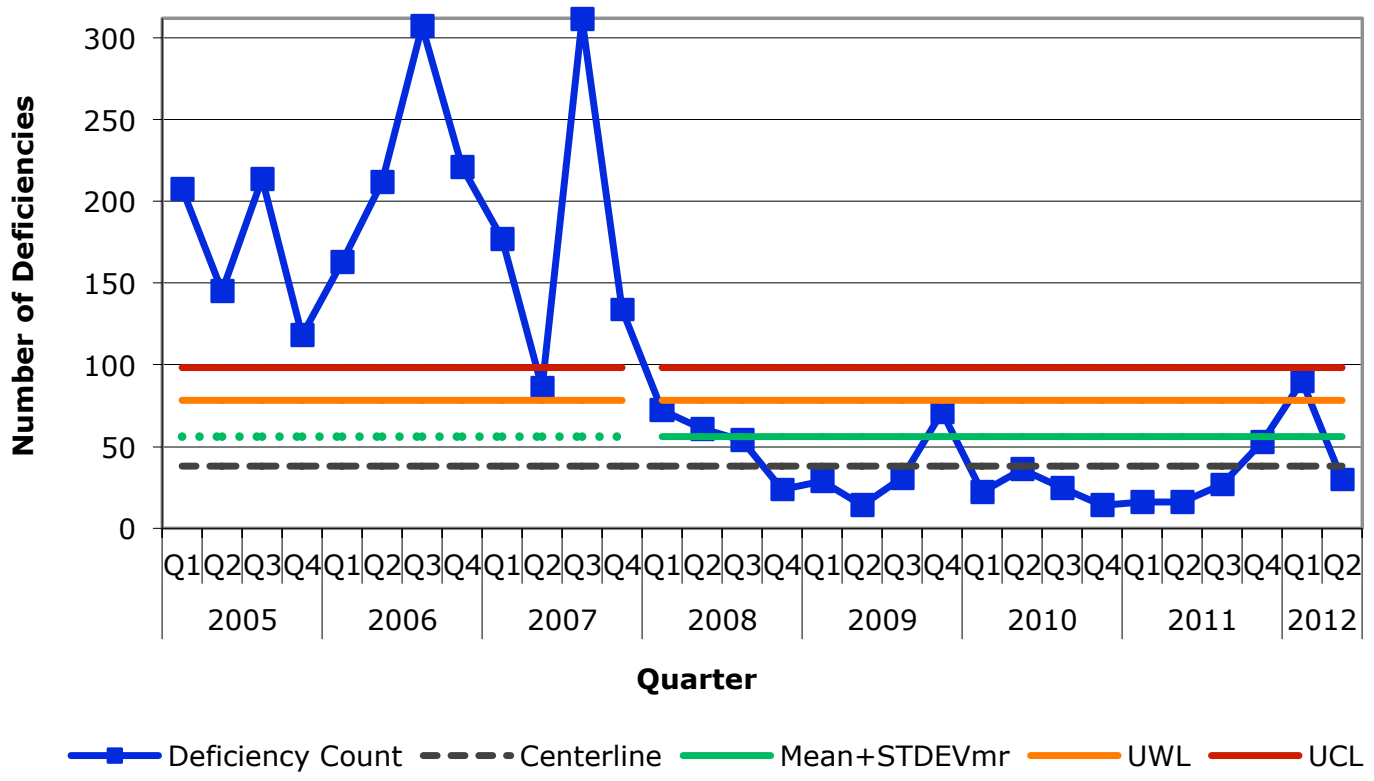

Figure 13. Frequency control chart of fire safety deficiencies.

During the second quarter in 2012, the most recent quarter of data analyzed, there were 30 fire safety deficiencies identified from a number of different assessments with 18 of the 30 owned by the Operations and Business (O\&B) Directorate. Twenty of the 30 deficiencies were from fire protection inspections of different facilities.

During the first quarter of 2012, the quarter with a point above the UWL, 90 fire safety deficiencies were identified. Sixty of the 90 deficiencies are owned by the O\&B Directorate, 65 are from different facility fire protection inspections, and the majority of the 90 deficiencies are categorized as fire suppression $(n=35)$, evacuation of occupants $(n=27)$, or fire prevention $(n=24)$. These safety subjects were analyzed using a control chart in the sections below. 


\section{Fire Suppression}

The control chart analysis (Figure 14) for fire suppression deficiencies shows a point above the UCL in the first quarter of 2012, an action limit. Therefore, this safety subject was analyzed to resolution.

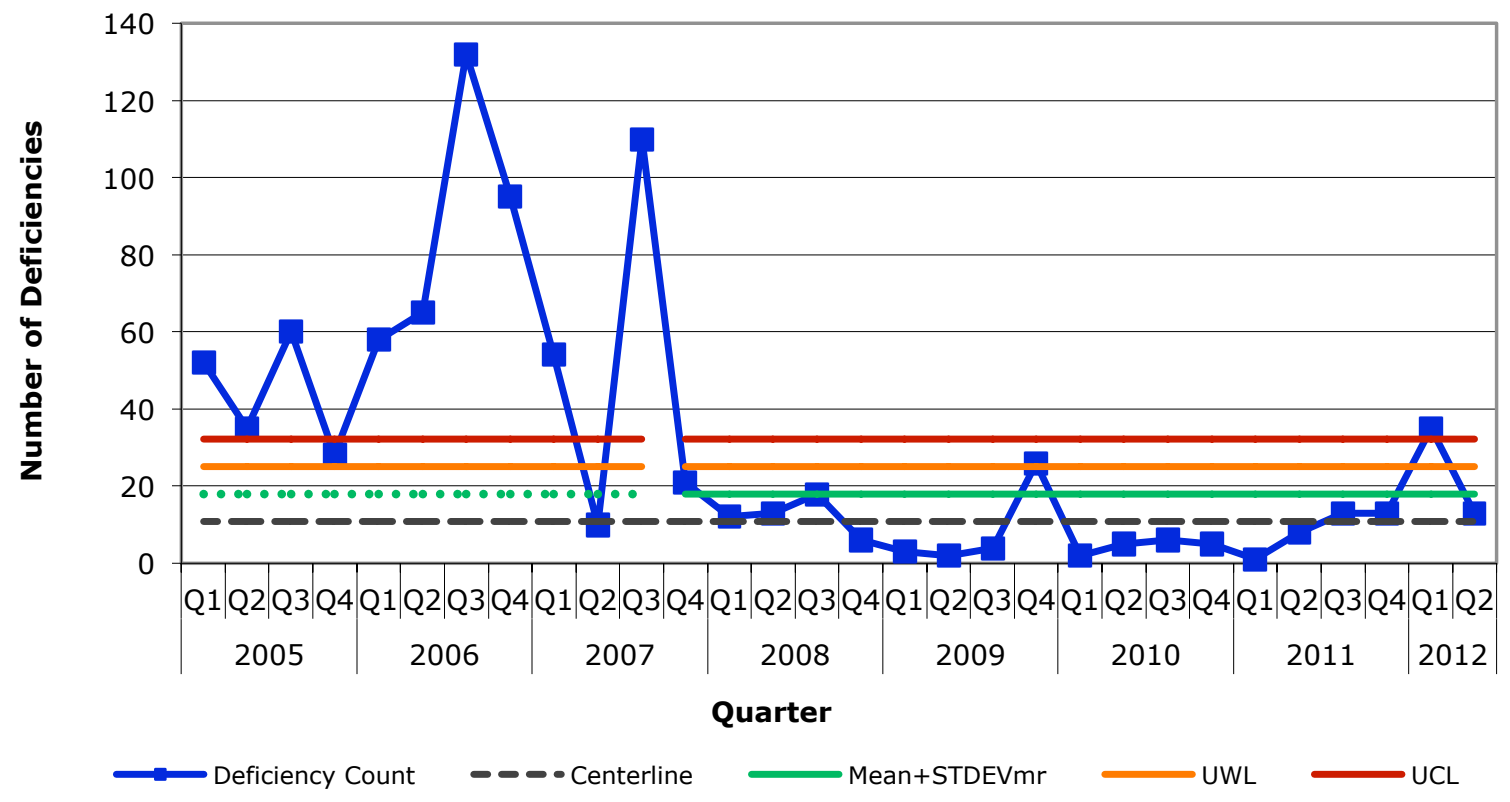

Figure 14. Frequency control chart of fire suppression deficiencies.

During the second quarter in 2012, the most recent quarter of data analyzed, 13 fire suppression deficiencies were identified; 10 of the 13 were identified during fire protection inspections of different facilities.

During the first quarter of 2012, the quarter with a data point above the UCL, 35 fire suppression deficiencies were identified. Twenty six of the 35 were from fire protection inspections of different facilities. Compared to the fourth quarter of 2011 and the second quarter of 2012, the first quarter of 2012 had the greatest number of assessment entries for fire protection inspections, with each inspection averaging more deficiencies than the fourth quarter of 2011 and the second quarter of 2012. For example, in the first quarter of 2012, there were 14 different assessment entries for fire protection inspections, with an average of three deficiencies per each fire inspection assessment. In the fourth quarter of 2011 there were seven and in the second quarter of 2012 there were nine different assessment entries for fire protection inspections, with an average of one deficiency per each fire inspection in both quarters. Using the ITS assessment report and searching on the term "fire protection," it was determined that fire inspections were completed in 58 different facilities from January 2012 - June 2012.

Since January 2012, the majority of fire suppression deficiencies were categorized in three different compliance codes as displayed in Table 3.

Eight of the 16 deficiencies categorized as "Fixed fire extinguishing system is not properly designed or installed and/or is not fully functional," were related to the fire sprinklers not acting at their full capacity due to some type of obstruction, a ceiling tile, 
phone rack, projector etc. Three of the 16 deficiencies were related to three different unsprinklered buildings. The 16 deficiencies were identified in 13 different facilities or $22 \%$ of the 58 facilities inspected from January 2012 to June 2012.

Seven of the 14 deficiencies categorized as, "Fixed fire extinguishing system is not properly inspected / tested or maintained and/or documentation is missing or inadequate," state that they are duplicates of an issue identified in 2011 that covers spare sprinkler head boxes missing for all facilities at the Laboratory. The 2011 issue is closed and was completed in December 2011. The seven deficiencies that are duplicates of the 2011 issue were all identified in 2012. This was discussed with the LLNL Fire Marshal. Although the 2011 issue/ action is closed, the Emergency Management Department is still in the process of replacing/ordering spare sprinkler head boxes. This is the reason the deficiencies identified in 2012 point to the 2011 issue. Two of the 14 deficiencies were related to the fire sprinklers not acting at their full capacity due to some type of obstruction, in these cases the obstructions were a wall and light. The 14 deficiencies were identified in 12 different facilities or $21 \%$ of the 58 facilities inspected from January to June 2012.

Eight of the ten noncompliances categorized as, "Adequate fire extinguishing capability is missing," were related to the fire sprinklers not acting at their full capacity due to some type of obstruction, a ceiling tile, phone rack, projector etc. The 10 deficiencies were identified in five different facilities or $9 \%$ of the 58 facilities inspected from January to June 2012.

Table 3. Categorization of fire suppression deficiencies from January-June 2012

\begin{tabular}{|lll|}
\hline Compliance Code & Description & Freq. \\
\hline S-FS-FE.00 & Not otherwise specified; description of deficiency required. (NOS) & 2 \\
\hline S-FS-FE.01 & Adequate fire extinguishing capability is missing. & 10 \\
\hline S-FS-FE.02 & $\begin{array}{l}\text { Fixed fire extinguishing system is not properly designed or } \\
\text { installed and/or is not fully functional. }\end{array}$ & 16 \\
\hline S-FS-FE.03 & $\begin{array}{l}\text { Fixed fire extinguishing system is not properly inspected/tested } \\
\text { or maintained and/or documentation is missing or inadequate. }\end{array}$ & 14 \\
\hline S-FS-FE.04 & $\begin{array}{l}\text { Portable fire extinguishers are missing, obstructed, not readily } \\
\text { accessible by employees, not functional and/or not the proper } \\
\text { type. }\end{array}$ & 1 \\
\hline S-FS-FE.05 & $\begin{array}{l}\text { Portable fire extinguishers are not properly inspected/tested or } \\
\text { maintained and/or documentation is missing or inadequate. }\end{array}$ & 5 \\
\hline
\end{tabular}

Some of the deficiencies categorized in different compliance codes from Table 3 are the same deficiency. Out of 48 fire suppression deficiencies identified from January 2012 through June 2012, 19 (40\%) were related to the fire sprinklers not acting at their full capacity due to some type of obstruction. At first this seemed to be of concern; however, these deficiencies were identified in $19 \%$ of the 58 facilities inspected from January-June 2012. The collection of these deficiencies do not appear to be systemic due to the number of facilities that were inspected from January-June 2012 and the number of 
facilities without deficient conditions identified. Based on a discussion with the LLNL Fire Marshal and the Assurance Manager for the Facilities and Infrastructure Directorate, any one issue is not a significant noncompliance because the fire sprinkler is still able to produce water to put out a fire. A significant noncompliance would be if a building requiring fire sprinklers did not have any installed or if there was not enough water supply in a building to supply water to the installed fire sprinklers. Management may need to educate employees on the need to not block sprinkler heads.

Three of the 48 fire suppression deficiencies identified from January 2012 through June 2012 were related to three different unsprinklered buildings, Buildings 855A, 855B, and 855C. This issue was discussed with the LLNL Fire Marshal. Although these issues were categorized as deficiencies, Buildings 855A, 855B, and $855 \mathrm{C}$ are not required to have sprinklers based on the Improved Risk Criteria used by DOE. Therefore, these issues would not constitute a noncompliance reportable to the DOE NTS and they should have been categorized observations in ITS.

In summary, a fire suppression data point was above the UCL in the first quarter of 2012. Seventy four percent (74\%) of the deficiencies identified in the first quarter of 2012 were from fire protection inspections. Compared to surrounding quarters, the first quarter of 2012 had the greatest number of fire protection inspections completed. Forty percent $(40 \%)$ of fire suppression deficiencies identified from January 2012 through June 2012 were related to an obstruction causing the sprinkler to not work at full capacity; however, this accounted for only $19 \%$ of the 58 facilities inspected from January 2012 to June 2012. This does not represent a systemic issue nor are these issues considered significant since the sprinkler can still procedure water. Three fire suppression deficiencies were related to unsprinklered buildings, a potential significant condition. However, The LLNL Fire Marshal confirmed that the three facilities identified to not have sprinklers do not require sprinklers. Therefore, a systemic or significant issue related to fire suppression deficiencies does not exist.

This review did find that issues identified in 2012 were closed stating that they were duplicates of the 2011 issue. However, the 2011 issue is closed prior to the identification of the 2012 issues. This indicates that the issues are unresolved and not tracked as open issues in ITS. The management of fire protection issues will need to be discussed further outside of the context of this report. 


\section{Fire Prevention}

The control chart analysis (Figure 15) for fire prevention deficiencies shows eight data points on one side of the centerline from the first quarter in 2010 to the fourth quarter in 2011, an action limit. The control chart also shows a point close to the UWL in the first quarter of 2012, a common test (Figure 15). Although an action limit was met, this is not an action limit that would lead to a systemic or repetitive noncompliance. The data points are not on the side of the centerline where an increase in deficiencies is the concern. Regardless, this safety subject was analyzed to resolution and the point above the UWL is discussed further.

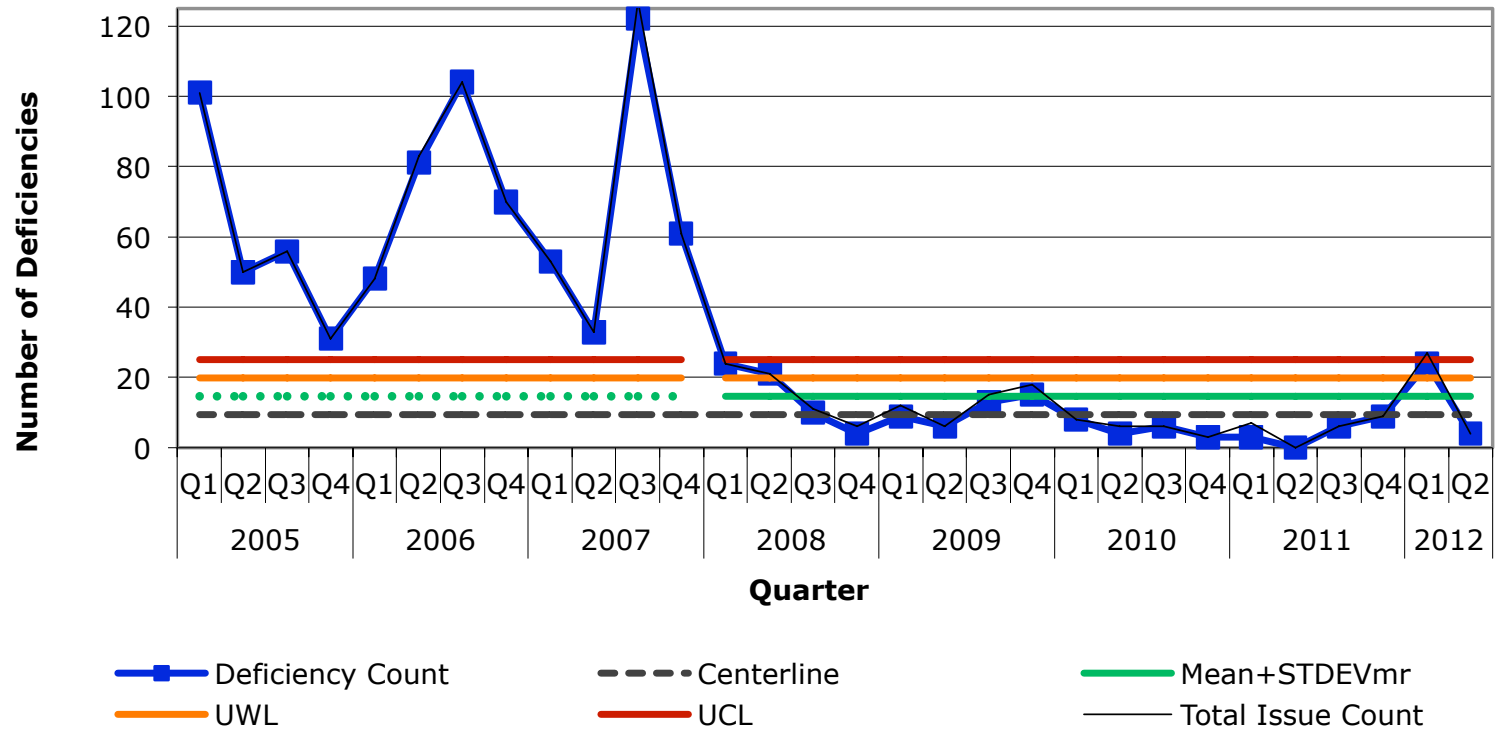

Figure 15. Frequency control chart of fire prevention deficiencies.

In 2010 and 2011, the years that the data points were below the centerline, few, if any of the fire prevention deficiencies were identified from management self-assessments (MSAs), three in 2010 and none in 2011. However, in 2009, 16 fire prevention deficiencies were identified from MSAs. The Institutional Assessment Plan (IAP) showed that, based on the assessment current plan due date, 11 emergency management MSAs were due in 2009, 14 in 2010, and 17 in 2011. In summary, LLNL did plan MSAs in the area of emergency management in 2010 and 2011, the years when fewer fire prevention deficiencies were identified; however, the number of planned MSAs that were specific to the area of fire prevention cannot be extracted from ITS.

The number of observations identified each quarter was also reviewed to determine if fire prevention issues were identified, but categorized as observations instead of deficiencies. However, because the total issue count from Figure 15 does not exceed the deficiency count, one can see that most of the fire prevention issues identified are deficiencies. 
During the second quarter in 2012, the most recent quarter of data analyzed, four fire prevention deficiencies were identified; two of the four were identified during fire protection inspections of different facilities.

During the first quarter of 2012, the quarter with a data point above the UWL, 24 fire prevention deficiencies were identified; 21 of the 24 deficiencies were from fire protection inspections in different facilities. Twenty one of the 24 deficiencies were categorized as either, "Integrity of fire barrier and/or smoke barrier is compromised (due to holes in rated walls, missing ceiling tiles, blocked/wedged fire doors, etc.)" $(\mathrm{n}=13)$, or "Flammable or combustible materials (not including gasses) are improperly stored, handled, and / or maintained" $(\mathrm{n}=8)$.

Fire protection inspections were pulled from ITS and it was determined that more fire protection inspections were completed in the first quarter of $2012(n=38)$ compared to the fourth quarter of $2011(n=26)$ and the second quarter of $2012(n=20)$. This could account for more fire preventions deficiencies identified in the first quarter of 2012, compared to the surrounding quarters.

In summary, fire prevention deficiencies met an action limit, eight points on one side of the centerline. However, this is not an action limit that would lead to a systemic or repetitive noncompliance. The data points are not on the side of the centerline where an increase in deficiencies is the concern. Therefore, fire prevention deficiencies do not represent a systemic, repetitive, or significant issue that is reportable to the DOE NTS.

\section{Evacuation of Occupants}

The control chart analysis (Figure 16) for evacuation of occupant deficiencies does not show any data points meeting a common test. Therefore, this safety subject is not discussed further.

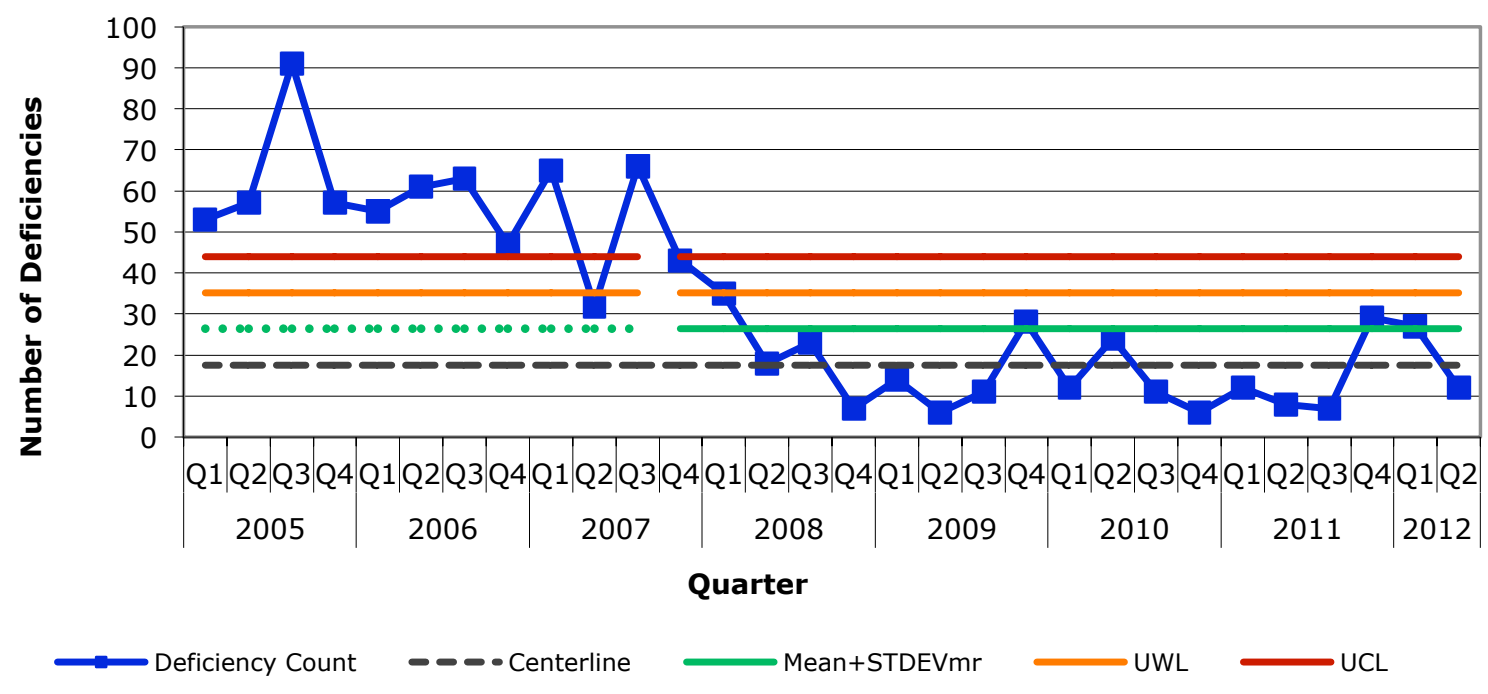

Figure 16. Frequency control chart of evacuation of occupant deficiencies. 
To conclude Section 6.6, recent data within the fire safety subject met a common test, a point above the UWL. The majority of fire safety deficiencies that caused a point to be above the UWL were categorized as fire suppression, fire prevention, and evacuation of occupants. A point was above the UWL for fire prevention deficiencies and an action limit was met for fire suppression deficiencies, a point above the UCL in the first quarter in 2012. Seventy four percent (74\%) of the fire suppression deficiencies identified in the first quarter of 2012 were from fire protection inspections. Compared to surrounding quarters, the first quarter of 2012 had the greatest number of fire protection inspections completed. Forty percent (40\%) of fire suppression deficiencies identified from January 2012 through June 2012 were related to an obstruction causing the sprinkler to not work at full capacity; however, this accounted for only $19 \%$ of the 58 facilities inspected from January 2012 to June 2012. This does not represent a systemic issue nor are these issues considered significant since the sprinkler can still procedure water. Management may need to educate employees on the need to not block sprinkler heads. Three fire suppression deficiencies were related to three different unsprinklered buildings, a potential significant condition. However, the LLNL Fire Marshal confirmed that the three facilities identified to not have sprinklers do not require sprinklers. Therefore, it was determined that fire safety deficiencies do not represent a systemic or repetitive noncompliance reportable to DOE, but this safety subject will be analyzed as it relates to fire prevention deficiencies, since a common test was met. Fire suppression deficiencies will not automatically be analyzed in future analyses because the reason for the point above the UCL was analyzed to resolution. This review did find that issues identified in 2012 were closed stating that they were duplicates of the 2011 issue. However, the 2011 issue is closed prior to the identification of the 2012 issues. This indicates that the issues are unresolved and not tracked as open issues in ITS. The management of fire protection issues will need to be discussed further out of the context of this report.

$$
\begin{aligned}
& \text { Potential Significant, } \\
& \text { Systemic or Repetitive }
\end{aligned} \begin{aligned}
& \text { Meets Common } \\
& \text { Tests }
\end{aligned}
$$

Downward Trend

\subsection{Occupational Medicine}

The visual analysis step did not warrant further analysis of deficiencies in ITS categorized as occupational medicine. Therefore, this safety subject was not discussed or analyzed further in this report.

\subsection{Other Industrial Hygiene}

The visual analysis step warranted further analysis of deficiencies in ITS categorized as the industrial hygiene (IH) topic, specifically those categorized as hazard communication. Deficiencies categorized as general IH are also discussed, not because of recently activity, but due to deficiencies identified in 2010 and a change in the control chart. Respiratory protection deficiencies and sanitation deficiencies were determined to need continued analysis due to an increase in the deficiency rate and a point above the UWL in January 2011, respectively. Therefore, both respiratory protection and sanitation deficiencies were also analyzed using control charts. 


\section{Hazard Communication}

The control chart analysis (Figure 17) for hazard communication deficiencies shows consecutive increases in the number of deficiencies identified per quarter, a common test. Although a common test was met, all data contributing to the consecutive increase in the number of deficiencies are below the centerline. Regardless, this safety subject is discussed further.

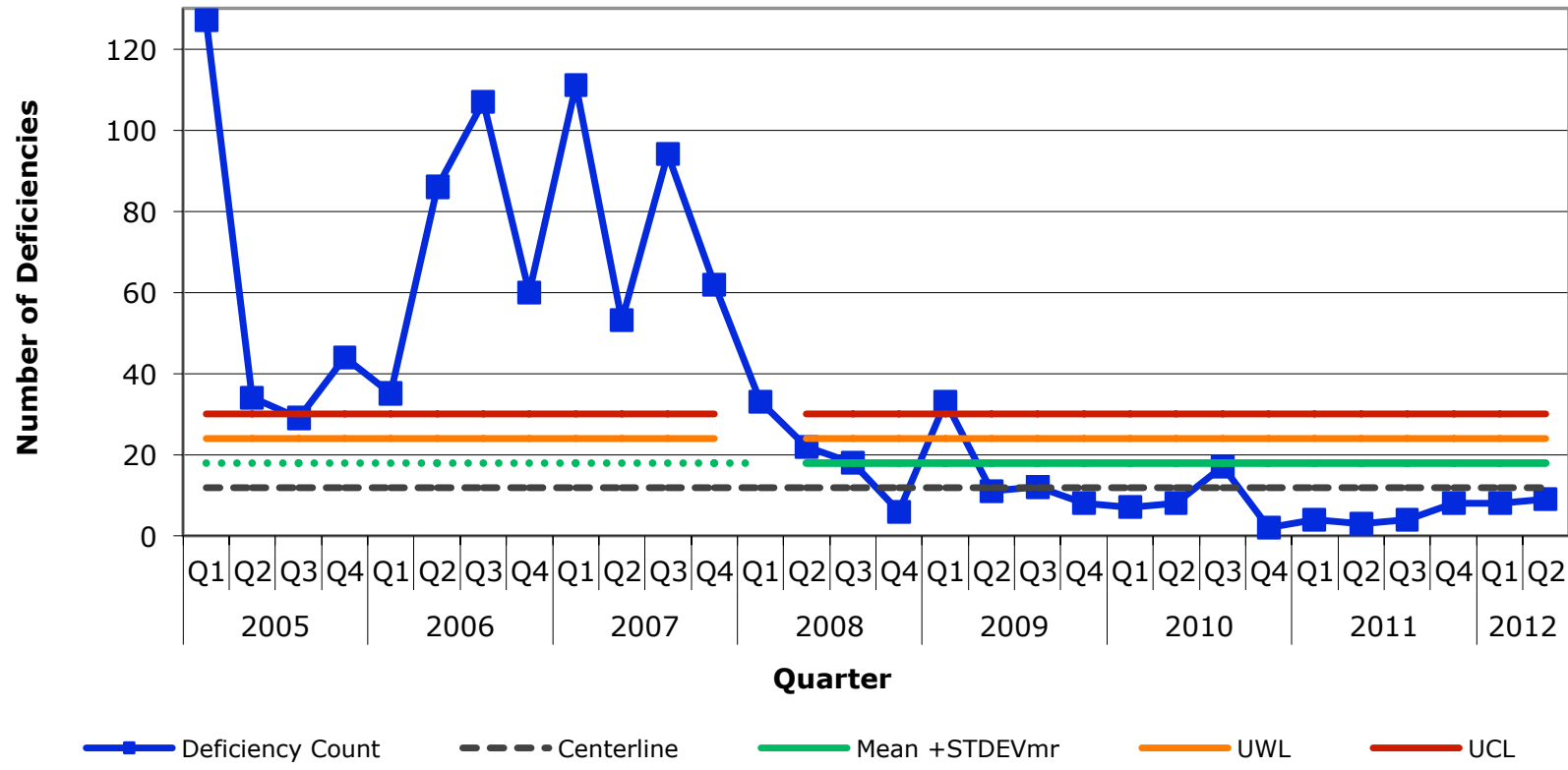

Note: Control Limits are Based on fewer quarters than displayed

Figure 17. Frequency control chart of hazard communication deficiencies.

During the second quarter of 2012, the most recent quarter of data analyzed, nine hazard communication deficiencies were identified from eight different assessments, three of the eight being NIF 2012 annual walkabouts for different Integration Work Sheets.

From the second quarter in 2011 to the second quarter in 2012 there were increases in the number of hazard communication deficiencies identified. In each quarter in 2012, compared to quarters in 2011, more assessments were conducted that identified hazard communication deficiencies.

In summary, there is a consecutive increase in hazard communication deficiencies identified from the second quarter in 2011 to the second quarter in 2012; however, this pattern is below the centerline and is not of concern at this time. Although no new issues within this safety subject are reportable to the DOE Office of Enforcement as either repetitive or systemic, the hazard communication safety subject will continue to be analyzed in future analyses.

\section{General Industrial Hygiene}

The visual analysis step did not warrant further analysis of recent deficiencies categorized as general IH; however, a data point in the third quarter of 2010 that was 
previously below the UWL is now above the UCL (Figure 18). Therefore, this safety subject is discussed further.

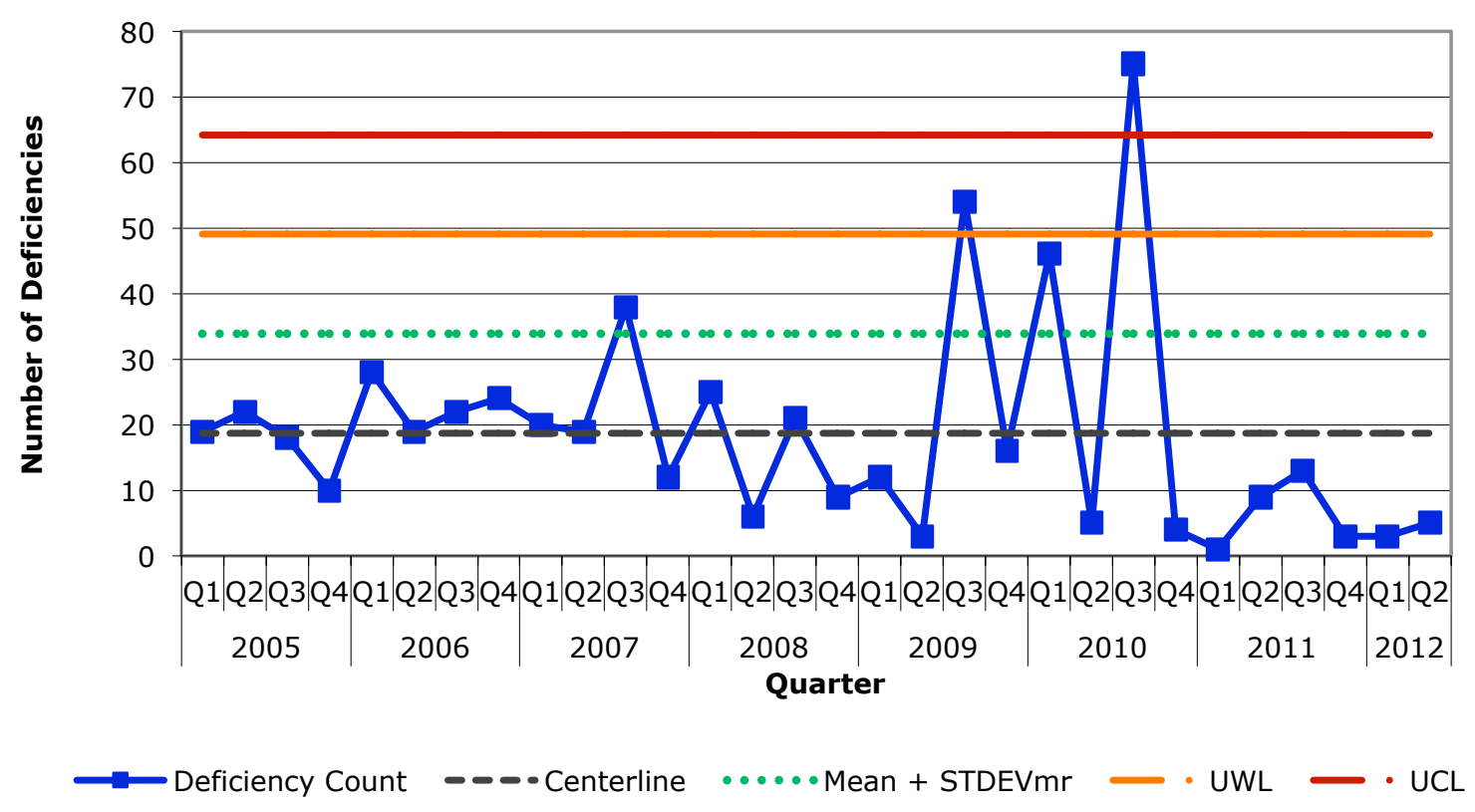

Figure 18. Frequency control chart of general industrial hygiene deficiencies.

In the analysis report titled, Performance Analysis: Issues Tracking System Data through December 2010, the data point for general IH in the third quarter of 2010 was just below the UWL, with the number of general IH deficiencies identified as 75, the same as in this analysis. However, due to the decreasing number of deficiencies identified since the third quarter of 2010, this point has gone from just below the UWL to above the UCL (Figure 18). Because the activity in the third quarter of 2010 was not discussed in previous analyses reports, due to the lack of a common test or action limit met, data from the third quarter in 2010 was discussed in this analysis.

In the third quarter of 2010,97\% of general IH deficiencies identified were from two main sources, a Management Pre-start Review (MPR) owned by the NIF and Photon Science (N\&PS) Directorate, and IH Periodic Baseline Surveys. More specifically, 65\% of the deficiencies identified in the third quarter of 2010 were from the MPR owned by N\&PS. The collection of deficiencies from the MPR were not considered as a systemic noncompliance because pre-start reviews, by design, are intended to find every issue associated with a single operation before it is operational. Without the 49 deficiencies from the MPR, the data point in Figure 18 for the third quarter in 2010 would be at 26, with 24 of the 26 deficiencies from IH Periodic Baseline Surveys. From 2009 through the second quarter in 2012, zero to 51 deficiencies were identified per quarter from the IH Periodic Baseline Surveys or backlog of surveys. Twenty four deficiencies identified in one quarter from IH Periodic Baseline Surveys is not an unusually high number of deficiencies compared to other quarters. In the first quarter of 2010, 34 general IH deficiencies were from IH Periodic Baseline Surveys and in the third quarter of 2009, 51 were from IH Periodic Baseline Surveys. The MPR discussed above is the unexpected 
source that caused a point to be above the UCL. Therefore, the data point above the UCL in the third quarter of 2010 was not discussed further.

In the second quarter of 2012, the most recent quarter of data analyzed, a common test was met, a recent increase in data for the quarter in question. In the second quarter of 2012, five deficiencies were identified, a slight increase from the previous quarter. Four of the five deficiencies were from a JFLMA on silica and all four deficiencies are owned by the Operations and Business Directorate. This assessment was evaluated for a WSH noncompliance that might be reportable to the DOE NTS; however, no significant, repetitive, or systemic noncompliance was identified by the assessors. The overall conclusion was, "It is apparent that a substantial effort has been made to ensure silica hazards are properly controlled for both "in house" and subcontracted work. Evidence obtained from personnel interviews, work control document review, and project observation shows that, for the most part, line management and workers engaged in concrete disturbance are aware of the hazards associated with silica and proper controls were observed in the field."

In summary, a point from 2010 was previously below the UWL, but in this analysis is now above the UCL. The number of deficiencies identified during the third quarter in 2010 did not change, but the control limits changed due to the few number of general IH deficiencies identified since the third quarter of 2010. More than half of these deficiencies are from an MPR owned by N\&PS. The collection of these deficiencies is not considered systemic due to the nature of the MPR, to identify all issues prior to startup of an operation/facility. No new noncompliances within this safety subject are reportable to the DOE Office of Enforcement as either repetitive or systemic; however, a recent common test was met, an increase in data for the quarter in question. Therefore, this safety subject will be analyzes in future performance analysis.

\section{Respiratory Protection}

The "rate per year" control chart analysis (Figure 19) for respiratory protection deficiencies shows that no new respiratory protection deficiencies were identified since the previous performance analysis was completed. The last respiratory protection deficiency was identified in September 2011. Therefore, this safety subject is not discussed further. For more information on the "rate per year" control chart refer to Section 11.2. 


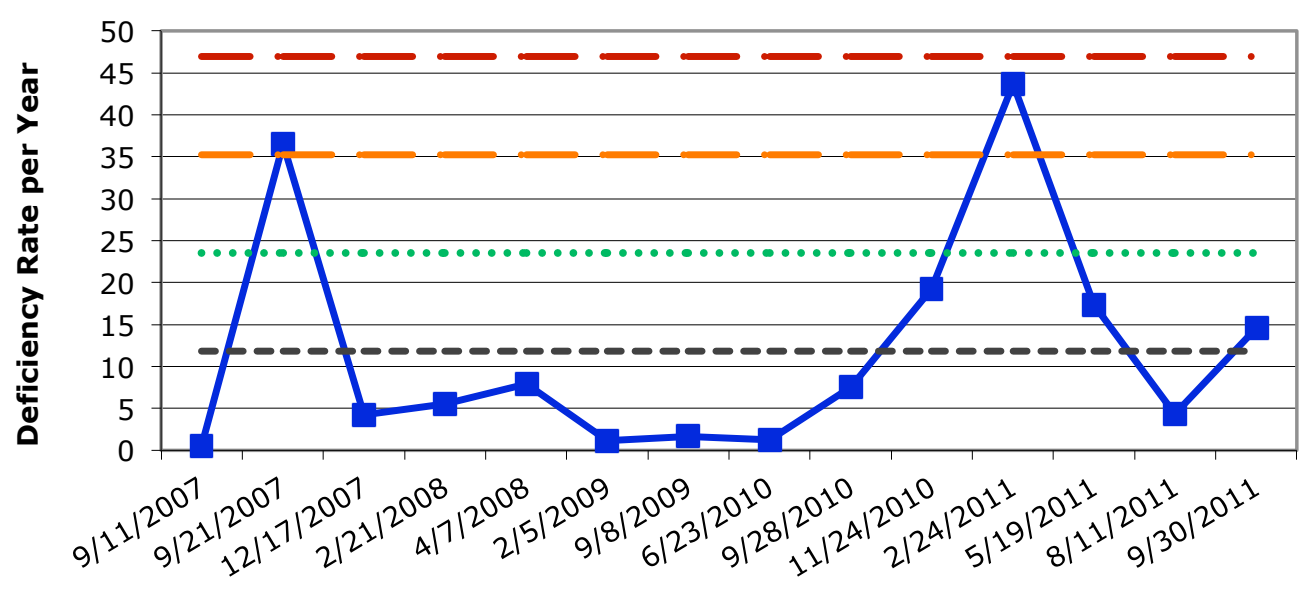

Date Deficiency Identified

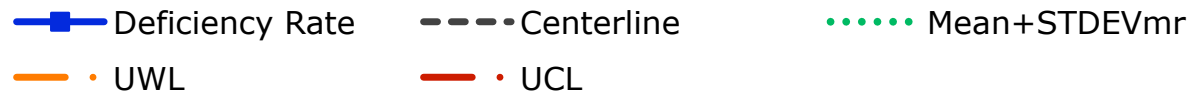

Figure 19. Deficiency rate per year control chart of respiratory protection deficiencies.

In summary, no recent respiratory protection deficiencies have been identified and no new issues within this safety subject are reportable to the DOE Office of Enforcement as either repetitive or systemic.

\section{Sanitation}

The "rate per year" control chart analysis for sanitation deficiencies (Figure 20) shows a slight increase in the October 2011 deficiency rate, a common test. However, during the two quarters of 2012, no sanitation deficiencies were identified and this safety subject is not discussed further. For more information on the "rate per year" control chart refer to Section 11.2.

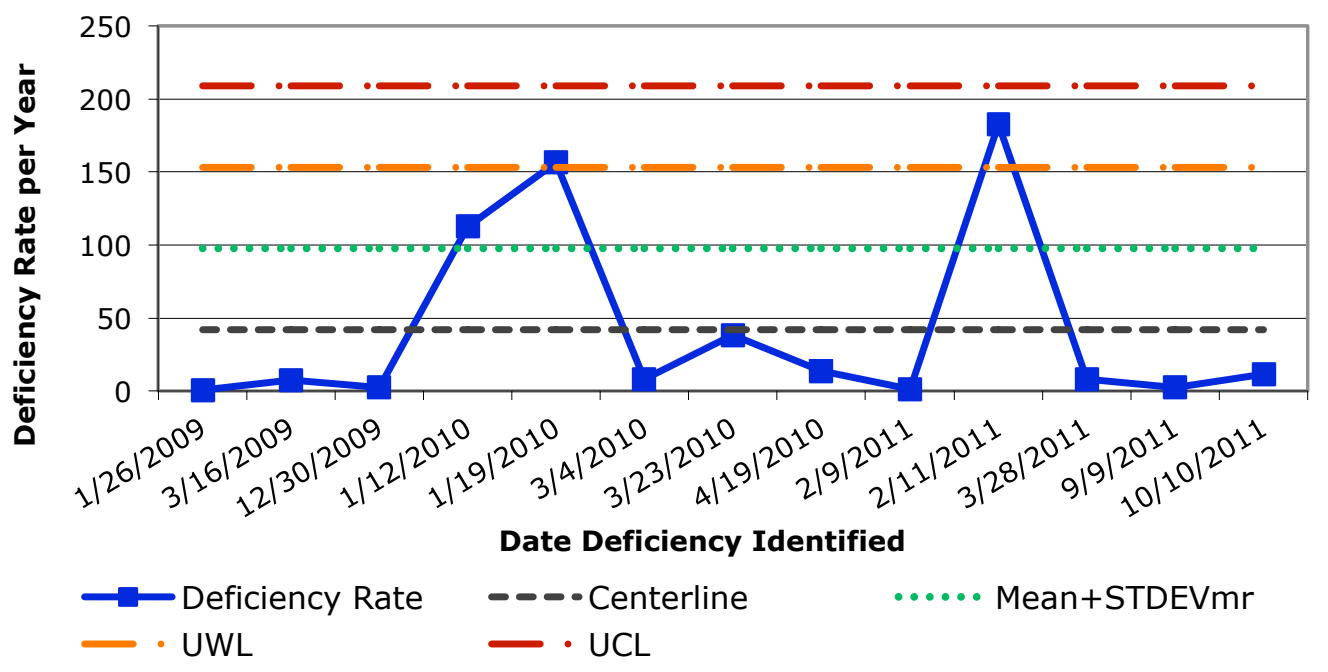

Figure 20. Deficiency rate per year control chart of sanitation deficiencies. 
In summary, no sanitation deficiencies were identified in the first and second quarters of 2012 and no new issues within this safety subject are reportable to the DOE Office of Enforcement as either repetitive or systemic.

To conclude Section 6.8, recent data within the industrial hygiene safety subject met a common test, specifically hazard communication. Two other safety subjects, respiratory protection and sanitation, were analyzed in this analysis due to a common test met in the previous analysis. It was determined that hazard communication deficiencies will continue to be analyzed in future analyses, but no new issues within industrial hygiene are reportable to the DOE Office of Enforcement as either repetitive or systemic.

Potential Significant, Systemic or Repetitive $\bigotimes$ Meets Common Tests
Within Expected Variation

Downward Trend

\subsection{Other Industrial Safety}

The visual analysis step warranted further analysis of deficiencies in ITS categorized as the industrial safety (IS) topic, specifically those categorized as general IS. Therefore, this safety subject was analyzed using a control chart.

\section{General Industrial Safety}

The control chart analysis (Figure 21) for general IS deficiencies shows consecutive increases in the number of deficiencies identified per quarter, a common test. Although a common test was met, all data that contributed to the consecutive increase in the number of deficiencies are below the centerline. However, this safety subject is discussed further.

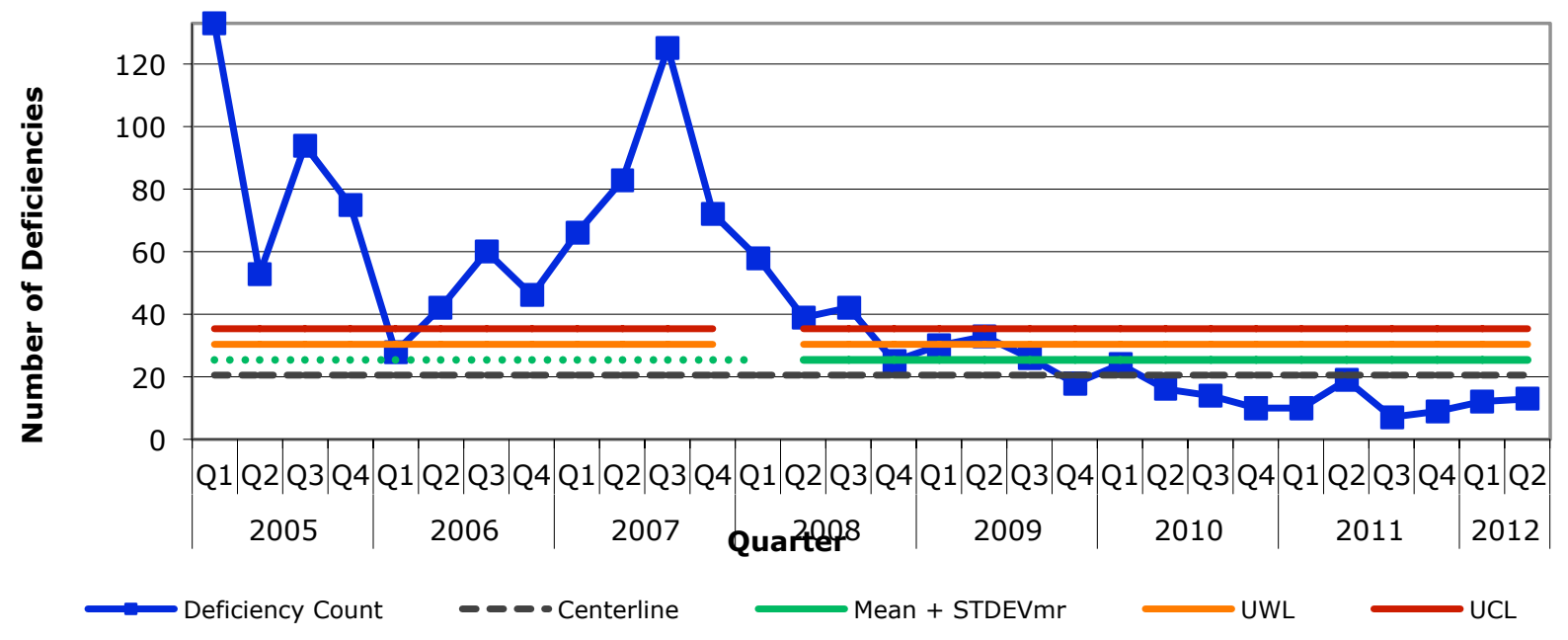

Note: Control Limits are Based on fewer quarters than displayed

Figure 21. Deficiency rate per year control chart of general industrial safety deficiencies. 
During the second quarter of 2012, the most recent quarter of data analyzed, 13 general IS deficiencies were identified; eight of the 13 were from injury / illness events.

From the third quarter in 2011 to the second quarter in 2012 there were increases in the number of general IS deficiencies identified. In each quarter in 2012, compared to quarters in 2011, more assessments were conducted that identified general IS deficiencies. In the second quarter of 2012, eight injury / illness events identified general IS deficiencies, compared to one or zero in previous quarters. Three of the eight deficiencies are titled as "Repetitive typing or key entry." Two of the eight deficiencies were titled as a type of overexertion; however, the activities performed when the employee experienced pain or discomfort were not the same activity. One activity was the cleaning of a vehicle and other was repetitive pushing/pulling of cable related to a computer rack installation. Two of the eight were duplicates of one of the repetitive motion deficiencies and the other deficiency appears to be a repetitive motion injury based on the issue description. All eight injury / illness deficiencies are owned by the Computation Directorate.

In summary, there is a consecutive increase in general IS deficiencies identified from the third quarter in 2011 to the second quarter in 2012; however, this pattern is below the centerline and is not of concern at this time. Although no new issues within this safety subject are reportable to the DOE Office of Enforcement as either repetitive or systemic, the general IS safety subject will continue to be analyzed in future analyses.

To conclude Section 6.9, recent data within the IS safety subject met a common test, specifically general IS. It was determined that deficiencies categorized as general IS will continue to be analyzed in future analyses, but no new issues within IS are reportable to the DOE Office of Enforcement as either repetitive or systemic.

\begin{tabular}{|c|c|}
\hline tt & $\bigotimes$ Meets Common \\
\hline
\end{tabular}

Downward Trend

\subsection{0 "Severity Level I" Noncompliances}

The WSH "Severity Level I," NTS reporting threshold, previous called the "Other Significant Condition," is defined as "a condition or hazard that has the potential to cause death or serious physical harm (injury or illness)." This reporting threshold would include, at a minimum, significant noncompliances with high relative risk, as defined in DES-0083. These deficiencies are identified in ITS as having an issue significance level of one, but could also be an issue with an issue significance level of two.

Two methods were used to review ITS data for deficiencies that may meet the "Severity Level I" NTS reporting threshold:

1. A review of all issue significance level one and two deficiencies with identification dates starting in October 2011 through October 2012

2. A review of all deficiencies with compliance codes that suggests an issue significance level of one, but the significance level was downgraded 
There were no issue significance level one deficiencies identified between October 2011 and October 2012. There were eight issue significance level two deficiencies identified between October 2011 and October 2012; all of the eight were either reported to the DOE NTS or were from a security incident.

Since the third quarter of 2011, there was one deficiency assigned a compliance code with a suggested issue significance level of one that was downgraded to another issue significance level. This issue was evaluated for reportability to the DOE NTS at the time the issue was identified, "An LLNL subcontractor was performing work in a permitrequired confined space (PRCS) without a confined space permit prior to entry into the space. This is a noncompliance with OSHA 1910.146(d)(10)." After gathering more information, it was determined that a number of controls were in place, even though the permit was not filled out prior to entry into the confined space. Controls in place were, the atmospheric monitoring was conducted, retrieval equipment was in place, and the three subcontract workers had some form of confined space training. Although it was determined this noncompliance does not rise to the level of an NTS report, a root cause analysis was conducted.

The Performance Analysis and Reporting Section of the Contractor Assurance Office reviewed the deficiency and determined that this deficiency that was downgraded from an issue significance level 1 does not meet the threshold for reporting to the DOE NTS as a "Severity Level I" noncompliance. 


\subsection{Nuclear Safety Management Issues}

Nuclear safety includes safety programs in nuclear operations (criticality safety, safety basis, and system engineering), nuclear packaging and transportation, quality assurance, and radiation protection. Data from 2005 through June 2012 were extracted from the Issues Tracking System (ITS) in July 2012 using the ITS Basic Issue Report. Three nuclear safety subjects, nuclear operations (specifically safety basis, analysis, design and documentation), packaging and transportation, and radiation protection, were identified in the previous analysis as needing follow-up analysis. Based on the frequency of deficiencies by functional area in the most recent quarters, all four nuclearrelated functional areas were analyzed using control charts.

As discussed in the sections below, the analysis for nuclear safety deficiencies identified two subjects with a point above the UCL, one subject with a point above the UWL, and three subjects with increased deficiencies in the second quarter of 2012, the most recent quarter of data analyzed.

\subsection{Nuclear Operations}

The visual analysis step warranted further analysis using a control chart of deficiencies in ITS categorized as the nuclear operations functional area. This functional area was also determined to need continued analysis in the previous performance analysis due to a point above the UWL in the second quarter of 2011 and a statistically significant increase in deficiencies from 2005 to the third quarter in 2011. Therefore, this safety subject was analyzed using control charts.

The control chart analysis (see Figure 22) shows a point above the UCL, which is an action limit, as well as a recent increase in deficiencies, which is a common test. Therefore, this functional area was analyzed to resolution.

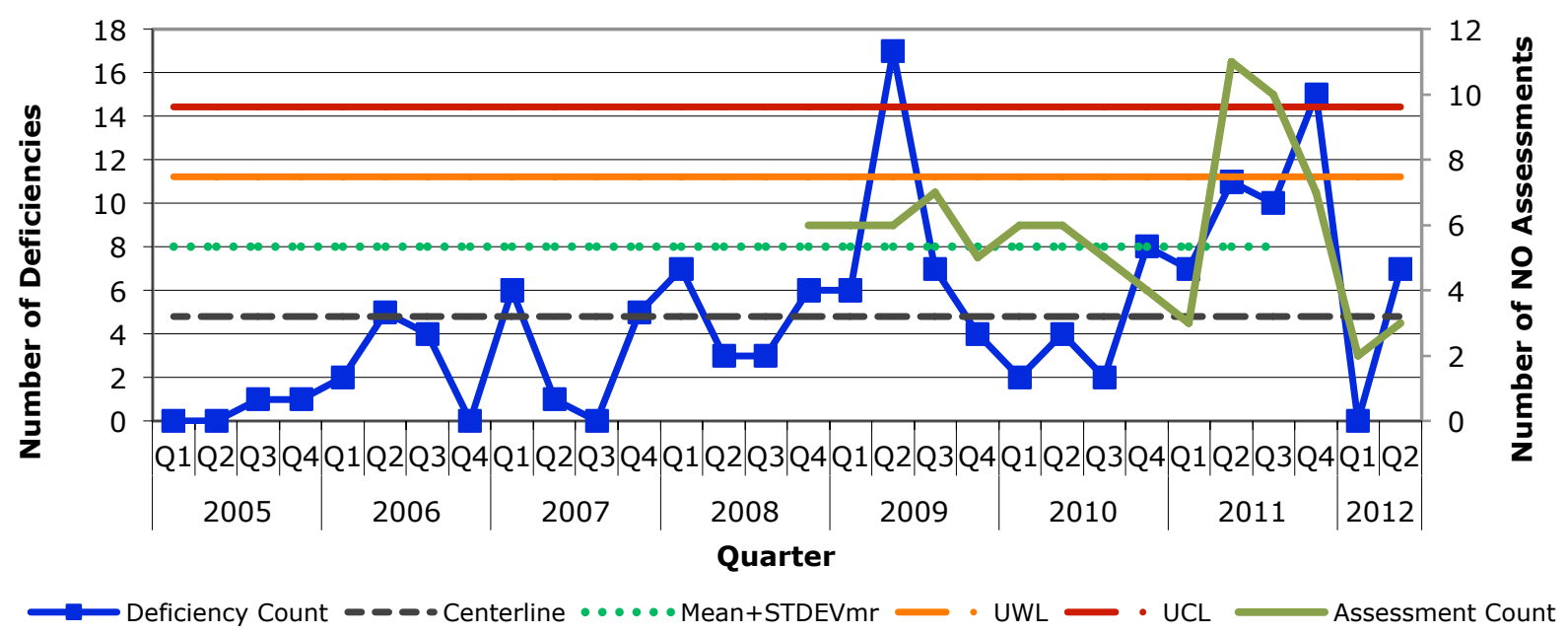

Figure 22. Frequency control chart of nuclear operations deficiencies.

During the second quarter of 2012, the most recent quarter of data analyzed, seven nuclear operation deficiencies were identified, as shown in Figure 22. The following five of these seven deficiencies, identified from four assessments all related to operations 
performed in nuclear facilities operated by the Nuclear Materials Technology Program (NMTP), were categorized under a single nuclear operations topic, namely startup/ restart of nuclear facilities and operations:

- One deficiency from assessment ITS 34365, LSO Readiness Assessment for B332 976 A Project 5/8/2012, an external assessment conducted by the NNSA Livermore Site Office (LSO) of an activity performed by the Nuclear Weapons Engineering Program (NWEP) in Building 332 (the Plutonium Facility).

○ ITS 34304.2, "Prestart Finding CR-9.1 Lack of documentation."

- One deficiency from assessment ITS 34436, B332 HC2 Activity Startup: Oxidation Furnace-HYDOX 5/16/12, a readiness assessment conducted by the NMTP of an activity in the Plutonium Facility.

○ ITS 34436.2, “Trial period operations Work Permit requires closing prior to operations."

- One deficiency from assessment ITS 34494, B332 HC2 Activity Startup: Oxidation Furnace-HYDOX 6/8/12, a readiness assessment conducted by NMTP of an activity in the Plutonium Facility.

○ ITS 34494.1, "Post-Start CR-8.1: Valve O2V502 not in Drawing."

- Two deficiencies from assessment ITS 34505, B334 Jerk Tester MSA 6/21/2012, a management self-assessment of operational readiness conducted by NMTP of an activity in Building 334 (the Hardened Engineering Test Building).

○ ITS 34505.1, “Prestart PR-9.1: Work Permit 334-12-D-0344 Needs to be Revised"

○ ITS 34505.4, "Post Start CR-7.b: Formal system maintenance plan"

The remaining two of the seven deficiencies in the nuclear operations functional area identified in the second quarter of 2012 came from two separate and independent topics unrelated to startup/restart of nuclear facilities and operations:

- One deficiency related to the topic criticality safety, from assessment ITS 34381, LSO Periodic Issues Report (May 2012)

- ITS 34381.3, "A criticality safety basis which formed the basis for criticality controls in OSP 332.075 was determined to be inadequate." A Criticality Safety Evaluation (CSE) of a nuclear operation involving fissile materials had determined that the operation was not safe to conduct. The Criticality Safety Group subsequently determined that the evaluation originally used was outdated and that an existing newer evaluation adequately addressed the operations, demonstrating that the activity was safe to conduct.

- One deficiency related to the topic safety basis analysis, design, and documentation, from assessment ITS 34421, OR\#12-20 Continuous Air Monitor (CAM) Alarm Actuation

○ ITS 34421.1, “OR\#12-20 Required Response Elements." Note that this issue was incorrectly categorized as a deficiency when initially entered into ITS and is included in Figure 22 (occurrence report "Required Response 
Elements" are correctly categorized into ITS as observations). However, this issue has since been correctly categorized as an observation.

During the fourth quarter of 2011, the quarter with a data point above the UCL, 15 nuclear operations deficiencies were identified from six different assessments. Eleven of the 15 were categorized as the nuclear facility startup/ restart topic and nine of the 15 were from readiness reviews. The nuclear facility startup/restart topic was analyzed using a control chart.

\section{Nuclear facility startup/restart}

The "rate per year" control chart analysis for nuclear facility startup/ restart deficiencies shows a data point above the UWL in May 2012, a common test (Figure 23). Therefore, this safety subject is discussed further. For more information on the "rate per year" control chart refer to Section 11.2.

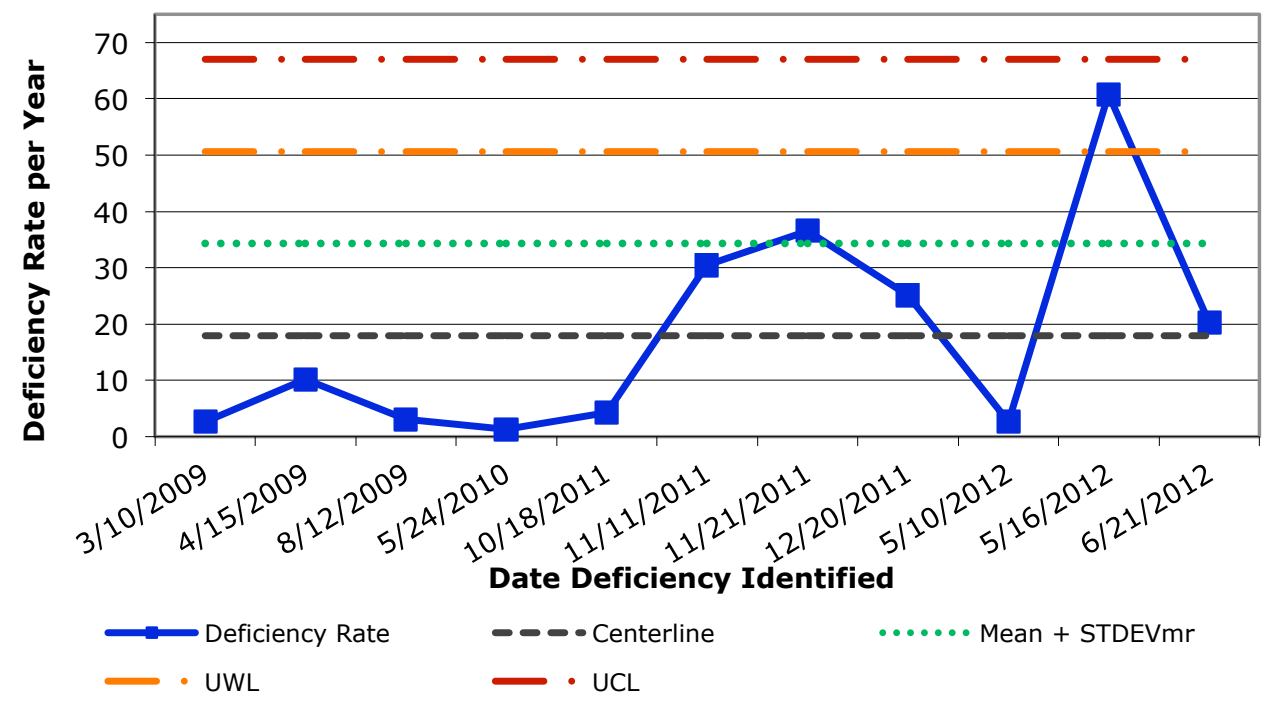

Figure 23. Deficiency rate per year control chart of nuclear facility startup/restart deficiencies.

In the second quarter of 2011, as discussed above, four issues were identified and categorized as nuclear facility startup/ restart, two identified in May 2012 (assessments ITS 34365 and 34436 in the above list) and two identified in June 2012 (assessments ITS 34494 and 35505). Only six days elapsed between the identification of the two issues in May 2012, causing a point to be above the UWL for the deficiency rate.

In the fourth quarter of 2011, the quarter with a data point above the UCL for the nuclear operations functional area, a similar concentration of deficiencies in the startup/restart topic was also observed. As shown by Figure 22, 15 nuclear operations deficiencies were identified from six different assessments.

Eleven of these 15 nuclear operations deficiencies were categorized under the nuclear facility startup/restart topic, of which the following nine of the 15 were findings from readiness reviews performed by LLNL and by LSO of a single device in a single Laboratory facility, namely the Building 334 vibration machine ("shaker"): 
- Six deficiencies from assessment ITS 33520, Building 334 Shaker Restart MSA, a readiness review performed by the Weapons \& Complex Integration Principal Directorate

○ ITS 33520.1, "Pre-start Finding PR-4.2-A No documentation to verify Senior Operator Training"

○ ITS 33520.2, "Pre-start Finding PR-12.1 No documented restart program for the Shaker"

○ ITS 33520.3, "Pre-start Finding CR-4-A Senior Operator to complete HS5030-W"

○ ITS 33520.4, "Pre-start Finding CR-4-B The assigned H\&S Tech has not completed required training"

○ ITS 33520.6, “CR-8-B No documentation for Shaker maintenance in Tracking System"

○ ITS 33520.8, "Pre-Start Finding CR-10-B No documentation to show PreStart items are complete"

- One deficiency from assessment ITS 33647, Building 334 Shaker Contractor Readiness Assessment, performed by the NMTP

○ ITS 33647.1, “The Start-Up Plan does not specify that management oversight will also be performed during the non-fissile material operations that are in preparations for operations with fissile material"

- Two deficiencies from assessment ITS 33770, LSO Readiness Assessment for B334 Shaker Operations, performed by the NNSA LSO

○ ITS 33770.1, “CR-7.1 Pre-Start Finding: Approved Changes to SB Docs not fully incorporated into the Shaker activity nor any work documents for the Shaker"

○ ITS 33770.2, “CR-7.2 LLNL IVR [Independent Verification Review] Process [incorrectly] stated full or satisfactory Implementation"

The additional two startup/ restart deficiencies during the analysis period were from an NMTP MSA of the overall readiness review process that had been applied to the same facility:

- ITS 32940, Management Self Assessment of the Readiness Review Process, performed by the Nuclear Operations Directorate

○ ITS 32940.1, “The Contractor Readiness Assessment breadth was not appropriate in that it did not cover Core Requirement 13"

○ ITS 32940.2, “Contractor Readiness Assessment Final Report Incomplete"

Readiness reviews are by intent robust examinations of planned operations and are designed to identify as many deficiencies as possible before operations are conducted for the first time. As can be seen from the above issue titles, the deficiencies that such reviews identify are typically highly specific for highly-specific operations. The 11 deficiencies identified above follow this pattern and cannot be considered evidence of 
any systemic or programmatic weakness in nuclear operations, or any programmatic noncompliance with DOE nuclear safety requirements for work planning. The relatively high count of deficiencies can be attributed to the fact that four separate assessments ("readiness reviews") of a single device in a single LLNL facility were performed by multiple organizations during the fourth quarter of 2011.

The remaining four nuclear operations deficiencies identified during the fourth quarter of 2011 came from two separate and independent sources unrelated to startup/ restart of nuclear facilities and operations:

- One deficiency from ITS 33763, LSO Periodic Issues Report (December 2011)

○ ITS 33763.3, “B331 Surveillance 'Glovebox Rate-of-Rise,' SRP-B3314.1.1/4," which identified that the basis for assumptions made in temperature calibration of certain glovebox instrumentation in Building 331 (the Tritium Facility) was not documented.

- Three deficiencies from ITS 33444, OR\#11-55 PISA: Security Firearm Inadvertent Discharge Not Evaluated in the DSA [Documented Safety Analysis] for Building 334

○ ITS 33444.1, “OR\#11-55 Required Response Elements.”

○ ITS 33444.2, “Firearm Inadvertent Discharge Scenario involving Bish Cans"

○ ITS 33444.3, “Noncompliance with DOE Nuclear Safety Requirements for the B334 Safety Basis"

Note that issue ITS 33444.1 was incorrectly categorized as a deficiency when initially entered into ITS and, as a result of this error being discovered during the performance analysis, was subsequently removed from the fourth quarter of 2011 deficiency count. Note also that had this issue been initially entered into ITS correctly, the reduced fourth quarter in 2011 nuclear operations deficiency count (14 rather than 15) would have remained below the UCL (the "action limit") for that analysis period.

In summary, nuclear facility startup / restart deficiencies were identified for two different facilities (Buildings 332 and 334) and for distinctly different operations and circumstances, and therefore do not constitute evidence of any systemic or programmatic nuclear operations issues.

\section{Safety Basis, Analysis, Design, and Documentation}

This safety subject was determined to need continued analysis in the previous performance analysis due to a point above the UWL in the second quarter of 2011 (Figure 24). In this analysis, the control chart shows two points above the UWL in the second and third quarters of 2011, an action limit. Since the previous analysis was performed, an additional deficiency was identified in the third quarter of 2011, causing a second point to be above the UWL in this analysis. This safety subject was discussed in detail in the previous analysis and it was determined in the current analysis that addition of one new deficiency does not change the overall conclusion in the previous analysis that a programmatic or repetitive noncompliance did not exist. In the previous analysis it was discovered that several of the deficiencies contributing to the control 
chart analysis should have been categorized as observations, which would change the results of the control chart analysis (i.e., by erroneous inflating the deficiency count).

Therefore, this analysis discusses only recent activity in further detail.

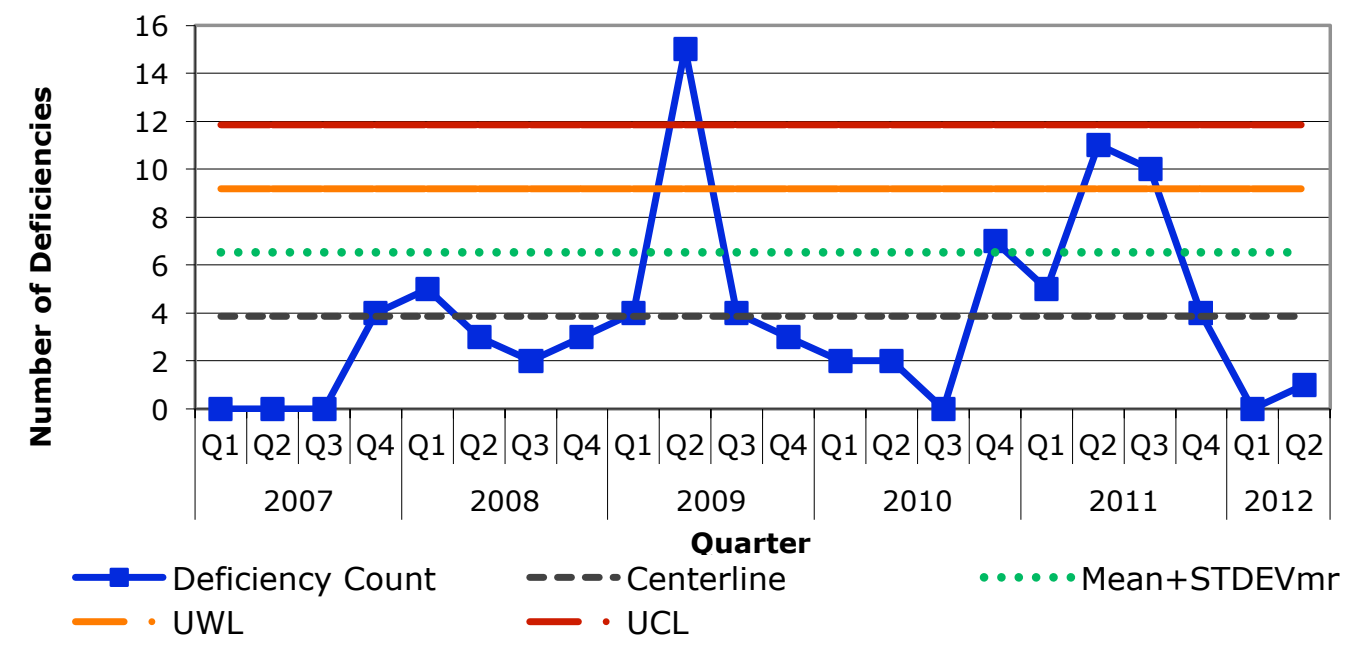

Figure 24. Frequency control chart of safety basis, analysis, design, and documentation deficiencies.

During the second quarter of 2012, the most recent quarter of data analyzed, one safety basis deficiency was identified. The sole safety basis deficiency during the analysis period was ITS 33444.1, “OR\#12-20 Required Response Elements." As was already discussed, this deficiency should have been categorized as an observation. Subsequent to the current analysis, the ITS issue was updated and is now correctly marked as an observation. Consequently, the true number of safety basis deficiencies for the second quarter of 2012 is zero.

Based on the detailed information provide in the analysis in the previous report and the control chart analysis here, it was determined that a programmatic or repetitive noncompliance related to safety basis does not exist.

To conclude Section 7.1, recent data within the nuclear operations functional area met an action limit. This functional area was analyzed to resolution. The current analysis determined that neither a programmatic or systemic weakness, nor a programmatic noncompliance with DOE nuclear safety requirements, exists in the nuclear operations functional area.

Because a common test was met (an increase in deficiencies in the most recent quarter of data analyzed), this safety subject will continue to be analyzed in future performance analyses.

Potential Significant, Systemic or Repetitive $\triangle$ Meets Common Tests
Within Expected Variation
Downward Trend 


\subsection{Packaging and Transportation (Nuclear)}

The visual analysis step did not warrant further analysis of deficiencies in ITS categorized as nuclear packaging and transportation (P\&T); however, in the previous analysis the on-site nuclear P\&T safety subject was determined to need continued analysis due to an increase in the deficiency rate in August and September of 2011. Therefore, this safety subject was analyzed using a control chart.

The "rate per year" control chart analysis (see Figure 25) indicated two consecutive increases in the rate of P\&T deficiencies related to on-site movement of nuclear material, which is a common test. However, this is the same common test analyzed and discussed in the previous report that found no concerns. Therefore, this safety subject is not discussed further. For more information on the "rate per year" control chart refer to Section 11.2.

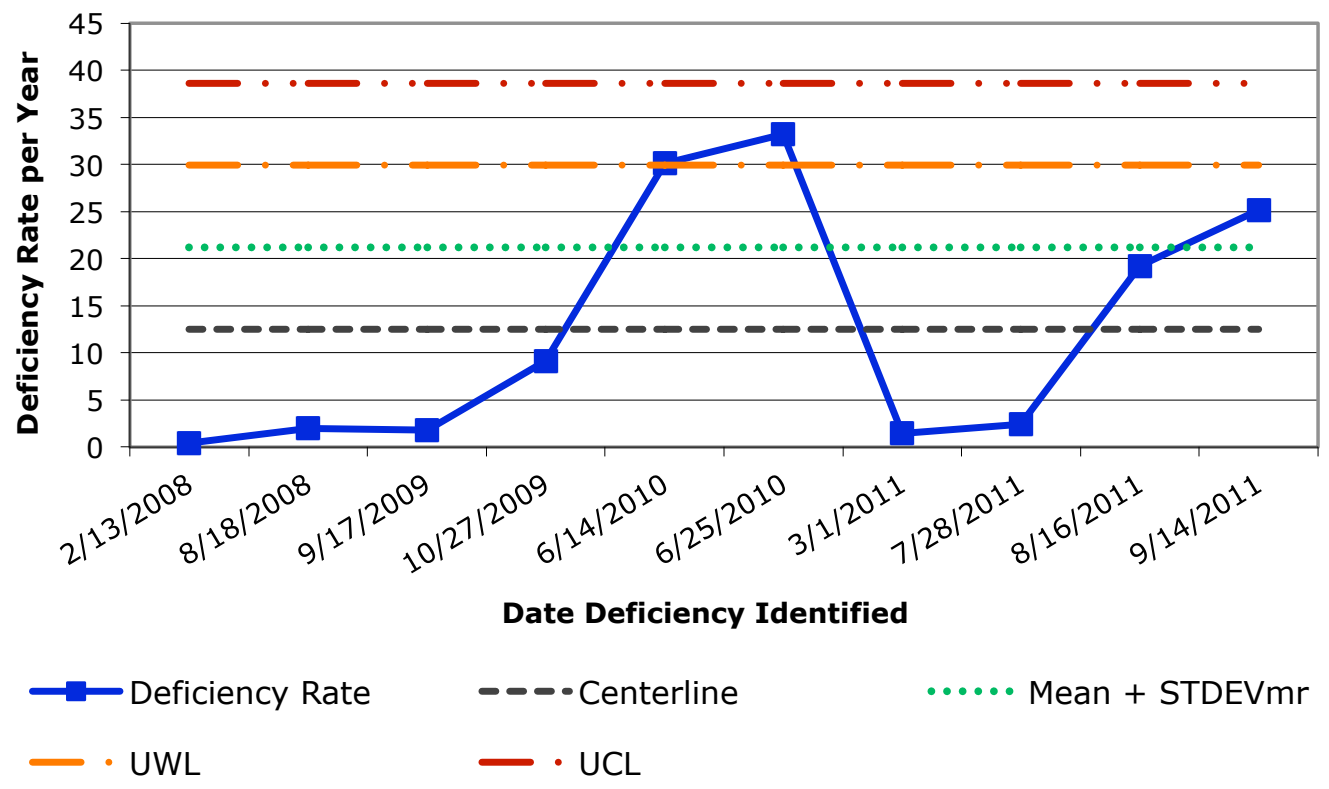

Figure 25. Deficiency rate control chart of packaging and transportation of on-site nuclear deficiencies.

In summary, there was a recent increase in the rate of P\&T on-site nuclear material deficiencies, a common test. However, this same common test was analyzed and discussed in the previous analysis. The previous analysis concluded that two of the five deficiencies identified in 2011 were either incorrectly categorized in the P\&T functional area or the deficiency should have been categorized as an observation. It was determined that the P\&T deficiencies do not represent a programmatic (systemic) or repetitive noncompliance reportable to DOE. Because no new common tests were met, this safety subject will not automatically be analyzed in future performance analyses.

Potential Significant, Systemic or Repetitive
Meets Common Tests $\bigotimes$ Within Expected Variation
Downward Trend 


\subsection{Quality Assurance (Nuclear)}

Quality assurance (QA) deficiencies that are nuclear safety related are identified in ITS by (1) a "Yes" answer to the nuclear safety question at the ITS issue level and (2) assignment to the QA functional area. Since 2005, there have been 4,025 deficiencies categorized as QA, with $353(9 \%)$ related to nuclear safety based on answers to the nuclear safety question in ITS. The majority of nuclear-safety-related QA deficiencies since 2005 fall within three of the ten criteria of the QA Order (DOE O 414.1) and the QA Rule (10 CFR 830, Subpart A): 43\% in Criterion 4 (Management/Documents and Records), 20\% in Criterion 5 (Performance/Work Processes), and 18\% in Criterion 2 (Management/Personnel Training and Qualification).

The visual analysis step warranted further analysis using a control chart of deficiencies identified in ITS as related to nuclear safety QA. Therefore, this functional area was analyzed using a control chart.

The control chart analysis (see Figure 26) indicated a recent increase in nuclear safety QA deficiencies, which is a common test. Therefore, this safety subject is discussed further.

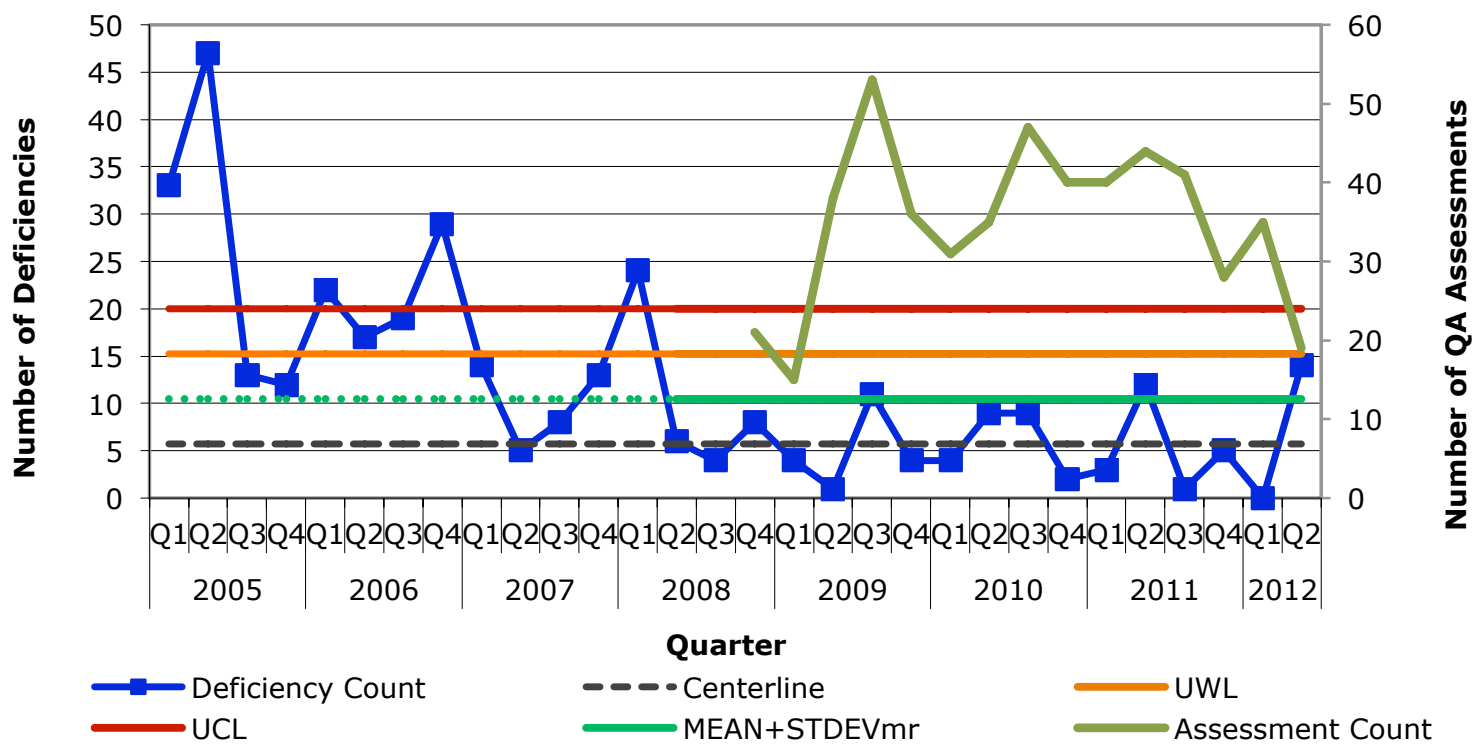

Note: Control limits are based on fewer quarters than displayed

Figure 26. Frequency control chart of nuclear safety quality assurance data.

During the second quarter of 2012, the most recent quarter of data analyzed, 14 nuclear QA deficiencies were identified, as shown in Figure 26. Thirteen of the 14 deficiencies were categorized as performance/work processes (criterion 5), and 10 of the 14 were identified from readiness reviews. The performance/work processes safety subject was analyzed using a control chart.

A statistically significant trend has been a topic of this section for many analyses. Although the decreasing trend from the first quarter in 2005 to the second quarter in 2012 still exists, there is no statistically significant trend from the second quarter of 2008 
to the second quarter of 2012. More recent data suggests that the pattern of deficiencies identified that are within expected variation.

\section{Criterion 5 - Performance/Work Processes}

The control chart analysis for nuclear safety QA deficiencies categorized under criterion 5 (performance/ work processes) shows a point above the UCL in the second quarter of 2012, an action limit (Figure 27). Therefore, this safety subject was analyzed to resolution.

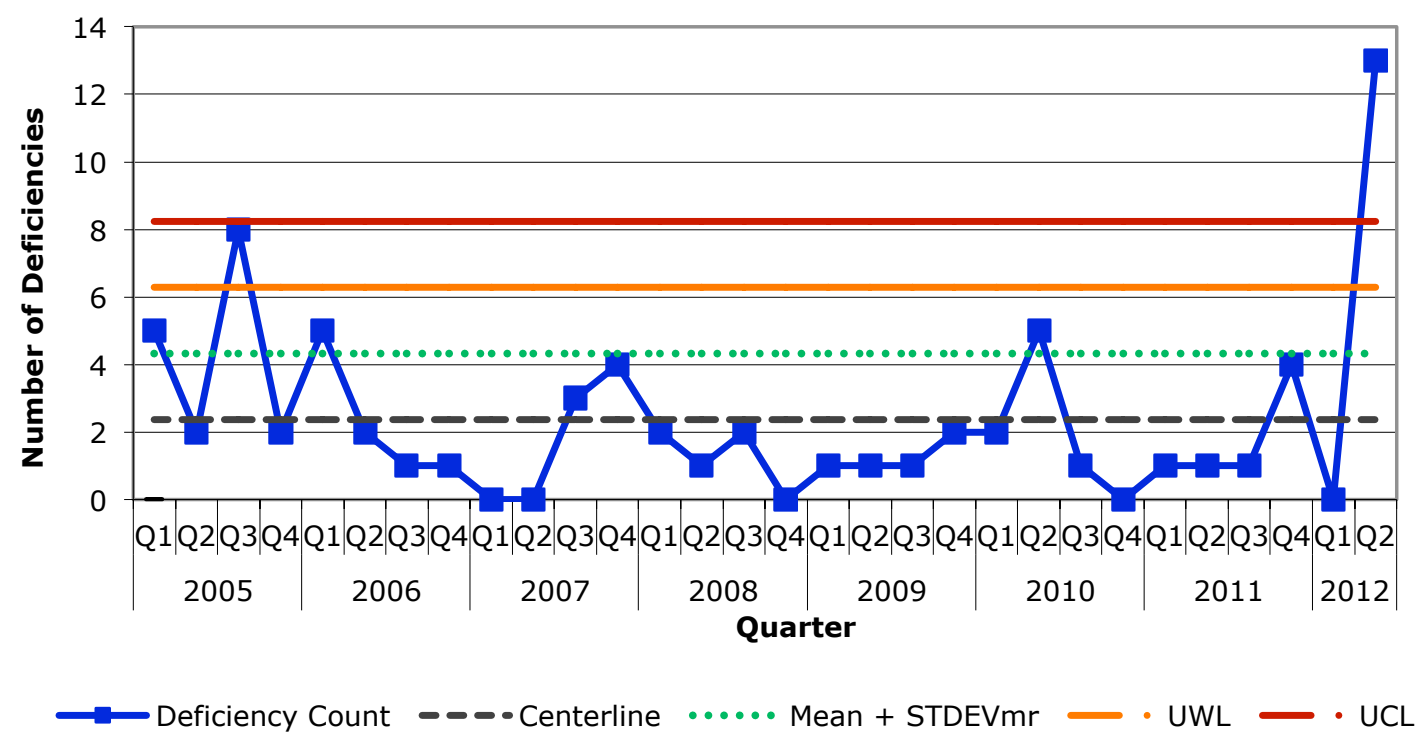

Figure 27. Frequency control chart of nuclear safety quality assurance performance/work process deficiencies.

During the second quarter of 2012, the most recent quarter of data analyzed and the quarter with a data point above the UCL, 13 nuclear safety QA deficiencies were identified and categorized as performance/work processes. As described below, 10 of the 13 deficiencies were specific to work planning and were identified from readiness reviews.

- Five deficiencies from assessment ITS 34304, 976A Contractor Readiness Assessment, of an activity performed by the Nuclear Weapons Engineering Program (NWEP).

- ITS 34304.2, "Expectations for proper implementation of the HEAF lightning warning system monitoring have not been communicated to monitoring personnel."

- ITS 34304.3, "The requirement for a post-shot inspection of the HE chamber by a qualified HE Handler is not being met for an off-normal scenario." 
- ITS 34304.4, "The full load path for the lifting fixture has not been adequately analyzed in mechanical engineering safety note (MESN) 11500072-AA."

- ITS 34304.5, "Various steps and sections of Appendix A (Off-Normal) of CODT-2012-0059, Issue AC, Zeroing Strain Gages and Firing Operations for 976A, cannot be performed as written."

○ ITS 34304.6, “CODT-2011-1431, Rev. 6, Appendix B, Step 11, which directs the transport of the contaminated item from one radioactive material area (RMA) room to another, is not consistent with the controls specified in the B332 Facility Safety Plan."

- Three deficiencies from assessment ITS 34494, B332 HC2 Activity Startup RA: Ox Furnace-HYDOX 6/8/12, an operation planned by the Nuclear Materials Technology Program (NMTP) in Building 332 (the LLNL Plutonium Facility).

○ ITS 34494.3: "High-radiation controls for the oxidation glovebox have not been fully developed and implemented."

○ ITS 34494.4: “OPP-B332-023 is not approved and the draft procedure does not satisfy the OSP control for ensuring hydride decomposition prior to oxidation."

○ ITS 34494.5: “OPP-B332-022 refers to an oxygen flow totalizer value which has not been installed/implemented within the oxidation system software."

- One deficiency from assessment ITS 34436, B332 HC2 Activity Startup: Oxidation Furnace-HYDOX 5/16/12, an NMTP operation in Building 332 similar in concept to that above.

○ ITS 34436.1: “The Assessor determined that OSP 332.194 contained a poorly written control for the operation and suggested that the OSP be revised."

- One deficiency from ITS 34505, B334 Jerk Tester MSA 6/21/2012, a readiness review of an activity performed by the NWEP in Building 334 (the Hardened Engineering Test Building).

- ERD11-500029-AB Mechanical Engineering Assembly Guide Jerk Test Machine, dated 4/12/12, Page 15 of 21 indicates bolts were torqued to 27 not $30 \mathrm{ft}-\mathrm{lb}$ as called out in the plan.

Readiness reviews are by intent especially robust examinations of planned operations and are designed to identify as many deficiencies as possible before operations are conducted for the first time. Therefore, an elevated deficiency count is not unexpected when one or more readiness reviews have been performed during the analysis period. As can be seen from the above issue descriptions, the deficiencies that such reviews identify are also typically highly specific for highly-specific operations. The 10 deficiencies identified above fit this pattern and consequently cannot be considered evidence of any systemic or programmatic noncompliance with DOE nuclear safety requirements for work planning. 
The following two of remaining three of these 13 deficiencies were identified by a MSA performed for the same NWEP activity subject to the readiness review in ITS 34303 above:

- ITS 34272, 976A Management Self-Assessment (MSA)-April 6, 2012, for the same NWEP activity addressed the readiness review in ITS 34304 above.

○ ITS 34272.2, "It was noted during the MSA that the training, planning, and preparations for contingency actions for off-normal conditions had not been completed."

- ITS 34272.3, "Early versions of the procedure [CODT-2011-1431] were written so tightly that it was impossible to execute the steps as written for all actual configurations of the experiment assembly process."

The last of these 13 deficiencies related to an isolated instance of exceeding a radiological materials limit during a Physics and Life Sciences (PSL), Chemistry and Materials Division (CHEM), activity involving yellow-cake uranium.

- ITS 34505.6, “Workers were working with amounts of uranium on a benchtop that exceeded limits allowed in the IWS."

To conclude Section 7.3, a common test and action limit were met within the nuclear safety QA functional area. Further evaluation determined, however, that the significant increase in work planning deficiencies during the reporting period can be attributed to the fact that four readiness reviews were performed during that period. The specific deficiencies identified are sufficiently diverse and sufficiently specific to their respective operations that none, either individually or collectively, constituted evidence of a systemic or programmatic weakness in work control.

Because a common test was met for the nuclear safety QA subject (an increase in deficiencies in the most recent quarter of data analyzed), this safety subject will continue to be analyzed in future performance analyses.

\begin{tabular}{|c|c|}
\hline $\begin{array}{l}\text { ignificant, } \\
\text { or Repetitive }\end{array}$ & $\begin{array}{l}\bigotimes \text { Meets Common } \\
\text { Tests }\end{array}$ \\
\hline
\end{tabular}

Downward Trend

\subsection{Radiation Protection}

The visual analysis step did not warrant further analysis of deficiencies in ITS categorized as radiation protection; however, this functional area was determined in the previous analysis to need continued analysis. Therefore, this functional area was analyzed using a control chart.

There was a slight increase in radiation protection deficiencies in the most recent quarter analyzed, a common test (Figure 28). Therefore, this safety subject is discussed further. 


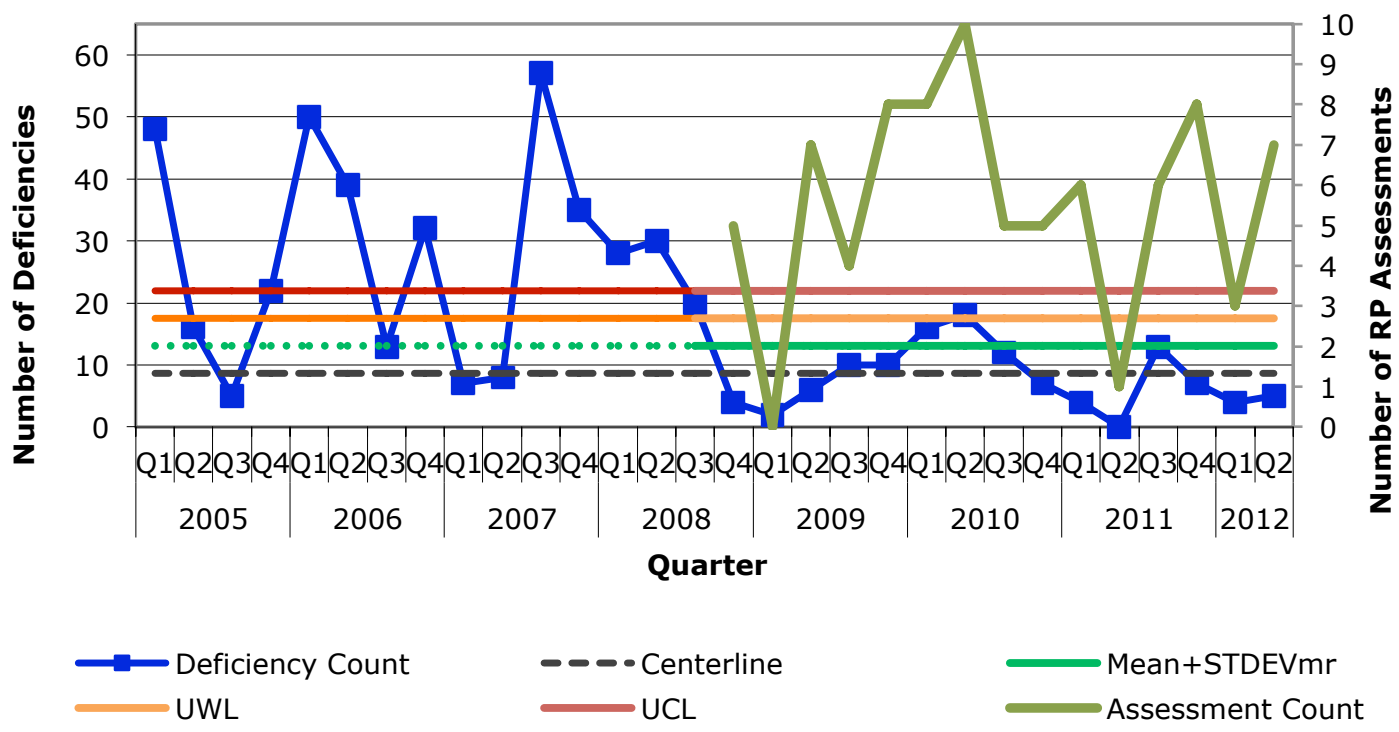

Note: Control limits are based on fewer quarters than displayed

Figure 28. Frequency control chart of radiation protection data.

During the second quarter of 2012, the most recent quarter of data analyzed, there were five radiation protection deficiencies identified from four different assessments. These deficiencies were categorized in five different topics, sub-topics and compliance codes:

- ITS 32942.1: During an emergency management exercise, the ES\&H Health Physicist did not perform any monitoring at the Command Post, even after hearing that radiological materials had been involved in a fire. After learning of a fire involving radiological materials, the Battalion Chief recommended that ES\&H report to the incident scene to monitor responders.

- ITS 32942.2: During an emergency management exercise, monitoring performed by Health \& Safety Technicians on people who were in hot zone utilized inappropriate techniques.

- ITS 34276.1: Contrary to the requirements of the relevant Radiological Work Permit, work conducted under Joint Nevada Program Office (JNPO) auspices in the Nevada National Security Site (NNSS) Area 12 Core Library was performed without a Continuous Air Monitor (CAM) in operation.

- ITS 34307.2: While working with uranium oxide on a laboratory benchtop, a Physical and Life Sciences (PLS) Directorate, Chemical Sciences Division, worker made an improper risk-based decision not to wear appropriate personal protective equipment (i.e., a lab coat).

- ITS 34415.3: Signage on the exterior of a PLS Directorate, Atmospheric, Earth and Energy Division (AEED), building did not comply with 10 CFR 835 requirements and needed to be relocated.

Further analysis determined that these deficiencies are sufficiently different in type, location, and circumstances that they do not constitute a programmatic (systemic) or repetitive noncompliance reportable to DOE. Because a common test was met (an 
Performance Analysis: Issues Tracking System Data through June 2012

increase in deficiencies in the most recent quarter of data analyzed), this safety subject will continue to be analyzed in future performance analyses.

$\square$ Potential Significant, Systemic or Repetitive $\bigotimes$ Meets Common Tests

\author{
Within Expected \\ Variation
}

$\square$ Downward Trend 


\subsection{Classified Information Security Management Issues}

LLNL safeguards and security issues tracked in the Issues Tracking System (ITS) are analyzed to identify programmatic or repetitive issues that may require additional management attention. Emphasis is placed on issues related to classified information security.

Issues within the safeguards and security functional area are categorized into one of nine topics when they are entered into ITS. The topics are program management and support, protective force, physical protection, information protection, cyber security, personnel security, unclassified visits and assignments, nuclear materials control and accountability, and identifying classified information. These topics are further categorized into subtopics. Issues related to classified information security (CIS) are required to have the CIS question marked "Yes" at the issue level in ITS.

Data from 2007 through the second quarter of 2012 were extracted from ITS in July 2012 using the ITS Basic Issue Report. Issues identified by security incidents are reflected in the ITS data from February 2010.

All issues were initially analyzed using a three-step process, as described in Section 11.0, Method for Analyzing for Assessments and Issues in the main analysis report, Performance Analysis: Issues Tracking System Data through June 2012. The first step, the visual analysis step warranted further analysis of the classified information security deficiencies. Two topics were further analyzed using a control chart; the information protection and cyber security topics met a common test and in previous analyses, the cyber security topic was identified as requiring continued analysis.

The control chart for all CIS deficiencies shown in Figure 29 below indicates there was an increase in CIS deficiencies from the first to the second quarters of 2012.

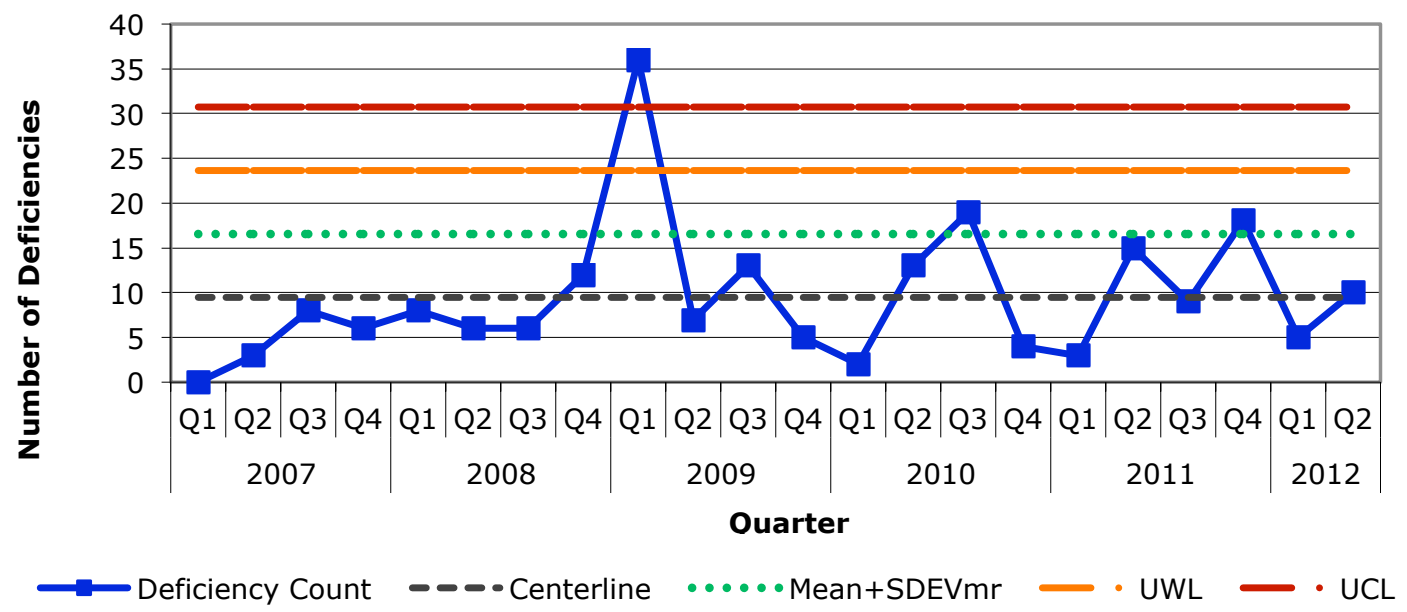

Figure 29. Frequency control chart of safeguards and security (CIS) deficiencies. 
In the second quarter of 2012, the most recent quarter of data analyzed, ten CIS deficiencies were identified in ITS compared to five CIS deficiencies in the first quarter of 2012, thus a common test was met, an increase in deficiencies from the first to the second quarter. The majority of the second quarter deficiencies fell under the information protection topic. This topic is discussed further in Section 8.3.

\subsection{Cyber Security}

The visual analysis step warranted further analysis of deficiencies in ITS categorized as cyber security. In the previous analysis this topic was also determined to need continued analysis due to an increase in deficiencies from the first to the second quarter of 2011. Therefore, this security subject was analyzed using a control chart. In the control chart, a common test was met; a point was above the UWL in the fourth quarter of 2011 as shown in Figure 30.

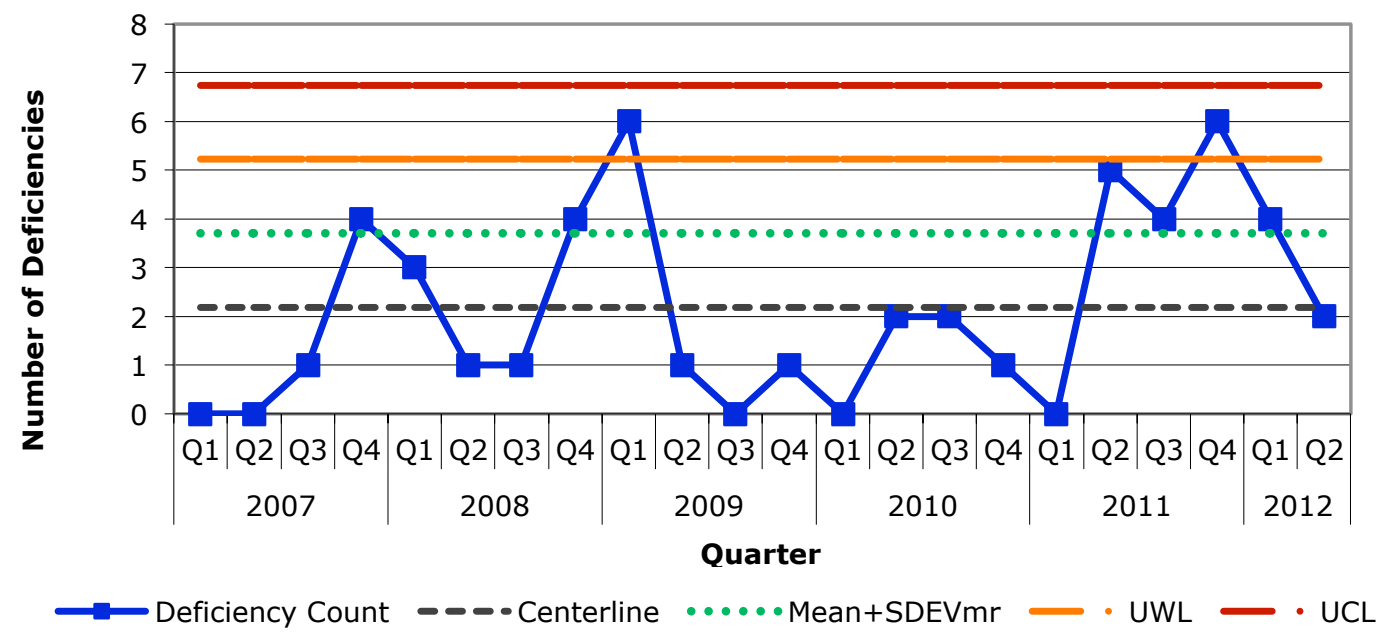

Figure 30. Frequency control chart of CIS cyber security deficiencies.

This safeguards and security topic is discussed further; however, the contents of the analysis are considered Official Use Only. For a copy of the entire CIS analysis, please contact Norma McTyer at mctyer1@1lnl.gov.

$\bigotimes$ Potential Significant, Programmatic or Repetitive $\bigotimes$ Meets Common Tests
Within Expected Variation
Downward Trend

\subsection{Identifying Classified Information}


The visual analysis step did not warrant further analysis of deficiencies categorized as identifying classified information. Therefore, this safeguards and security subject was not discussed or analyzed further in this report.

\subsection{Information Protection}

The visual analysis step warranted further analysis of CIS information protection deficiencies identified in 2012. Therefore, this security subject was analyzed using a control chart. In the control chart, a common test was met, a recent increase in information protection deficiencies from the first to the second quarter of 2012 as shown in Figure 31.

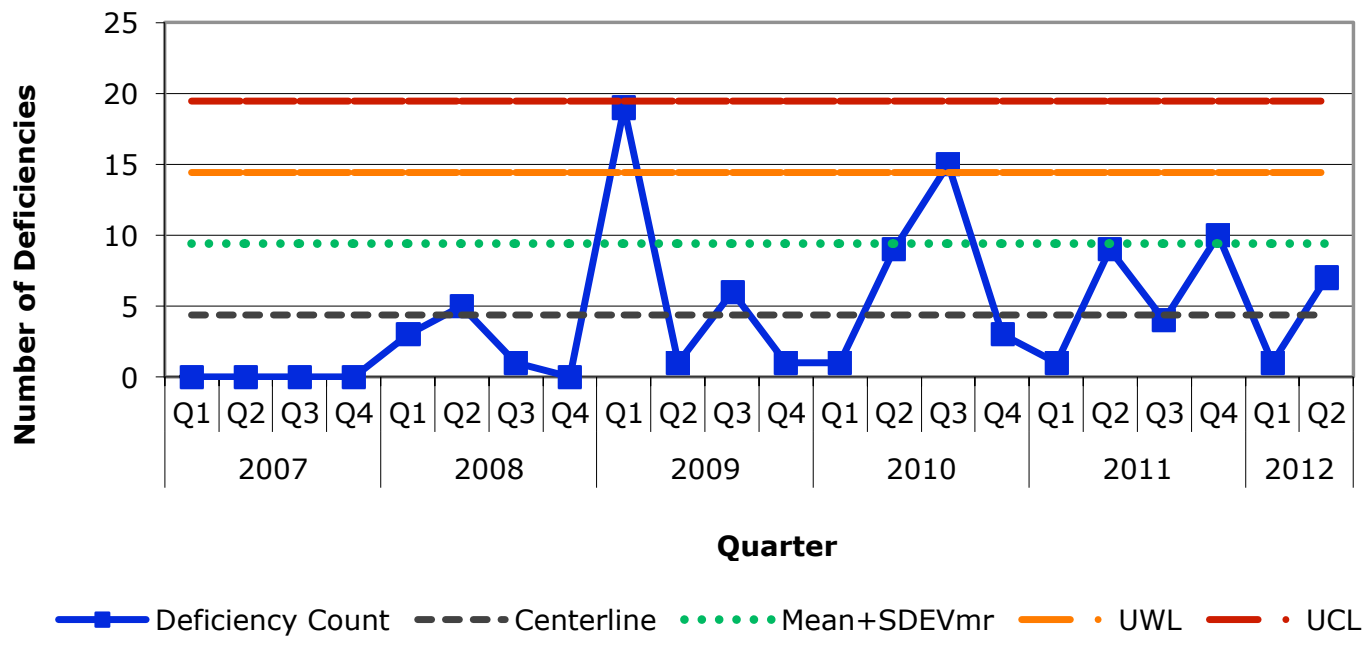

Figure 31. Frequency control chart of CIS information protection deficiencies.

This safeguards and security topic is discussed further; however, the contents of the analysis are considered Official Use Only. For a copy of the entire CIS analysis, please contact Norma McTyer at mctyer1@1lnl.gov.

$\square$ Potential Significant, Programmatic or Repetitive $\bigotimes$ Meets Common Tests
Within Expected Variation
Downward Trend

\subsection{Nuclear Materials Control \& Accountability}

The visual analysis step did not warrant further analysis using a control chart of nuclear materials control and accountability deficiencies. Therefore, this safeguards and security topic was not discussed or analyzed further.

\subsection{Personnel Security Program}


The visual analysis step did not warrant further analysis using a control chart of personnel security program deficiencies. Therefore, this safeguards and security subject was not discussed or analyzed further.

\subsection{Physical Protection}

The visual analysis step did not warrant further analysis using a control chart of deficiencies categorized as physical protection. Therefore, this safeguards and security topic was not discussed or analyzed further.

\subsection{Program Management and Support}

The visual analysis step did not warrant further analysis of deficiencies categorized as program management and support. Therefore, this safeguards and security topic was not discussed or analyzed further.

\subsection{Protective Force}

The visual analysis step did not warrant further analysis using a control chart of deficiencies categorized as protective force. Therefore, this safeguards and security topic was not discussed or analyzed further.

\subsection{Unclassified Visits \& Assignments by Foreign Nationals}

The visual analysis step did not warrant further analysis of deficiencies categorized as unclassified visits and assignments by foreign nationals. Therefore, this safeguards and security topic was not discussed or analyzed further.

\subsection{Unclassified Visits \& Assignments By Foreign Nationals}

The visual analysis step did not warrant further analysis of deficiencies categorized as unclassified visits and assignments by foreign nationals. Therefore, this safeguards and security topic was not discussed or analyzed further. 


\subsection{Other Functional Areas}

This section reviews deficiencies from other functional areas not regulated by the DOE Office of Enforcement and not analyzed in sections 6.0, 7.0, and 8.0.

As discussed in the sections below, the analysis of other functional areas showed one functional area with an increase in the deficiency rate in the second quarter of 2012, the most recent quarter of data analyzed. Recent data from all other functional areas were within expected variation.

\subsection{Environment}

The visual analysis step warranted further analysis using a control chart of deficiencies categorized as environmental protection. Therefore, this functional area was analyzed using a control chart (Figure 32). No common tests were recently met.

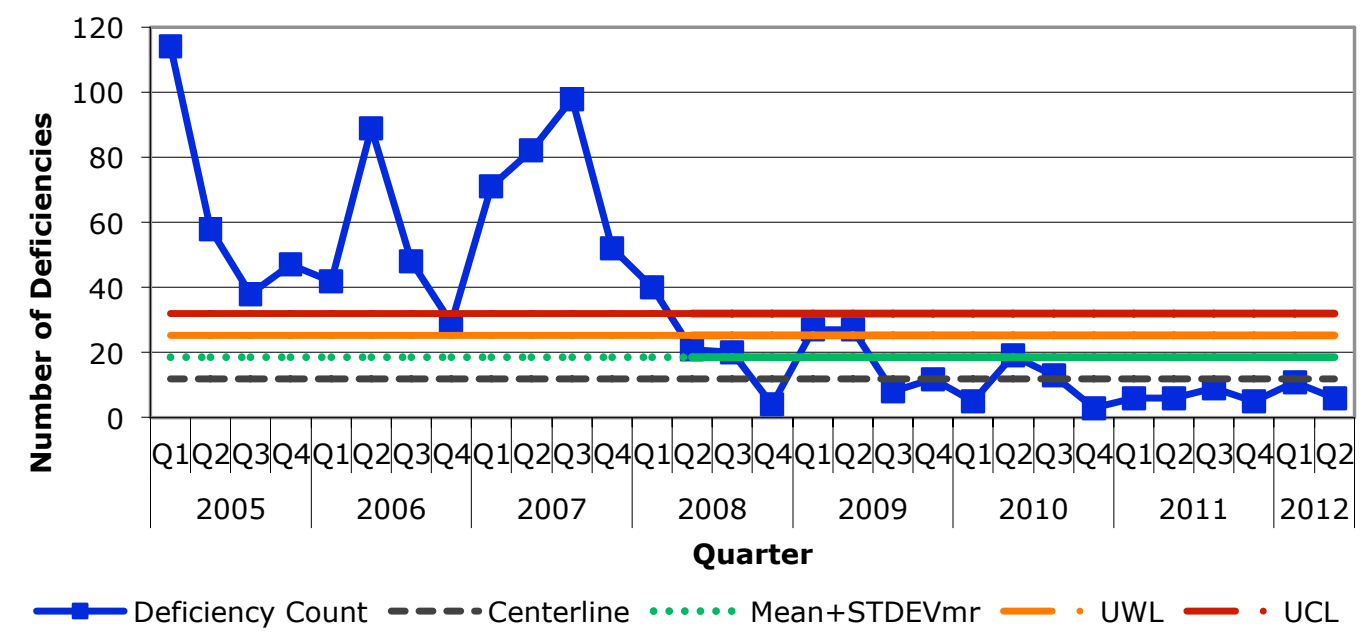

Note: Control Limits are based on fewer quarters than are displayed

Figure 32. Frequency control chart of environmental deficiencies.

In the second quarter of 2012, the most recent quarter of data analyzed, six environmental deficiencies were identified, two from the ISO 14001 and OHSAS 18001 JFLMA and the other four from three different MOVIs. The six deficiencies were categorized under four different topical areas.

The control chart analysis concludes that recent data was within expected variation.

Potential Significant, Systemic or Repetitive $\square$ Meets Common Tests $\bigotimes$ Within Expected Variation
Downward Trend 


\subsection{Facility Management and Support Systems}

The visual analysis step did not warrant further analysis using a control chart of deficiencies categorized as facility management and support systems; however, this functional area is analyzed using a control chart regardless of the visual analysis step.

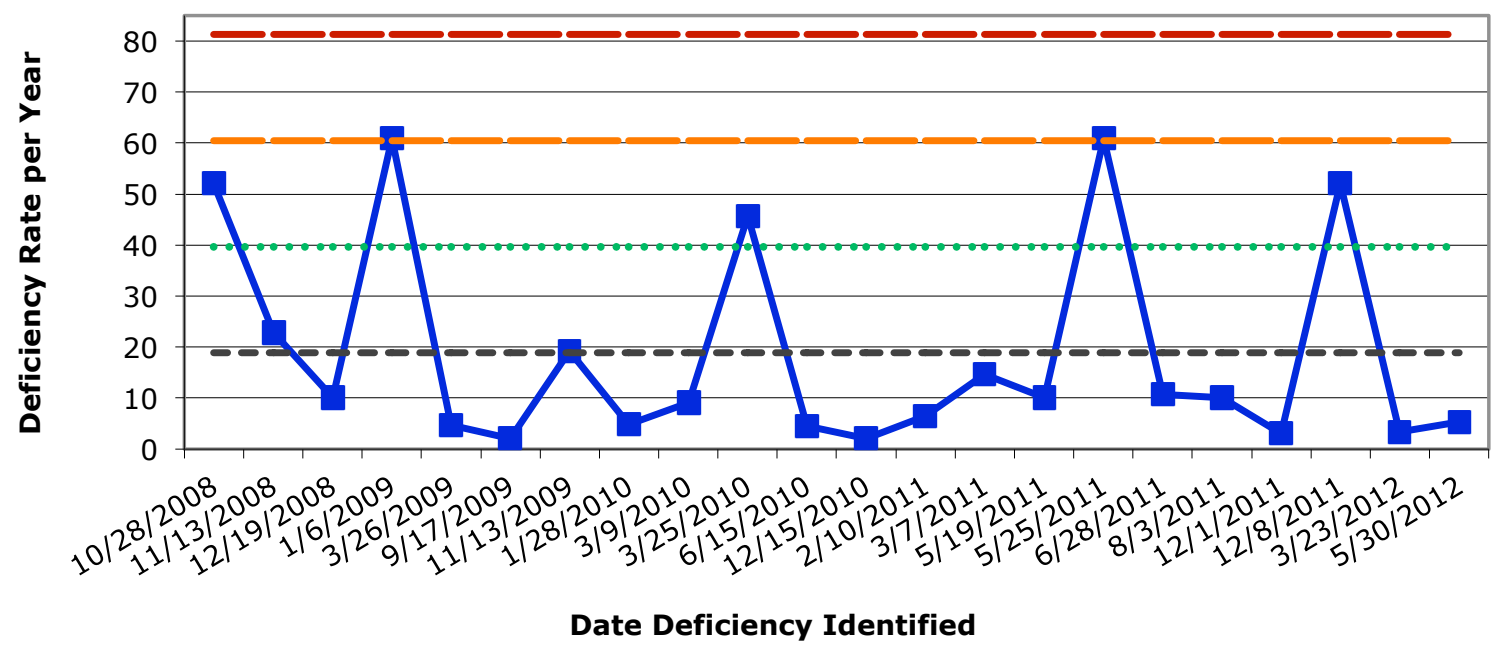

$\rightarrow$ Deficiency Rate $\quad--\cdot$ Centerline $\cdots$ Mean + STDEVmr $\quad \cdot$ UWL $\quad \cdot$ UCL

Figure 33. Deficiency rate per year control chart of facility management deficiencies.

There were two facility management deficiencies identified in 2012, one in March and one in May, as shown in Figure 33. One of the deficiencies was a below Occurrence Reporting and Process System (ORPS) reportable issue related to a radiological inventory that exceeded the administrative limit. The other deficiency was from a MOVI and was related to one transportainer that had three different DOE numbers. The "rate per year" control chart analysis shows a slight increase in the deficiency rate of deficiencies categorized in the facility management functional area from March to May 2012, but both deficiency rates for March and May are below the centerline (Figure 33). For more information on the "rate per year" control chart refer to Section 11.2.

The "rate per year" control chart analysis concludes that a common test was met, a recent increase in the deficiency rate. Therefore, this functional area will be analyzed in future performance analyses.

Potential Significant, Systemic or Repetitive $\bigotimes$ Meets Common Tests
Within Expected Variation

Downward Trend 


\subsection{Packaging and Transportation (Non-Nuclear)}

The visual analysis step did not warrant further analysis using a control chart of deficiencies categorized as non-nuclear packaging and transportation (P\&T); however, this functional area was determined to need continued analysis in the previous analysis report. No common tests were met in the control chart (Figure 34). The control chart does show a consecutive decrease in the number of $P \& T$ deficiencies from the third quarter in 2011 to the second quarter in 2012. The point above the UCL in the second quarter of 2010 was discussed in the previous report.

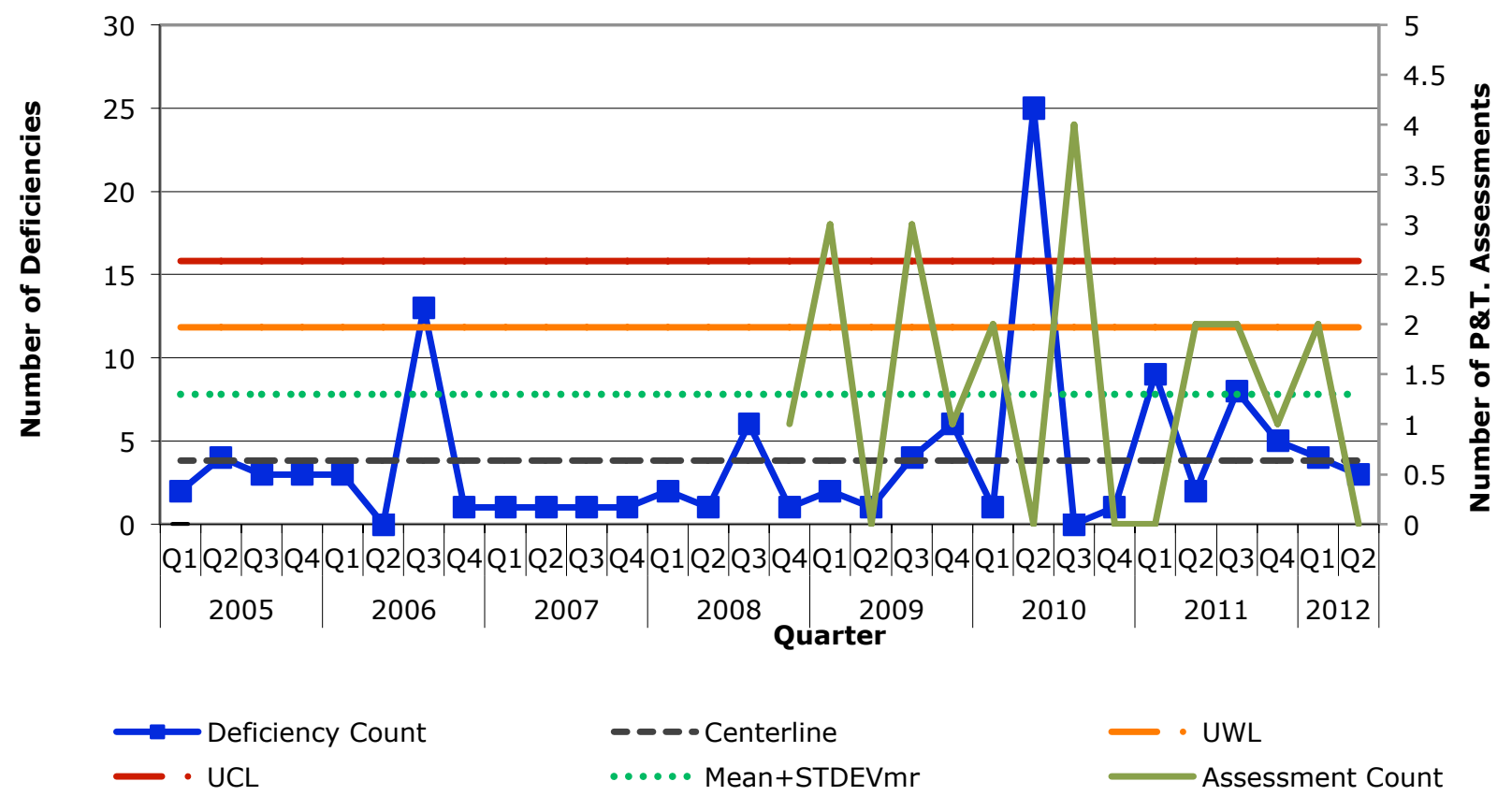

Figure 34. Frequency control chart of packaging and transportation deficiencies.

In the second quarter of 2012, the most recent quarter of data analyzed, three P\&T deficiencies were identified. All three deficiencies are from the Operations and Business FY12 P\&T safety receipt inspection related to a high pressure plug that failed the leak test. These are not considered deficiencies in LLNL operations.

The control chart analysis concludes that no common tests were met and recent data is within expected variation.

$\square$ Potential Significant, Systemic or Repetitive $\square$ Meets Common Tests $\bigotimes$ Within Expected Variation
Downward Trend 


\subsection{Quality Assurance (Non-Nuclear)}

The visual analysis step did not warrant further analysis using a control chart of deficiencies categorized as non-nuclear quality assurance (QA); however, this functional area is analyzed using a control chart regardless of the visual analysis step. No common tests were met in the control chart analysis. There was a recent decrease in non-nuclear QA deficiencies from the first to the second quarter of 2012 (Figure 35).

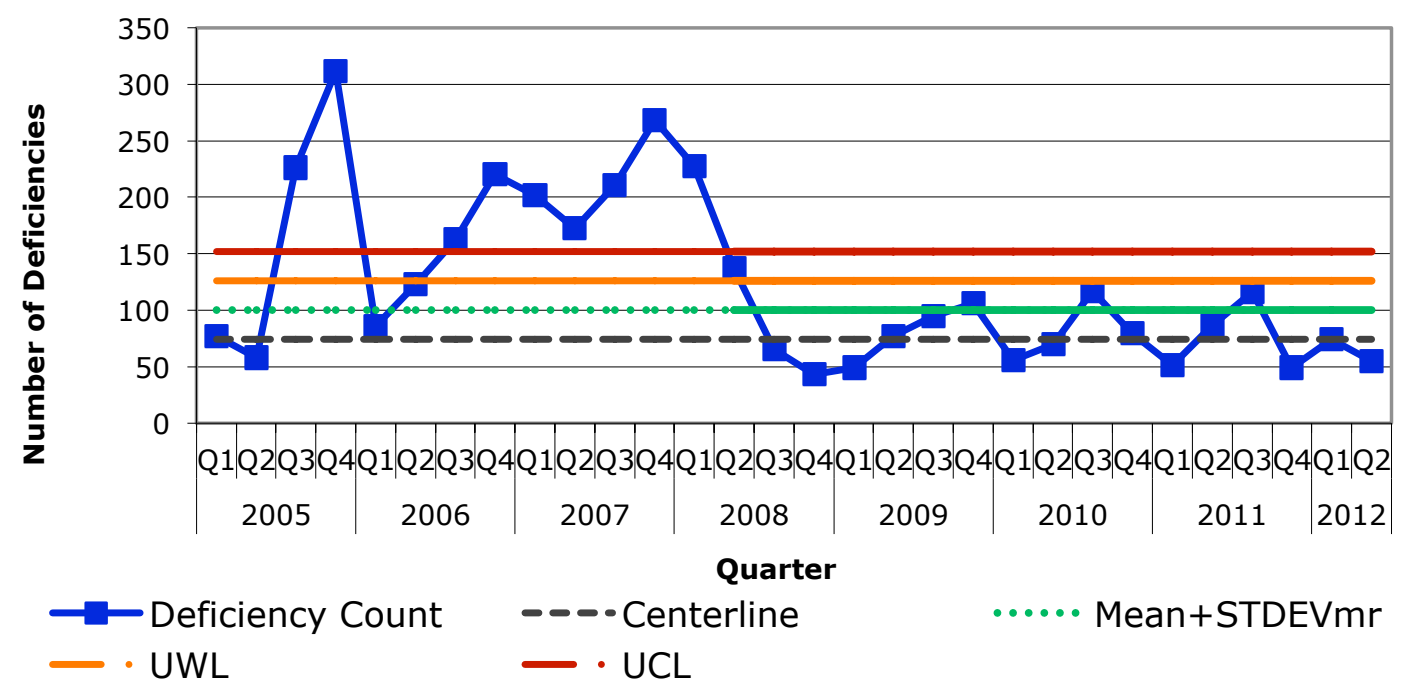

Note: Control Limits are based on fewer quarters than are displayed

Figure 35. Frequency control chart of non-nuclear QA deficiencies.

During the second quarter of 2012, the most recent quarter of data analyzed, 55 nonnuclear QA deficiencies were identified. Sixty seven percent $(67 \%)$ of the 55 deficiencies are owned by the Global Security Directorate with the majority of deficiencies identified from IWS training and verification of a program. Twenty three percent (23\%) of the 55 deficiencies are owned by the NIF and Photon Sciences Directorate and all of these deficiencies were identified from NIF walkabouts related to an Integration Work Sheet (IWS). Eighty percent $(80 \%)$ of the 55 deficiencies were categorized within the performance/work processes topic and $71 \%$ were categorized as, "Workers are not adequately trained and qualified to perform work tasks assigned, or have not read and signed IWS." Deficiencies within this compliance code were included in the analysis in Section 9.5.

These deficiencies were evaluated for potential significant, programmatic, and repetitive noncompliances and do not appear to meet the DOE NTS reporting threshold.

In summary, non-nuclear QA deficiencies did not meet a common test, and data within this subject is considered within expected variation.
$\square$ Potential Significant, Systemic or Repetitive

\section{Meets Common Tests}
$\bigotimes$ Within Expected Variation
Downward Trend 


\subsection{Training and Qualification}

Training and qualification deficiencies can be categorized under the training and qualification functional area and under other topics, subtopics and compliance codes. This analysis includes training and qualification data from a collection of training related functional areas, topics, subtopics and compliance codes from across 10 different functional areas: contractor assurance, conduct of operations, emergency management, environment, nuclear operations, QA, radiation protection, safeguards and security, training, and worker safety and health. The majority $(90 \%)$ of training and qualification deficiencies are from the QA functional area and $90 \%$ of those deficiencies categorized in the QA functional area were categorized as, "Failure to train or qualify personnel to perform their assigned work (initial or continuing training/ qualification) (QA Criterion 2 - Management/Personnel Training and Qualification)."

The visual analysis step did not warrant further analysis using a control chart of deficiencies categorized as training and qualification; however, training and qualification deficiencies are analyzed using a control chart regardless of the visual analysis step. In the control chart there appears to be an increasing trend from the beginning of 2009 to the third quarter in 2011 (Figure 36). Although the sample size is small, linear regression was used to test the trend. There is no statistically significant increasing trend in training and qualification deficiencies since the beginning of 2009 ( $p$ value $>0.05$ ).

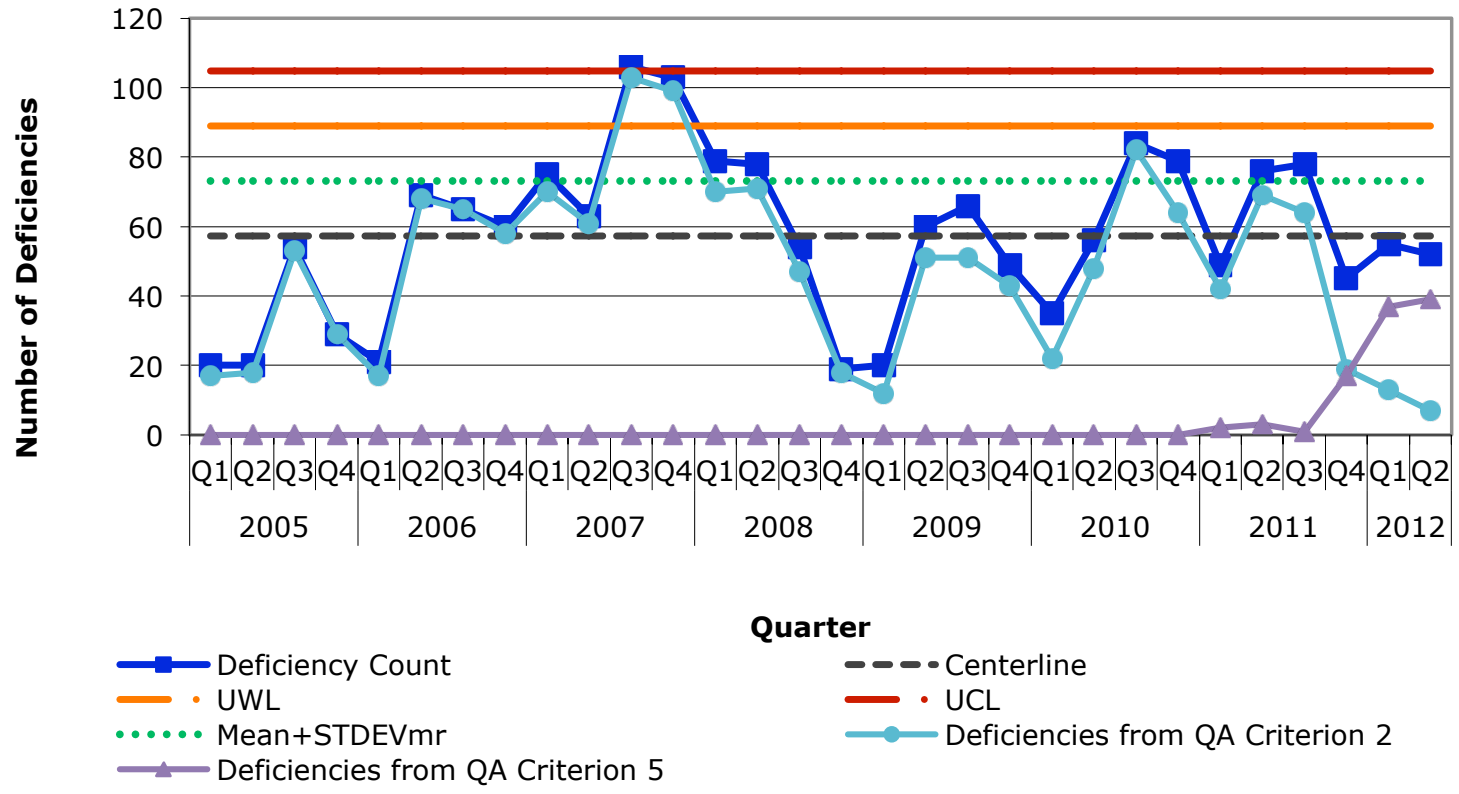

Figure 36. Frequency control chart of training deficiencies across multiple functional areas.

Figure 36 shows that prior to the fourth quarter of 2011, most of the training and qualification deficiencies are categorized in the QA functional area under criterion 2, management/ personnel training and qualification. From the fourth quarter of 2011 to the most recent quarter analyzed, more training deficiencies were categorized under criterion 5, performance/work processes. In the first three quarters of 2011 all 
deficiencies from IWS training verifications of different programs and program management walkthroughs of IWSs, which are all assessments within the Global Security (GS) Directorate, were categorized under QA criterion 2. In the fourth quarter of 2011 and the first and second quarters of 2012, deficiencies from these same sources were categorized under QA criterion 5. Feedback from subject matter experts suggested the use of criterion 5 instead of criterion 2 as a more appropriate topic for GS training deficiencies.

In the second quarter of 2012, the most recent quarter of data analyzed, 52 training deficiencies were identified, a decrease from the previous quarter. Seventy one percent (71\%) of the 52 deficiencies are owned by the GS Directorate. Eighty eight percent $(88 \%)$ of the 52 deficiencies were categorized within the QA functional area with $81 \%$ categorized in the following compliance code, "Workers are not adequately trained and qualified to perform work tasks assigned, or have not read and signed IWS." Twenty nine of the 37 GS owned deficiencies are from IWS training/verification of a specific program.

In summary, training and qualification deficiencies did not meet a common test. This functional area will be analyzed in future performance analyses to determine if what appeared to be a potential increasing trend does turn into a statistically significant increasing trend.

$\square$ Potential Significant, Systemic or Repetitive

\author{
Meets Common \\ Tests
}

$\bigotimes$ Within Expected Variation
Downward Trend 


\subsection{Conclusion}

ITS issues identified from July 2011 through June 2012, were analyzed focusing on identifying issues that may require additional management attention and noncompliances that meet the threshold for reporting to the DOE NTS or to the DOE SSIMS.

The analysis concluded that data for 15 of the 23 Office of Enforcement regulated safety and security subjects were within expected variation or there was a decreasing trend. These subjects are shown in green in Table 4 . The data for seven of the 23 safety and security subjects, shown in yellow in Table 4, met a common test. All seven regulated safety and security subjects that met a common test are discussed in this report and will be monitored over future quarters. Data for three of the seven regulated safety and security subjects met an action limit, a point above the Upper Control Limit (UCL). Data within these three subjects were analyzed further to resolution to determine if a repetitive or programmatic (i.e., systemic) noncompliance exists that warrants a noncompliance report to DOE. The data for one security subject is identified as a potential repetitive or programmatic noncompliance (shown in red in Table 4); additional analysis is needed to make a final determination. The complete Section 8.0 of this report is considered Official Use Only. For a copy of the complete Section 8.0 contact Norma McTyer at mctyer1@1lnl.gov.

Table 4. Summary of safety and security subjects regulated by the DOE Office of Enforcement.

\begin{tabular}{|l|l|}
\hline \multicolumn{2}{|l|}{ Worker Safety and Health Management Issues } \\
\hline & Beryllium \\
& Eiological Safety \\
& Emergency Program \\
Explosive Safety \\
Fire Safety \\
Occupational Medicine \\
Other Industrial Hygiene \\
Other Industrial Safety \\
\hline & Severity Level I Noncompliances \\
\hline \multicolumn{2}{|l|}{$\begin{array}{l}\text { Nuclear Operations } \\
\text { Packaging and Transportation (Nuclear) } \\
\text { Quality Assurance (Nuclear) } \\
\text { Radiation Protection }\end{array}$} \\
\hline Classified Information Security Management Issues \\
\hline & $\begin{array}{l}\text { Cyber Security } \\
\text { Identifying Classified Information } \\
\text { Information Protection } \\
\text { Nuclear Materials Control \& Accountability }\end{array}$ \\
\hline
\end{tabular}


Personnel Security Program

Physical Protection

Program Management and Support

Protective Force

Unclassified Visits \& Assignments By Foreign Nationals

Legend

Data within this subject was within expected variation or there was a decreasing trend in the data

Data within this subject met a common test and will be analyzed in future performance analyses

Data within this subject met a common test and might represents a significant, systemic, or repetitive noncompliance reportable to DOE

The three Office of Enforcement regulated safety subjects with data meeting an action limit in the control chart analysis were, fire safety, nuclear operations, and nuclear safety quality assurance (QA).

The majority of fire safety deficiencies that caused a point to be above the UCL in the first quarter of 2012, specifically from the fire suppression topic, were from fire protection inspections. Compared to surrounding quarters, the first quarter of 2012 had the greatest number of fire protection inspections completed. Forty percent $(40 \%)$ of fire suppression deficiencies identified from January 2012 through June 2012 were related to an obstruction causing the sprinkler to not work at full capacity; however, this accounted for only 19\% of the 58 facilities inspected from January 2012 to June 2012.

Recommendation: There may be a need to educate employees on the need to not block sprinkler heads. This might be communicated in a Lessons Learned bulletin.

Three fire suppression deficiencies were related to three different unsprinklered buildings, a potential significant noncompliance. However, the LLNL Fire Marshal confirmed that the three facilities identified to not have sprinklers do not require sprinklers. Therefore, it was determined that fire safety deficiencies do not represent a systemic or repetitive noncompliance reportable to DOE.

This review did find that issues identified in 2012 were closed stating that they were duplicates of the 2011 issue. However, the 2011 issue is closed prior to the identification of the 2012 issues. This indicates that the issues are unresolved and not tracked as open issues in ITS. The management of fire protection issues will need to be discussed further out of the context of this report. 
Recommendation: Evaluate management and visibility of Fire Suppression issues.

Eleven of the 15 nuclear operations deficiencies that caused a point to be above the UCL were categorized as related to nuclear facility startup/ restart. Nine of the 15 were from readiness reviews performed by LLNL and by LSO of a single device in a single Laboratory facility. Readiness reviews are by intent robust examinations of planned operations and are designed to identify as many deficiencies as possible before operations are conducted for the first time. The nine nuclear facility startup/ restart deficiencies cannot be considered evidence of any systemic or programmatic weakness in nuclear operations, or any programmatic noncompliance with DOE nuclear safety requirements for work planning. The relatively high count of deficiencies can be attributed to the fact that four separate assessments ("readiness reviews") of a single device in a single LLNL facility were performed by multiple organizations during the analysis period.

Ten of the 13 deficiencies categorized as nuclear safety QA, specifically as criterion 5 (performance/work processes) that caused a point to be above the UCL were identified from readiness reviews. Readiness reviews are by intent robust examinations of planned operations and are designed to identify as many deficiencies as possible before operations are conducted for the first time. The 10 deficiencies cannot be considered evidence of any systemic or programmatic noncompliance with DOE nuclear safety requirements for work planning.

A review of the safeguards and security deficiencies identified a potential programmatic or repetitive noncompliance. In the fourth quarter of 2011, the quarter with a data point above the UWL, three of the six deficiencies were related to security incidents and categorized as Impact Measurement Index 4.13. Additionally, one information protection deficiency identified in the second quarter of 2012 was categorized as Impact Measurement Index 4.13. A review of the causal analysis reports for these four deficiencies indicated that in each case, a derivative classification (DC) review was not conducted as required by LLNL's Classification Review Policy. The four similar security incidents were not clustered in a particular directorate but spread across four directorates. In order to determine if a classified information security noncompliance exists, the common causes associated with similar security incidents will need to be analyzed further. This analysis will be documented in a separate report.

Recommendation: Analyze CIS deficiencies in more detail to determine if a programmatic or repetitive noncompliance exists that may be reportable to SSIMS.

The analysis identified eight regulated safety and security subjects that will be monitored over future quarters:

- Fire Safety (Section 6.6)

- Other Industrial Hygiene (Section 6.8)

- Other Industrial Safety (Section 6.9) 
- Nuclear Operations (7.1)

- Nuclear Quality Assurance (7.3)

- Radiation Protection (Section 7.4)

- Cyber Security (Section 8.1)

- Information Protection (Section 8.3)

No issues were determined to meet the WSH "Severity Level I" threshold for reporting to the DOE NTS. There were no issue significance level one deficiencies identified in ITS between October 2011 and October 2012. All issue significance level two deficiencies identified between October 2011 and October 2012 were either reported to the DOE NTS or were from a security incident. There was one WSH related deficiency entered in ITS between October 2011 and October 2012 that was downgraded from a suggested issue significance level of one to a lower issue significance level. This deficiency was evaluated as a WSH "Severity Level I" noncompliance at the time it was identified; it was determined that it did not meet the threshold. 


\subsection{Methods}

\subsection{Method for Analyzing Assessments}

Internal assessments at LLNL include Internal Independent Assessments (IIAs) chartered by the Director's Office; management self-assessments chartered by either the functional area managers, the principal associate director, or the associate director; and management observations, verifications, and inspections (MOVIs). DOE and regulatory agencies conduct external assessments. The results of internal and external assessments are entered into the LLNL Issues Tracking System (ITS). In addition, deficiencies, observations, and corrective actions identified during the analysis of events (e.g., illnesses / injuries and occurrences) are also entered into ITS.

Data on assessments conducted from 2005 through 2010 was extracted in February 2011 using the ITS Mega Report; duplicate values were deleted. The ITS Mega Report includes all assessments performed, whether or not the assessment resulted in an issue (i.e., deficiency or observation). The ITS allows the user to categorize assessments by type. For this analysis, the ITS assessment types were binned into the following nine assessing categories:

- "Event" includes assessment types event-illness/injury case analysis report, event-occurrence event-below occurrence reporting process system (ORPS) (site) reportable and security incident.

- "External" includes assessment types external-Livermore site office (LSO) monthly assessment or periodic issues reports, external-LSO surveillance and external-other.

- "Internal Independent" includes assessment types internal independent, independent audit and oversight department audit, and LLNL parent org functional management assessment.

- “Joint FAM/Line" includes assessment type joint FAM/Line.

- "Management Self" includes assessment type management self.

- "MOVI" includes assessment types management observation, verification or inspection.

- "Other External" includes the combination of assessment type other and assessments performed by external assessors.

- "Other Internal" includes the combination of assessment type other and assessments performed by internal assessors.

- “Quick ITS” includes assessment type quick ITS.

- "Readiness Review" includes assessment type readiness review.

The data was reviewed to determine if the frequency or categories of assessments (above) changed comparing recently collected data to data collected since 2005. Process control charts for individual measurements were produced to look at variations of internal assessment data. The process control chart can be considered a way of performing a statistical test to determine whether the process under study is in a state of control. One control chart was used to analyze variation within internal assessment data, referred to as a frequency control chart. The frequency control chart in this case plots the internal assessment frequency over time (i.e., quarters). 
The control chart provides a means to evaluate and compare the number of assessments over time to the following seven key elements:

1. Centerline: the average number of assessments over the time period (mean)

2. One standard deviation: one times the average moving range divided by a constant with value 1.128 above the mean

3. One standard deviation: one times the average moving range divided by a constant with value 1.128 below the mean

4. Upper Warning Limit (UWL): two times the average moving range divided by a constant with value 1.128 above the mean

5. Upper Control Limit (UCL): three times the average moving range divided by a constant with value 1.128 above the mean

6. Lower Warning Limit (LWL): two times the average moving range divided by a constant with value 1.128 below the mean

7. Lower Control Limit (LCL): three times the average moving range divided by a constant with value 1.128 below the mean

The key element, the UCL, is a common calculation for control charts. Ideally, the majority of data would lie within the UCL and the LCL.

The moving range is defined as $\left|\mathrm{x}_{\mathrm{i}}-\mathrm{x}_{\mathrm{i}-1}\right|$, where $\mathrm{x}$ is the number of internal assessments for a specific quarter. The moving range can also be defined as the absolute difference between two successive data points, in this case quarterly assessment counts. The constant discussed above, referred to as $\mathrm{d}_{2}$ in the Introduction to Statistical Quality Control (Montgomery, 1997) is defined as the mean of the distribution of the relative range and is used in calculating the estimate of the standard deviation, which is defined as the average moving range divided by this constant $\left(\mathrm{d}_{2}\right)$. The value of $\mathrm{d}_{2}$ ranges anywhere from 1.128 to 3.931 , depending on how many observations are in each sample. The moving range is used instead of the range because each data point in the control charts used in this analysis is based on individual counts and not a sample average. Because the moving range is calculated using two successive data points, our value of $n$ is two $(\mathrm{n}=2)$. Therefore, the value of $\mathrm{d}_{2}$ is defined as 1.128 in Table VI in the Introduction to Statistical Quality Control.

We look within the process control charts for special causes of variation, which can be found by using common tests. The common tests (below) are called action limits, as listed in the Introduction to Statistical Quality Control:

1. One data point falling above the UCL or below the LCL

2. Two (or three) out of three points in a row are more than the UWL from the mean or are less than the LWL from the mean in the same direction

3. Four out of five points in a row are more than one standard deviation from the mean in the same direction

4. Eight consecutive points plot on one side of the centerline

Theoretically, if a process is "in-control" then none of the data points meet the requirements of an action limit. If an action limit is met, the assessment data is analyzed further. 


\subsection{Method for Analyzing for Management Issues}

Management issue noncompliances are defined as repetitive noncompliances, programmatic (i.e., systemic) issues, and intentional violations or misrepresentations. One goal of analyzing Issues Tracking System (ITS) data is to look for a possible programmatic noncompliance by reviewing deficiencies within the same safety or security subject. Second, the analysis may identify a previously overlooked repetition of the same type of deficiency. A programmatic problem generally involves some weakness in administrative or management controls or their implementation, to such a degree that a broader management or process control problem exists. A repetitive problem is generally two or more different events that involve substantially similar conditions, locations, equipment, or individuals. Repetitive problems tend to be narrower in scope than programmatic problems. The ITS issue analysis included a three-step process of 1) looking at the data as a whole to identify visual variations; 2 ) performing statistical tests of the sets of data gleaned from the first step; and 3) evaluating the sets of data gleaned from the second step by reviewing the context of the noncompliances, such as discovery method, location in terms of facility, the compliance code, and the description of the noncompliance.

The process for analyzing ITS data was to first, visually review the deficiencies by quarter, looking for groupings with large numbers of deficiencies, observed changes in the number of deficiencies, or other observations that look different from what is expected. Then, if the numbers appeared to be of interest, create a process control chart for individual measurements for the safety subjects within the functional areas related to worker safety and health (WSH) and nuclear safety and the security subjects within the safeguards and security functional area. The control charts utilize the "IndividualX/MR" method, described in Introduction to Statistical Quality Control.

A process control chart can be considered a way of performing a statistical test to determine whether the process is in a state of control. Frequency control charts were used to look at variations of issues within safety and security subjects. These control charts plot the deficiency frequency and sometimes the observation frequency per quarter along with the number of assessments within a quarter for a particular safety or security subject. The number of assessments, which in previous analyses was included in the control chart, is not plotted prior to the fourth quarter of 2008 because the functional area for assessments became a required field in ITS as of the fourth quarter of 2008.

Along with the frequency of deficiencies, these control charts consist of four key elements:

- Centerline: the average number of deficiencies over the time period (mean)

- One Standard Deviation: one times the average moving range divided by a constant with value 1.128 above the mean

- Upper warning limit (UWL): two times the average moving range divided by a constant with value 1.128 above the mean

- Upper Control-limit (UCL): three times the average moving range divided by a constant with value 1.128 above the mean

Two other key elements, which are typically part of a process control chart, are not shown in the control charts in this analysis. These two elements are the Lower Warning 
Limit (LWL) and the Lower Control Limit (LCL). The LWL is two times the average moving range divided by a constant with value 1.128 below the mean. The LCL is three times the average moving range divided by a constant with value 1.128 below the mean. These elements have not been incorporated in the control charts because the number of deficiencies per quarter cannot be below one or zero, and in many cases the LWL and LCL would have been below one or zero had it been incorporated in the control charts.

The key element, the UCL, is a common calculation for control charts. Ideally, the majority of data would lie within the UCL and the LCL.

The moving range is defined as $|x \mathrm{i}-\mathrm{xi}-1|$, where $\mathrm{x}$ is the number of deficiencies (and sometimes observations) for a specific quarter. The moving range can also be defined as the absolute difference between two successive data points, in this case quarterly assessment counts. The constant discussed above, referred to as $\mathrm{d} 2$ in Introduction to Statistical Quality Control, is defined as the mean of the distribution of the relative range and is used in calculating the estimate of the standard deviation, which is defined as the average moving range divided by this constant (d2). The value of $\mathrm{d} 2$ ranges anywhere from 1.128 to 3.931 depending on how many observations are in each sample. The moving range is used instead of the range because each data point in the control charts used in this analysis is based on individual counts and not a sample average. Because the moving range is calculated using two successive data points, our value of $n$ is two $(\mathrm{n}=2)$. Therefore, the value of $\mathrm{d} 2$ is defined as 1.128 in Table VI in Introduction to Statistical Quality Control.

In many cases, the control limits were adjusted and calculated for fewer quarters than what is displayed on the control chart in order to emphasize the more recent data, which often produces tighter control limits. If this adjustment was done for a control chart, it is noted on the bottom of the chart.

If there was a rare incidence of deficiencies within a subject, then the frequency of deficiencies was converted to a rate of deficiencies per year, and this rate was used as each data point on the control chart. The centerline becomes the average rate of deficiencies per year, but the formula for calculating the UCL and UWL does not change. This control chart is referred to as the deficiency rate per year control chart. Note that the $\mathrm{x}$-axis becomes the date, not the quarter, the deficiency was identified. We look within the process control charts for special causes of variation, which can be found by using common tests. The common tests (below) are called action limits, as listed in the Introduction to Statistical Quality Control:

- One data point falling above the UCL or below the LCL

- Two (or three) out of three points in a row are more than UWL from the mean in the same direction

- Four out of five points in a row are more than one standard deviation from the mean in the same direction

- Eight consecutive points plot on one side of the centerline

Theoretically, if a process is "in-control," then none of the data points meet the requirements of an action limit. If an action limit is met, a more detailed examination of 
the specific deficiencies will occur in order to determine if repetitive, programmatic, or systemic weaknesses exist that may be reportable to the DOE Noncompliance Tracking System (NTS). If data within a subject meets an action limit, but has already been reported to NTS, further explanation will not be provided. The following four other common tests are used, but are not considered action limits:

- One data point above the UWL

- Single increase in data points for the quarter in question

- Recent increasing trend for more than one quarter

- An unusual or nonrandom pattern in the data

Some of the common tests described above are more conservative than the typical set of decision rules listed in Introduction to Statistical Quality Control. These non-typical common tests are meant to detect subjects that should be analyzed using control charts in future performance analyses to watch for potential nonrandom patterns.

- One standard deviation: one times the average moving range divided by a constant with value 1.128 below the mean

- Upper Warning Limit (UWL): two times the average moving range divided by a constant with value 1.128 above the mean

- Upper Control Limit (UCL): three times the average moving range divided by a constant with value 1.128 above the mean

- Lower Warning Limit (LWL): two times the average moving range divided by a constant with value 1.128 below the mean

- Lower Control Limit (LCL): three times the average moving range divided by a constant with value 1.128 below the mean

The key element, the UCL, is a common calculation for control charts. Ideally, the majority of data would lie within the UCL and the LCL.

The moving range is defined as $|x i-x i-1|$, where $x$ is the number of internal assessments for a specific quarter. The moving range can also be defined as the absolute difference between two successive data points, in this case quarterly assessment counts. The constant discussed above, referred to as $\mathrm{d} 2$ in the Introduction to Statistical Quality Control (Montgomery, 1997) is defined as the mean of the distribution of the relative range and is used in calculating the estimate of the standard deviation, which is defined as the average moving range divided by this constant $(\mathrm{d} 2)$. The value of $\mathrm{d} 2$ ranges anywhere from 1.128 to 3.931, depending on how many observations are in each sample. The moving range is used instead of the range because each data point in the control charts used in this analysis is based on individual counts and not a sample average. Because the moving range is calculated using two successive data points, our value of $n$ is two $(n=2)$. Therefore, the value of $d 2$ is defined as 1.128 in Table VI in the Introduction to Statistical Quality Control.

We look within the process control charts for special causes of variation, which can be found by using common tests. The common tests (below) are called action limits, as listed in the Introduction to Statistical Quality Control:

- One data point falling above the UCL or below the LCL 
Performance Analysis: Issues Tracking System Data through June 2012

- Two (or three) out of three points in a row are more than UWL from the mean in the same direction

- Four out of five points in a row are more than one standard deviation from the mean in the same direction

- Eight consecutive points plot on one side of the centerline

Theoretically, if a process is "in-control" then none of the data points meet the requirements of an action limit. If an action limit is met, the assessment data is analyzed further. 


\subsection{Definitions}

Correlation: The strength of the linear relation between two quantitative variables (e.g., observations and deficiencies).

Correlation Coefficient (Rho): A number between -1 and 1 that measures the degree to which two variables are linearly related. If there is perfect linear relationship with positive slope between the two variables, we have a correlation coefficient of 1 ; if there is positive correlation, whenever one variable has a high (low) value, so does the other. If there is a perfect linear relationship with negative slope between the two variables, we have a correlation coefficient of -1 ; if there is negative correlation, whenever one variable has a high (low) value, the other has a low (high) value. A correlation coefficient of 0 means that there is no linear relationship between the variables.

Correlation Test (Pearson): The statistical significance of $r$ is tested using a t-test. The hypotheses for this test are:

$$
\begin{aligned}
& \mathrm{H}_{0}: \text { rho }=0 \\
& \mathrm{H}_{\mathrm{a}}: \text { rho }<>0
\end{aligned}
$$

A low p-value for this test (less than 0.05 , for example) means that there is evidence to reject the null hypothesis in favor of the alternative hypothesis, or that there is a statistically significant relationship between the two variables.

P-value: The probability of wrongly rejecting the null hypothesis if it is in fact true. Examples of null hypotheses used in this analysis:

$\mathrm{H}_{0}$ : The process is in a state of control

$\mathrm{H}_{0}$ : rho (correlation coefficient) $=0$

Simple Linear Regression: Simple linear regression aims to find a linear relationship between a response variable and a possible predictor variable by the method of least squares and production of a regression equation. A regression equation allows us to express the relationship between two variables algebraically. It indicates the nature of the relationship between two variables. In particular, it indicates the extent to which you can predict a variable by knowing another, or the extent to which variables are associated with one another.

Standard deviation: A way to measure how far the observations are from their mean. It is also referred to as a measure of spread.

State of Control: The extent of variation of the output of the process does not exceed that which is expected on the basis of the natural statistical variability of the process. None of the data points fall outside of the Upper or Lower Control Limits.

Statistically Significant: The probability (usually less than 5 percent or less than a pvalue of 0.05 ) that a finding or result is caused by something other than just chance. 


\subsection{References}

Lawrence Livermore National Laboratory, LLNL Approved Document for Contractor Assurance DES-0083, "Regulatory Compliance Assurance Program for DOE Safety and Security Requirements," LLNL-AR-425062, Approval date of January 24, 2012, available online at https: / / portal.llnl.gov/ portal/ page/ portal/MYLLNL / ITEMS / DOCUMENTS / BOOKSHELF / DES_0083.pdf.

Lawrence Livermore National Laboratory, LLNL Approved Document for Contractor Assurance, PRO004200, "Issues and Corrective Action Management," LLNL-AM-412811, Effective Date of October 1, 2012, available online at https: / / portal.1lnl.gov/portal/page/portal/MYLLNL/ITEMS / DOCUMENTS / BOOKSHELF / PRO_0042_Issues_and_Corrective_Action_Management.pdf.

Lawrence Livermore National Laboratory, "Worker Safety and Health Program," Approval date by LLNL of August 30, 2012.

Montgomery, D. (1997), Introduction to Statistical Quality Control (John Wiley \& Sons, Inc., New York, NY).

U.S. Department of Energy Office of Enforcement (August 2012), Safety and Security Enforcement Coordinator Handbook, available online at

http: / / www.hss.doe.gov/enforce/docs / overview / Enforcement_Coordinator_Handbook.pdf.

U.S. Department of Energy Office of Enforcement (August 2012), Safety and Security Enforcement

Process Overview, available online at

http: / / www.hss.doe.gov/enforce/docs / overview/Enforcement_Process_Overview.pdf. 